\title{
WestVirginiaUniversity
}

THE RESEARCH REPOSITORY @ WVU

Graduate Theses, Dissertations, and Problem Reports

1999

\section{Heavy-duty emissions inventory and prediction}

\author{
Ravishankar Ramamurthy \\ West Virginia University
}

Follow this and additional works at: https://researchrepository.wvu.edu/etd

\section{Recommended Citation}

Ramamurthy, Ravishankar, "Heavy-duty emissions inventory and prediction" (1999). Graduate Theses, Dissertations, and Problem Reports. 955.

https://researchrepository.wvu.edu/etd/955

This Thesis is protected by copyright and/or related rights. It has been brought to you by the The Research Repository @ WVU with permission from the rights-holder(s). You are free to use this Thesis in any way that is permitted by the copyright and related rights legislation that applies to your use. For other uses you must obtain permission from the rights-holder(s) directly, unless additional rights are indicated by a Creative Commons license in the record and/ or on the work itself. This Thesis has been accepted for inclusion in WVU Graduate Theses, Dissertations, and Problem Reports collection by an authorized administrator of The Research Repository @ WVU. For more information, please contact researchrepository@mail.wvu.edu. 


\title{
Heavy Duty Emissions Inventory and Prediction
}

\author{
Ravishankar Ramamurthy
}

Thesis submitted to

The College of Engineering and Mineral Resources at West Virginia University

in partial fulfillment of the requirements

for the degree of

Master of Science
in
Mechanical Engineering

Nigel N. Clark, Ph.D., Chair Christopher M. Atkinson, Sc.D.

Mridul Gautam, Ph.D.

Department of Mechanical and Aerospace Engineering

\author{
Morgantown, West Virginia \\ 1999
}

Keywords: Emissions, Prediction, Chassis Testing 


\section{Acknowledgements}

I express my sincere gratitude to Dr. Nigel Clark for providing me with an opportunity to work with him and for guiding me to prepare myself for a professional career. The technical insights that he provided during the course of the research could never be matched. I am grateful to Dr. Atkinson for his technical guidance and for showing me the importance to be a perfectionist. I thank Dr. Gautam for his constant encouragement and interest that he showed in the research.

I would like to thank Dave McKain, Ralph Nine, Wenwie Xie, Jim Boyce, Tom McDaniel, Richard Atkinson, Tom Spencer, Marcus Gilbert and Wayne Hildebrand for their valuable help during the course of the research. Special words of thanks go to Ron Jarrett for working with me in the project and for the long hours of technical discussion. I cannot forget my group of six friends, Anand, Prasanna, Srikanth, Ganesh, Venkat and Rana who have been a part of all my efforts in the span of two years. The moral support that they provided cannot be compensated. I thank Sreene, Mani and Diwi for having seen me through this ordeal. I also thank Justin, Subhash, Srinivas, V3, Dileep, Naveen and Lakshmi for their support.

I thank my brother Suresh and Lakshmi who have been my mentors, friends and guides. Last but not the least I am searching for words to thank my mom and dad. Words cannot explain what they have done for me. I dedicate my thesis research and future work to them. 


\section{ABSTRACT \\ Heavy Duty Emissions Inventory and Prediction \\ Ravishankar Ramamurthy}

Heavy duty vehicle emissions represent a significant portion of the mobile source emissions inventory. Accurate estimation of their contribution is essential as on-highway and non-road heavy duty diesel emissions account for at least one third of the oxides of nitrogen (NOx) in the inventory. West Virginia University (WVU) has developed an extensive database of continuous transient gaseous emissions levels from a wide variety of heavy duty vehicles in field operation, from which a subset of vehicles (A to J) have been chosen for further analysis. The database was built using WVU transportable heavy duty chassis dynamometer testing laboratories. Several different transient cycles were utilized for testing including the Central Business District schedule. The resulting continuous emissions data from trucks and buses (vehicles A to J) were correlated with instantaneous axle power, but before correlating it was necessary to perform optimal time alignment or shifting of the exhaust emissions data with respect to the instantaneous power produced by the vehicle. Residence time distributions associated with the emissions measurement were addressed by applying a dispersion function to the measured axle power. The emissions inventory data obtained using transient chassis testing of vehicles of different model years and different engines, and their correlation with axle power can be employed in inventory models. Linear regression models were developed for gaseous emissions as a function of axle power. NOx and $\mathrm{CO} 2$ were predicted reliably for transient driving cycles based on the model developed for other cycles. CO prediction was found to be less reliable and was found to be engine and fuel specific. PM data were obtained gravimetrically while real-time continuous PM data are necessary for prediction. Ultimately these models can be applied to known vehicle activity to provide an estimate of the vehicle's contribution to the emissions inventory. The emissions data were also presented as the ratio $\mathrm{NOx} / \mathrm{CO} 2$, which is valuable for comparison with remote sensing emissions results. Data for $\mathrm{NOx} / \mathrm{CO} 2$ are widely scattered, but the average value of 0.0141 , for all vehicles considered, agrees with remote sensing and road tunnel study data for trucks. Data were repeatable across runs and test schedules, but vehicle type and test cycle influenced all exhaust emissions rates. 


\section{Table of Contents}

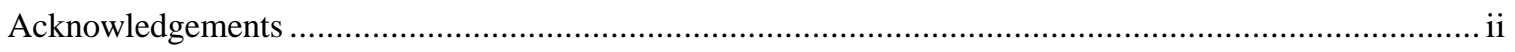

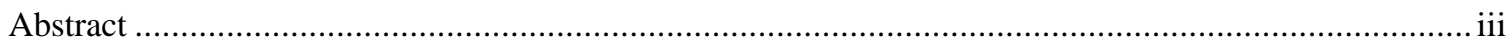

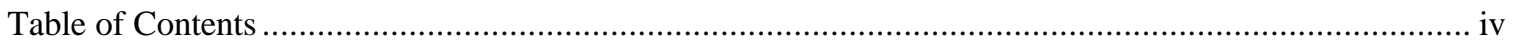

List 0

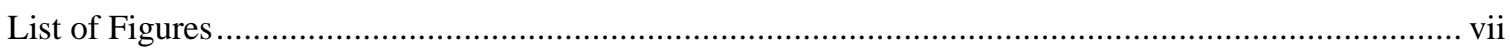

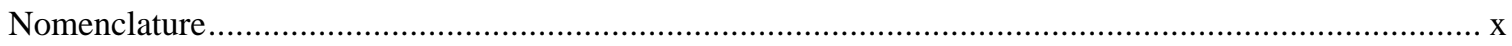

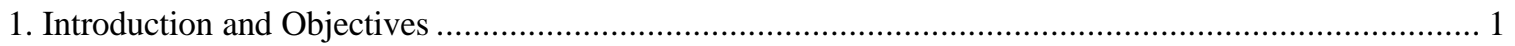

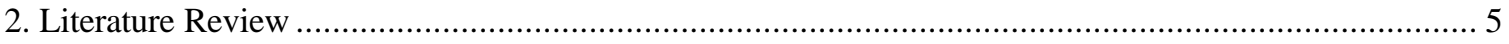

2.1 Motor Vehicle Emission Inventory Program (MVEI) ......................................................... 5

2.1.1 EMFAC MODEL .............................................................................................. 7

2.2 Present Heavy Duty Emissions Inventory ….................................................................. 9

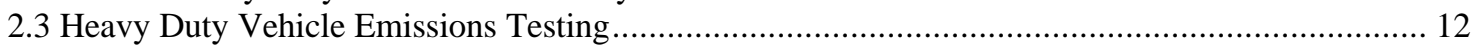

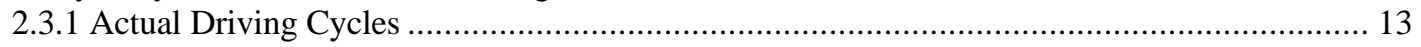

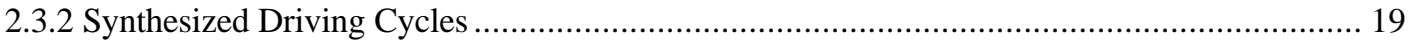

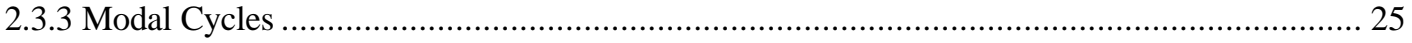

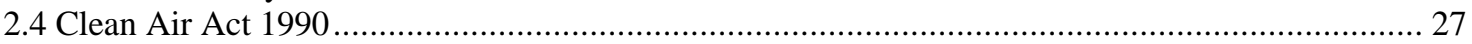

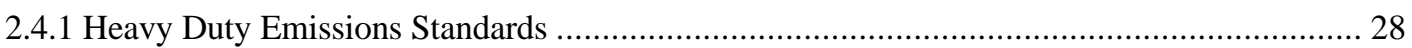

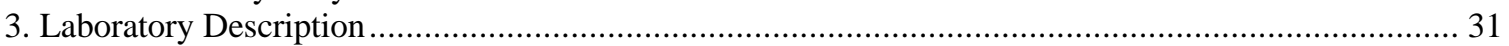

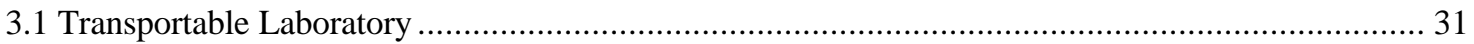

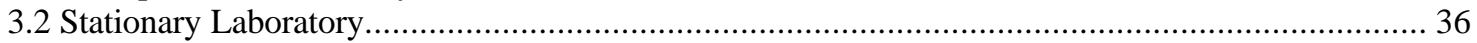

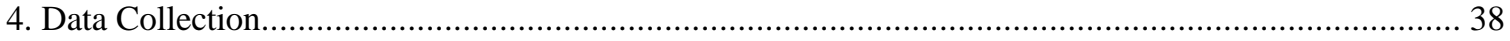

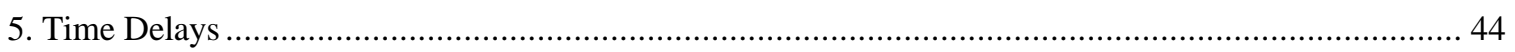

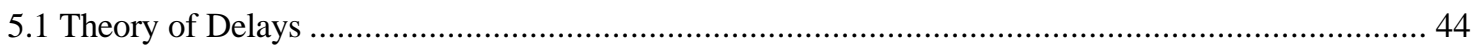

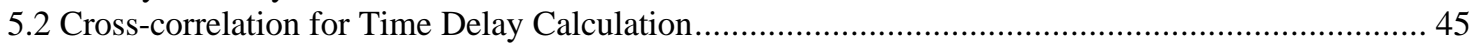

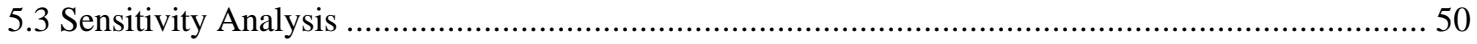

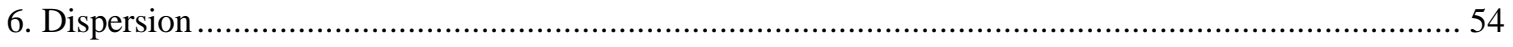

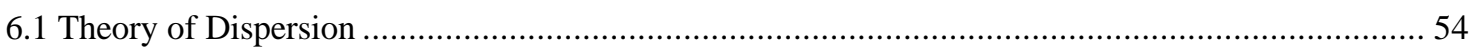

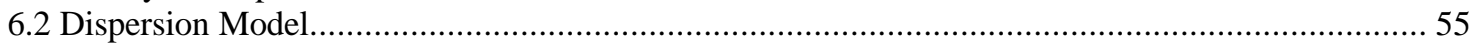

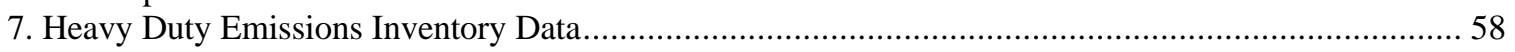

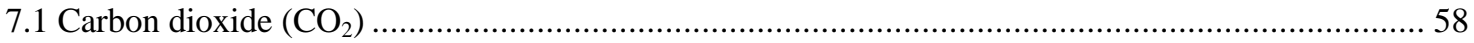

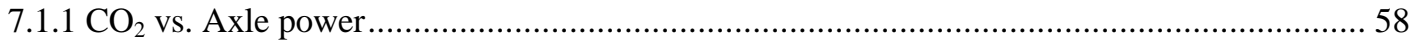

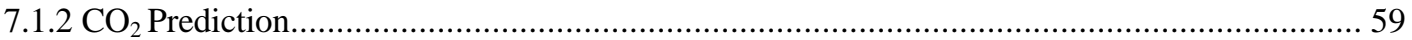

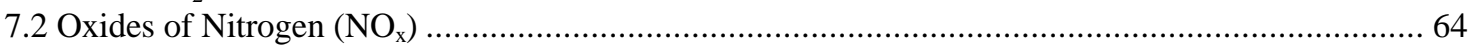

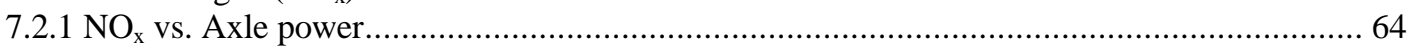

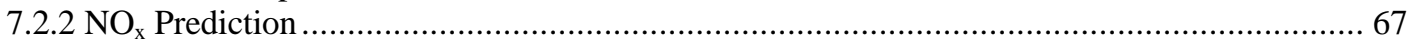

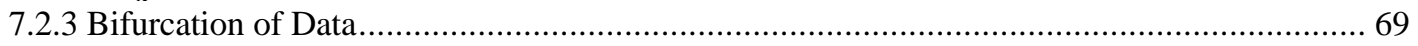

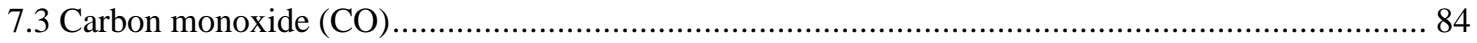

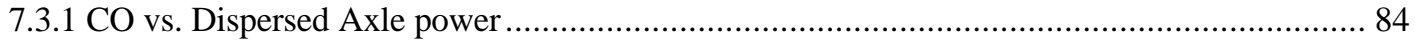

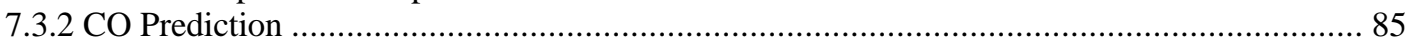

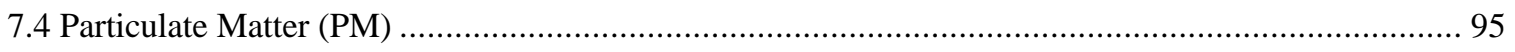

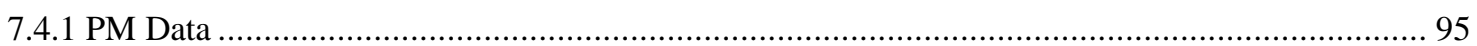

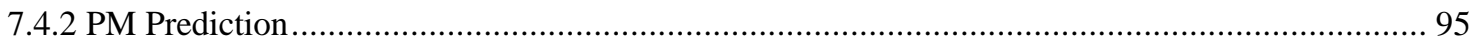

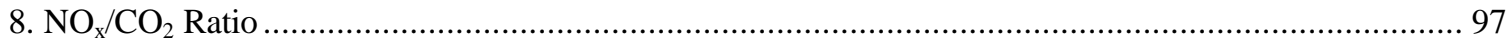

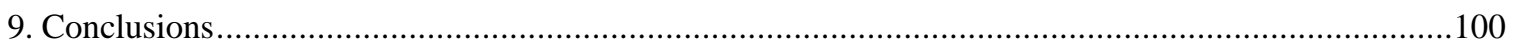




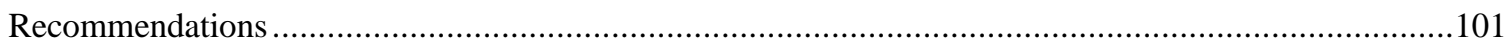

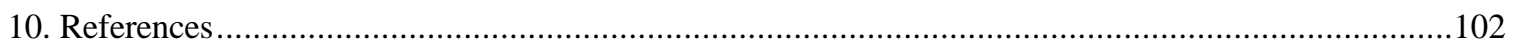

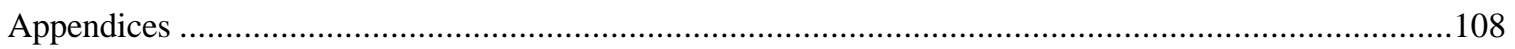

Appendix A- Speed Correction Factors ......................................................................... 108

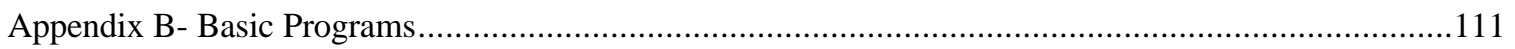




\section{List of Tables}

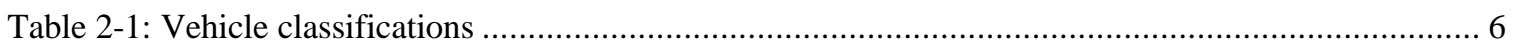

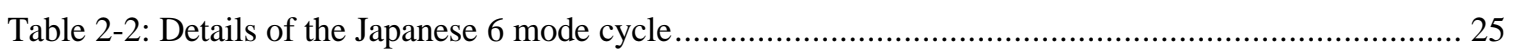

Table 2-3: Speed, load, weighting factors for the ECE R49 13 mode cycle …….................................... 26

Table 2-4: EPA emission standards for heavy duty diesel engines, g/bhp-hr ......................................... 28

Table 2-5: California emission standards for heavy duty diesel engines, g/bhp-hr ................................... 29

Table 2-6: EPA emission standards for model year 2004 and later heavy duty diesel engines, g/bhp-hr.... 30

Table 3-1: Manufacturers and model numbers of the specific analyzers used by the transportable

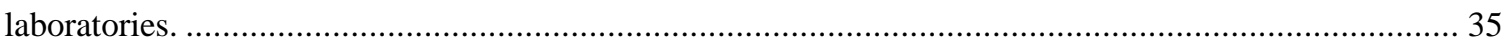

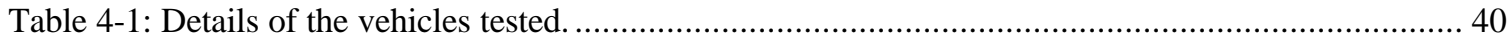

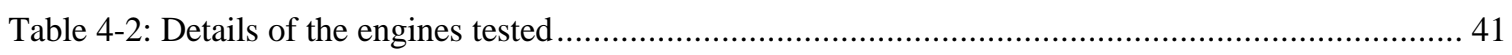

Table 4-3: Vehicles and cycles used for testing and emissions measured. ............................................... 42

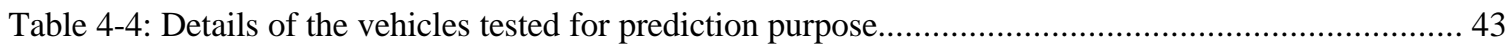

Table 7-1: Comparison between measured and predicted emissions......................................................... 83 


\section{List of Figures}

Figure 2-1: Block diagram of the different stages in the MVEI Model ................................................. 5

Figure 2-2: EPA Heavy Duty Engine Transient Cycle Federal Test Procedure (FTP) ............................... 10

Figure 2-3: EPA Heavy Duty Engine Transient Cycle Federal Test Cycle Procedure (FTP) ..................... 11

Figure 2-4: EPA Urban Dynamometer Driving Schedule for Heavy Duty Vehicles................................. 14

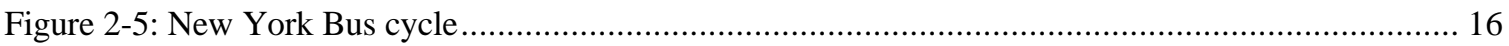

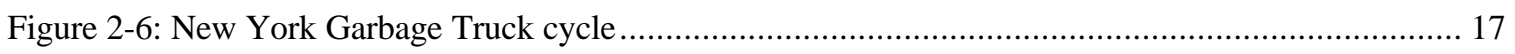

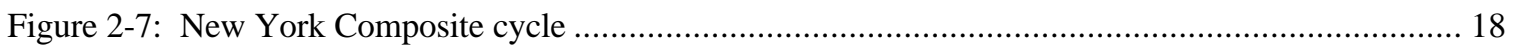

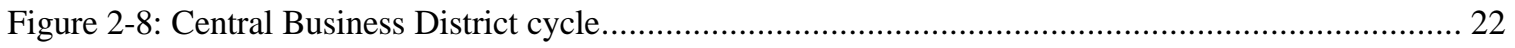

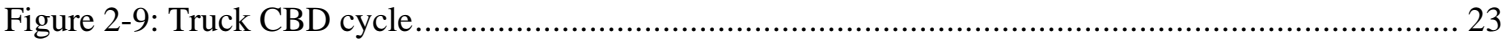

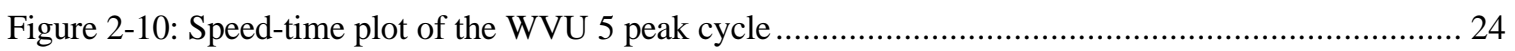

Figure 2-11: Speed-time plot of a vehicle following a 5 mile route …..................................................... 24

Figure 5-1: Shifted $\mathrm{NO}_{\mathrm{x}}(\mathrm{g} / \mathrm{s})$, axle power $(\mathrm{kW})$, and $\mathrm{CO}(\mathrm{g} / \mathrm{s})$ for a tractor truck (vehicle J) with a Detroit

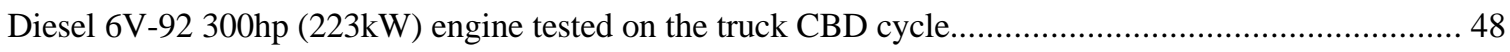

Figure 5-2: Shifted $\mathrm{NO}_{\mathrm{x}}$ and smoothed axle power for a tractor truck (Vehicle J) with a Detroit Diesel 6V$92300 \mathrm{hp}(223 \mathrm{~kW})$ engine tested on truck CBD cycle.

Figure 5-3: $\mathrm{NO}_{\mathrm{x}}$ vs. smoothed axle power with a time shift of $10 \mathrm{sec}$ for a tractor truck (vehicle J) with a

Detroit Diesel 6V-92 300hp (223kW) engine tested on the truck CBD cycle. 51

Figure 5-5: $\mathrm{NO}_{\mathrm{x}}$ vs. smoothed axle power with a time shift of $16 \mathrm{sec}$ for a Tractor Truck (vehicle J) with a Detroit Diesel 6V-92 300hp (223kW) engine tested on the truck CBD cycle. 52

Figure 5-6: Correlation Coefficient vs. phase lag of $\mathrm{NO}_{\mathrm{x}}$ emissions for a Tractor Truck (vehicle J) with a

Detroit Diesel 6V-92 300hp(223kW) engine tested on the truck CBD cycle. .53

Figure 7-1: Shifted $\mathrm{CO}_{2}$ and smoothed power for a transit bus (vehicle I) with a Detroit Diesel 6V-92 253hp $(188 \mathrm{~kW})$ engine tested on the CBD cycle.

Figure 7-2: Shifted $\mathrm{CO}_{2}$ and smoothed power for a transit bus (vehicle I) with a Detroit Diesel 6V-92 253hp $(188 \mathrm{~kW})$ engine tested on the New York Composite cycle. 60

Figure 7-3: Shifted $\mathrm{CO}_{2}$ and smoothed power for a tractor truck (vehicle J) with a Detroit Diesel 6V-92 $300 \mathrm{hp}(223 \mathrm{~kW})$ engine tested on the truck CBD cycle.

Figure 7-4: Shifted $\mathrm{CO}_{2}$ and smoothed power for a tractor truck (vehicle J) with a Detroit Diesel 6V-92 $300 \mathrm{hp}(223 \mathrm{~kW})$ engine tested on the 5 peak WVU test cycle. 61

Figure 7-5: Shifted $\mathrm{CO}_{2}$ as a function of smoothed axle power for a transit bus (vehicle I) with a Detroit Diesel 6V-92 $253 \mathrm{hp}(188 \mathrm{~kW})$ engine tested on the New York Composite cycle.

Figure 7-6: Shifted $\mathrm{CO}_{2}$ as a function of smoothed axle power for a transit bus (vehicle I) with a Detroit Diesel 6V-92 $253 \mathrm{hp}(188 \mathrm{~kW})$ engine tested on the CBD cycle 62

Figure 7-7: Shifted $\mathrm{CO}_{2}$ as a function of smoothed axle power for a tractor truck (vehicle J) with a Detroit Diesel 6V-92 $253 \mathrm{hp}(188 \mathrm{~kW})$ engine tested on the 5 peak WVU test cycle. 63 
Figure 7-8: Shifted $\mathrm{CO}_{2}$ as a function of smoothed axle power for a tractor truck (vehicle J) with a Detroit Diesel 6V-92 $300 \mathrm{hp}(223 \mathrm{~kW})$ engine tested on the truck CBD cycle

Figure 7-10: Vehicle A (transit bus, MY 96) on two consecutive runs tested on a CBD cycle................... 71

Figure 7-11: Comparison of emissions on different cycles tested on vehicle A........................................ 72

Figure 7-12: Emissions rate vs. Dispersed axle power for vehicles A, D, E and F tested on the CBD cycle.

Figure 7-13: Emissions rate vs. Dispersed axle power for vehicles $\mathrm{G}$ and $\mathrm{H}$ with manual transmissions tested on the truck CBD and CBD cycles respectively.

Figure 7-14: Data from vehicle A tested on a CBD cycle. The inverse of the customary emissions units has been because $\mathrm{g} / \mathrm{bhp}$-hr is undefined at zero power output. 75

Figure 7-15: Shifted $\mathrm{NO}_{\mathrm{x}}$ vs. Dispersed power for a transit bus (vehicle I) with a Detroit Diesel 6V-92 253 hp $(188 \mathrm{~kW})$ engine tested on the New York Composite cycle.

Figure 7-16: Shifted $\mathrm{NO}_{\mathrm{x}}$ vs. Dispersed power for a transit bus (vehicle I) with a Detroit Diesel 6V-92 253 $\mathrm{hp}(188 \mathrm{~kW})$ engine tested on the CBD cycle.

Figure 7-17: Shifted $\mathrm{NO}_{\mathrm{x}}$ vs. Dispersed power for a tractor truck (vehicle J) with a Detroit Diesel 6V-92 $300 \mathrm{hp}(223 \mathrm{~kW})$ engine tested on the 5-peak WVU test cycle. .78

Figure 7-18: Shifted $\mathrm{NO}_{\mathrm{x}}$ vs. Dispersed power for a tractor truck (vehicle J) with a Detroit Diesel 6V-92 $300 \mathrm{hp}(223 \mathrm{~kW})$ engine tested on the truck CBD cycle.

Figure 7-19: Shifted $\mathrm{NO}_{\mathrm{x}} /(\mathrm{a} * \mathrm{P}+\mathrm{b})$ vs. Engine speed for a tractor truck tested on a 5 mile route (1162-02) in Riverside, CA. 80

Figure 7-20: Shifted $\mathrm{NO}_{\mathrm{x}}$ vs. axle power for a tractor truck tested on a 5 mile route (1162-02) in Riverside, CA.

Figure 7-21: Shifted $\mathrm{NO}_{\mathrm{x}}$ vs. axle power for a Cummins M11 tractor truck tested on a 5 mile route (106101) in Sacramento, CA.

Figure 7-22: Shifted CO vs. Dispersed axle power for a tractor truck (vehicle J) with a Detroit Diesel 6V-92 $300 \mathrm{hp}(223 \mathrm{~kW})$ engine tested on the truck CBD cycle.

Figure 7-23: Measured vs. Predicted CO for a transit bus (vehicle I) with a Detroit Diesel 6V-92 253hp $(188 \mathrm{~kW})$ engine tested on the CBD cycle.

Figure 7-24: Measured vs. Predicted CO for a Transit Bus (vehicle I) with a Detroit Diesel 6V-92 253hp $(188 \mathrm{~kW})$ engine tested on the CBD cycle.

Figure 7-25: Measured vs. Predicted CO for a transit bus (vehicle I) with a Detroit Diesel 6V-92 253hp $(188 \mathrm{~kW})$ engine tested on the New York Composite cycle.

Figure 7-26: Measured vs. Predicted CO for a transit bus (vehicle I) with a Detroit Diesel 6V-92 253hp $(188 \mathrm{~kW})$ engine tested on the New York Composite cycle

Figure 7-27: Measured vs. Predicted CO for a tractor truck (vehicle J) with a Detroit Diesel 6V-92 300hp $(223 \mathrm{~kW})$ engine tested on the truck CBD cycle. 
Figure 7-28: Measured vs. Predicted CO for a tractor truck (vehicle J) with a Detroit Diesel 6V-92 300hp $(223 \mathrm{~kW})$ engine tested on the truck CBD cycle.

Figure 7-29: Measured vs. Predicted CO for a tractor truck (vehicle J) with a Detroit Diesel 6V-92 300hp $(223 \mathrm{~kW})$ engine tested on the 5-peak WVU test cycle. Correlation model based on the dispersed power data

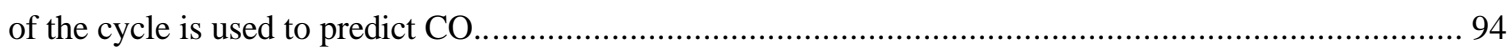

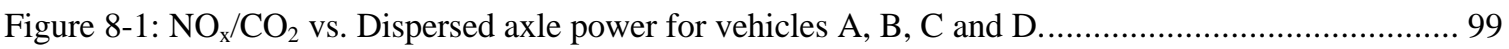

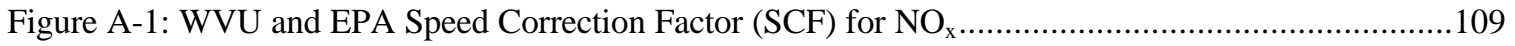

Figure A-2: WVU and EPA Speed Correction Factor (SCF) for CO .................................................110 


\section{Nomenclature}

\begin{tabular}{|c|c|}
\hline$\Delta \mathrm{t}$ & time interval \\
\hline ahp & axle horsepower \\
\hline BER & Basic Emissions Rate \\
\hline BSFC & Brake-Specific Fuel Consumption \\
\hline${ }^{\circ} \mathrm{C}$ & degree Celsius \\
\hline $\mathrm{CA}$ & California \\
\hline CAA & Clean Air Act \\
\hline CARB & California Air Resources Board \\
\hline CAT & catalyst equipped \\
\hline CBD & Central Business District Simulation \\
\hline CFR & Code of Federal Regulations \\
\hline $\mathrm{CH}_{3} \mathrm{OH}$ & Methanol \\
\hline $\mathrm{CH}_{4}$ & Methane \\
\hline $\mathrm{CO}$ & Carbon monoxide \\
\hline $\mathrm{CO}_{2}$ & Carbon dioxide \\
\hline$\Pi$ & Correlation Coefficient \\
\hline $\mathrm{D}$ & axial dispersion coefficient \\
\hline $\mathrm{d}$ & coefficient of molecular diffusion \\
\hline $\mathrm{D} / \mathrm{uL}$ & vessel dispersion number \\
\hline DC & direct current \\
\hline DDC & Detroit Diesel Corporation \\
\hline DSL & Diesel Fueled Vehicles \\
\hline ECE & Economic Commission for Europe \\
\hline EMFAC & Emission Factor Model \\
\hline EPA & Environmental Protection Agency \\
\hline${ }^{\circ} \mathrm{F}$ & degree Fahrenheit \\
\hline
\end{tabular}




\begin{tabular}{|c|c|}
\hline FE & fuel economy \\
\hline FTP & Federal Test Procedure \\
\hline$\rho$ & fuel density \\
\hline $\mathrm{g} / \mathrm{bhp}-\mathrm{hr}$ & grams per brake horsepower hour \\
\hline $\mathrm{g} / \mathrm{mile}$ & grams per mile \\
\hline$g / s$ & grams per second \\
\hline gal & gallon \\
\hline GVW & Gross Vehicle Weight \\
\hline $\mathrm{HC}$ & Hydrocarbons \\
\hline $\mathrm{HCHO}$ & Formaldehyde \\
\hline HHDT & Heavy-Heavy Duty Diesel Trucks \\
\hline $\mathrm{hp}$ & horsepower \\
\hline $\mathrm{Hz}$ & hertz \\
\hline $\mathrm{I} / \mathrm{M}$ & Inspection and Maintenance \\
\hline $\mathrm{kg}$ & kilograms \\
\hline $\mathrm{km}$ & kilometer \\
\hline $\mathrm{kW}$ & kilowatts \\
\hline $\mathrm{L}$ & length \\
\hline $\mathrm{lbs}$ & pounds \\
\hline LDA & Light-Duty Automobiles \\
\hline LDT & Light-Duty Trucks \\
\hline LHDT & Light-Heavy Diesel Trucks \\
\hline LHGT & Light-Heavy Gas Trucks \\
\hline $\mathrm{m} / \mathrm{s}$ & meters per second \\
\hline $\mathrm{m} / \mathrm{s}^{2}$ & meters per second squared \\
\hline $\mathrm{MCY}$ & Motorcycles \\
\hline MDT & Medium-Duty Trucks \\
\hline$\tau$ & mean time shift \\
\hline
\end{tabular}




\begin{tabular}{|c|c|}
\hline MHDT & Medium-Heavy Diesel Trucks \\
\hline MHGT & Medium-Heavy Gas Trucks \\
\hline $\mathrm{mm}$ & millimeters \\
\hline $\mathrm{mph}$ & miles per hour \\
\hline MVEI & Motor Vehicle Emission Inventory \\
\hline MY & Model Year \\
\hline NCAT & non-catalyst equipped \\
\hline NMHC & non-methane hydrocarbons \\
\hline $\mathrm{NO}_{\mathrm{x}}$ & Oxides of Nitrogen \\
\hline NYGTC & New York Garbage Truck Cycle \\
\hline $\mathrm{O}_{3}$ & Ozone \\
\hline $\mathrm{P}(\mathrm{t})$ & power \\
\hline PM & Particulate Matter \\
\hline $\mathrm{R}^{2}$ & coefficient of Regression \\
\hline RTD & Residence Time Distribution \\
\hline SAE & Society of Automotive Engineers \\
\hline $\operatorname{scfm}$ & standard cubic feet per minute \\
\hline SOP & Statement of Principle \\
\hline SwRI & Southwest Research Institute \\
\hline $\mathrm{u}$ & average velocity \\
\hline UTB & Urban Transit Buses \\
\hline VMT & Vehicle Miles Traveled \\
\hline WVU & West Virginia University \\
\hline
\end{tabular}




\section{Introduction and Objectives}

Emissions inventory involves estimation of total emissions released into the atmosphere from stationary, area, and mobile sources of pollution within an air basin. Heavy duty emissions represent a significant portion of the mobile source emissions inventory. Accurate estimation of their contribution is essential as on-highway and nonroad heavy duty diesel emissions are argued to account for at least one third of the oxides of nitrogen $\left(\mathrm{NO}_{\mathrm{x}}\right)$ in the inventory [Grumet et al., 1997]. A 1997 Standard and Poor's report prepared for the American Trucking Association argues that U.S. freight volume will increase by $21.5 \%$ from 1997 to 2006, which will increase the concern over truck emissions. Many studies argue that $\mathrm{NO}_{\mathrm{x}}$ and Particulate Matter (PM) mass are mainly contributed by diesel engines while carbon monoxide (CO) and hydrocarbons (HC) are mainly contributed by gasoline engines. It is argued from a tunnel study that diesel engines produce five times the mass of $\mathrm{NO}_{\mathrm{x}}$ per mass of fuel burned compared to gasoline vehicles [Kirchstetter et al., 1998]. $\mathrm{NO}_{\mathrm{x}}$ and gas phase hydrocarbons (HC) are the main precursors of urban/regional ozone $\left(\mathrm{O}_{3}\right)$, which results in an increase in the ambient ozone levels. The increase of $\mathrm{O}_{3}$ at the ground level is undesirable, as $\mathrm{O}_{3}$ is a poisonous gas. However, despite this level of contribution, precise data on the levels of heavy duty $\mathrm{NO}_{\mathrm{x}}$ emissions are lacking and the present emissions inventory are primitive. "As the in-use light duty fleet becomes cleaner, the role of heavy duty vehicles on ambient air quality becomes important" [Cadle et al., 1997]. The estimated emissions for heavy duty diesel-powered vehicles are uncertain due to problems with the emission rate quantification, highly inaccurate vehicle activity estimates, and test cycles that are not representative of real road conditions and questionable activity emission rate correction 
factors [Guensler et al., 1991]. The total amount of uncertainty may be greater than the uncertainty in each step of the emission inventory preparation process. The insufficient data with respect to heavy duty vehicles can be overcome with the extensive database of continuous transient gaseous emission levels developed by West Virginia University, from testing a wide variety of heavy duty vehicles in field operation.

The objective of this project is to provide the research community with representative emissions data from present day heavy duty trucks and buses by examining the relationship between tailpipe emissions and axle power of the vehicle with a view to developing models that can be used in emissions inventory. It is the intent of the author to provide a vignette of gaseous emissions found for heavy duty trucks and buses that are currently in use. These data obtained by the staff of the WVU transportable heavy duty vehicle emissions testing laboratories, using transient chassis testing of vehicles of different model years and different engines, may be employed in inventory models or in the verification of remote sensing technology, which is emerging for heavy duty vehicles. For inventory purposes the data are presented in units of grams per second as a function of power at the vehicle rear wheels, where as for comparison with remote sensing results, the data are presented in a ratio of oxides of nitrogen to carbon dioxide $\left(\mathrm{NO}_{\mathrm{x}} / \mathrm{CO}_{2}\right)$ against power. The $\mathrm{NO}_{\mathrm{x}} / \mathrm{CO}_{2}$ ratios may also be employed for inventory purposes if inventory is based upon the mass of the fuel consumed since weight of $\mathrm{CO}_{2}(3.2 \mathrm{~g})$ produced reliably indicates the consumption of $1 \mathrm{~g}$ of heavy diesel fuel, which has a carbon to hydrogen ratio of 1.7 . Heavy duty $\mathrm{NO}_{\mathrm{x}} / \mathrm{CO}_{2}$ ratios will also be of interest to those performing road tunnel studies [Countess et al., 1998]. Tunnel studies also report ratios such as $\mathrm{CO} / \mathrm{NO}_{\mathrm{x}}$ and $\mathrm{HC} / \mathrm{NO}_{\mathrm{x}}$ [Kirchstetter et al., 1994] and compare the 
predictions with the mobile source emission factor model predictions. Fujita et al. [1992] documented the ambient versus inventory $\mathrm{CO} / \mathrm{NO}_{\mathrm{x}}, \mathrm{HC} / \mathrm{NO}_{\mathrm{x}}$ ratios and discrepancies in the Los Angeles basin and concluded that the automotive $\mathrm{CO}$ and $\mathrm{HC}$ emissions were badly underestimated while the $\mathrm{NO}_{\mathrm{x}}$ was fairly well predicted.

The idea of building the emissions inventory by correlating emissions with real world activity, in terms of the instantaneous power of the vehicle, could be improved by using engine speed, engine load and time derivatives of engine load rather than merely axle power, but the bulk of heavy duty vehicle emissions data available has only axle power and vehicle speed as independent parameters, and the vehicle speed cannot be unambiguously related to engine speed due to gearing. The ability of the axle power as a lone parameter to predict emissions is therefore explored. In emission prediction and inventory the delay time due to the analyzer and sampling lines is calculated and residential time distribution is applied. A simple correlation model of emission components such as $\mathrm{NO}_{\mathrm{x}}, \mathrm{CO}_{2}, \mathrm{CO}$ and $\mathrm{PM}$ with the axle power is developed and emission prediction on the basis of axle power is attempted. $\mathrm{NO}_{\mathrm{x}}$ and $\mathrm{CO}_{2}$ are almost linear with axle power and the emission prediction of these components on the basis on axle power matches closely with the measured ones, except during the cases of "off-cycle injection timing", which refers to the advancing of the injection timing to improve fuel economy. CO and PM depend on engine control strategies and they are specific to a particular engine, so their prediction results in deviation with the test values. Emission inventory data for trucks and buses of different model years (diesel engines) on the basis of axle power are reported for different test cycles. Attempts are made to predict $\mathrm{NO}_{\mathrm{x}}$ and $\mathrm{CO}$ emissions during one test cycle on the basis of emissions produced during a different 
cycle and comparison between measured and predicted emissions are made. Particulate Matter (PM) is measured gravimetrically by measuring the difference in the weight of the filter before the start and after the end of the test. Since the PM measurement is not continuous but integrated, it is difficult to predict unlike the other gaseous components. Emission inventory data are repeatable across runs and test schedules, but vehicle type and test cycle influenced all exhaust emissions rates. 


\section{Literature Review}

\subsection{Motor Vehicle Emission Inventory Program (MVEI)}

Motor Vehicle Emissions Inventory Program was initiated by the California Air Resources Board (CARB) to estimate the emissions inventory of diesel vehicles and correct the inconsistencies in the existing model. Review of the MVEI model presented in the "Methodology for estimating emissions from on-road vehicles", Report, October 1996 is presented below.

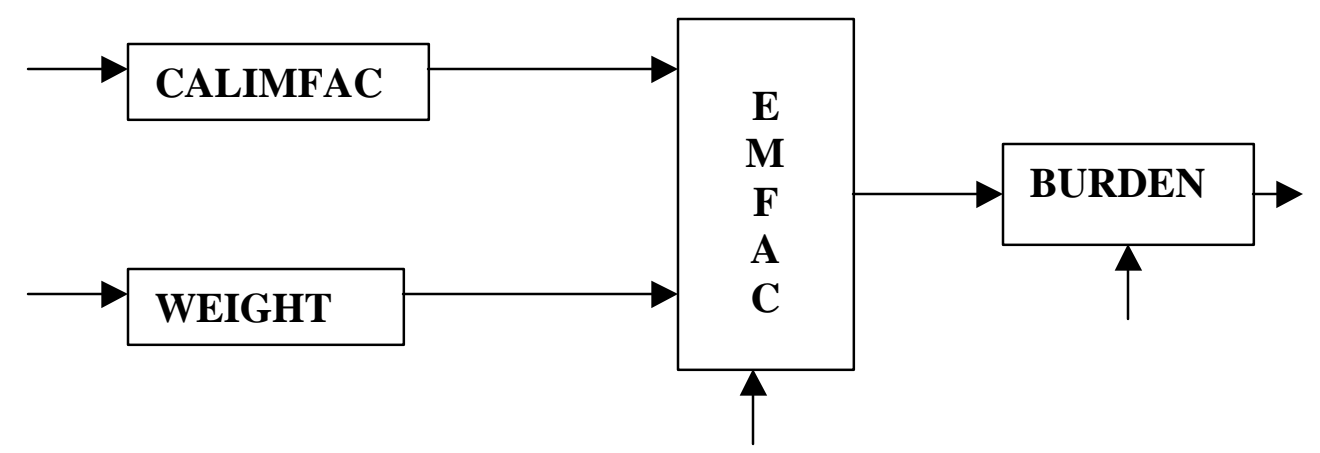

Figure 2-1: Block diagram of the different stages in the MVEI Model

The MVEI Model is composed of four computer models namely CALIMFAC, WEIGHT, BURDEN and EMFAC as shown in figure 2-1. The CALIMFAC model produces emission rates for each model year when the vehicle is new and as it accumulates mileage and emission controls deteriorate. The WEIGHT model calculates the relative weighting each model year should be given in the total inventory, and each model year's accumulated mileage. The EMFAC model uses these pieces of information, along with correction factors and other data, to produce fleet composite emission factors. 
Finally the BURDEN model combines the emission factors with the county specific activity data to produce emission inventories.

Initially the Vehicles are classified according to the Vehicle Class and the Technology Groups to categorize the emissions. The Technology Groups include noncatalyst (NCAT), catalyst equipped (CAT), and diesel (DSL) fueled vehicles.

Table 2-1 Vehicle classifications

\begin{tabular}{|l|l|l|l|}
\hline Class \# & Class & Technology Groups & Vehicle Class \\
\hline 1 & LDA & NCAT, CAT, DSL & Light-Duty Automobiles \\
\hline 2 & LDT & NCAT, CAT, DSL & Light-Duty Trucks \\
\hline 3 & MDT & NCAT, CAT, DSL & Medium-Duty Trucks \\
\hline 4 & LHGT & NCAT, CAT, DSL & Light-Heavy Gas Trucks \\
\hline 5 & LHDT & NCAT, CAT, DSL & Light-Heavy Diesel Trucks \\
\hline 6 & MHGT & NCAT, CAT, DSL & Medium-Heavy Gas Trucks \\
\hline 7 & MHDT & NCAT, CAT, DSL & Medium-Heavy Diesel Trucks \\
\hline 8 & HHDT & NCAT, CAT, DSL & Heavy-Heavy Diesel Trucks \\
\hline 9 & UTB & NCAT, CAT, DSL & Urban Transit Buses \\
\hline 10 & MCY & NCAT, CAT, DSL & Motorcycles \\
\hline
\end{tabular}

The possible sources of emissions from these vehicles are identified as Exhaust Emissions Sources. Oxides of nitrogen $\left(\mathrm{NO}_{\mathrm{x}}\right)$ are a combustion by-product at high temperatures, when oxygen and nitrogen combine. $\mathrm{NO}_{\mathrm{x}}$ is formed especially when the 
engine is loaded or is under slightly lean conditions and is sensitive to timing advances and air/fuel ratio. Incomplete combustion of the fuel is the primary cause for carbon monoxide $(\mathrm{CO})$ and particulate matter (PM) emissions. Evaporative Emissions sources consists of diurnal, hot-soak, resting and running losses.

\subsubsection{EMFAC MODEL}

\section{CALIMFAC MODEL}

The CALIMFAC Model signifies California Inspection and Maintenance Emission Factor Model. The Basic Emissions Rate (BER) in terms of the Vehicle Miles Traveled (VMT) in g/mile for the particular vehicle category of the vehicle is calculated from the chassis dynamometer testing done on the vehicle. The Basic Emissions Rate consists of zero mile rate in $\mathrm{g} / \mathrm{mile}$ and the deterioration rate to account for the increase in the emissions of the vehicle due to the accumulation of miles. The zero mile rate is the average model year emission rate of a brand-new vehicle for a particular vehicle class/tech type and pollutant. There are separate BERs for each vehicle class, technology, model year, pollutant, and process and I/M program.

\section{WEIGHT}

WEIGHT is a part of the model and it calculates the mileage accumulated by different vehicle categories and different model years. The model provides the travel fraction by technology group and model year. The WEIGHT provides the model year travel fraction, which is applied on the Basic Emissions Rate to calculate the composite emission factors. 


\section{EMFAC}

The Emission Factor model combines the information from other models and utilizes correction factors to compute the fleet composite emission factors. The correction factors are developed to calculate the emissions of the vehicles on a broader range of operating conditions than the ones simulated by the driving cycle. The driving cycle may test the vehicle at a particular speed and temperature, which is not representative of the real road conditions and necessitates the use of correction factors. The correction factors used in the model are for temperature, cycle, speed and fuel applicable for LDA, LDT and MDT catalyst vehicles while speed correction factor alone exist for heavy duty diesel vehicles.

\section{BURDEN}

BURDEN develops the emissions inventory for the county by taking the emission factors from the EMFAC model and estimates the total emissions for each air basin, and state. The model also estimates fuel consumption and lead emissions from fuel consumption data. To run the model, various input parameters like name of basin, calendar year, and model year need to be specified. The BURDEN report summarizes the emissions data in a tabular format. 


\subsection{Present Heavy Duty Emissions Inventory}

The existing emission inventory models for heavy duty engines follow measurements from the Transient Federal Test Procedure (FTP), figures 2-2, 2-3 which is an engine-based, well defined, speed-time and torque-time trace as specified in the Code of Federal Regulations, CFR40, Pt. 86, Subpart N. A chassis dynamometer test with the engine in a vehicle may be preferred for gathering inventory data because the engine FTP is both time consuming and expensive, due to the process of removing the engine for test purposes, testing it on the engine dynamometer and refitting it to the vehicle [McKain et al., 1998].

There is no assurance that the FTP yields emissions from an engine that are indicative of emissions in real use. The FTP was developed over two decades ago [EPA, 1978] using a mix of vehicles, both diesel and gasoline, that do not represent today's fleet. Although a chassis test cycle was also developed from the same bank of data as the FTP, correlation between the chassis and engine tests were not found to be good [Dietzmann et al., 1985]. Dietzmann et al. [1985] found that even the best correlating emission component $\left(\mathrm{NO}_{\mathrm{x}}\right)$, had different emissions rates in the engine and the chassis tests and therefore making prediction difficult. The heavy duty engine testing provides emissions in mass per unit work done or grams per brake horsepower-hour (g/bhp-hr). In preparation of the emissions inventory, emissions are required in units of mass per distance traveled or grams per mile ( $\mathrm{g} / \mathrm{mile}$ ), to correlate the emissions directly to the vehicle activity, in terms of vehicle miles traveled (VMT). A conversion factor developed by Machiele [1989] is utilized for converting emissions results from the engine FTP. The 
conversion factor employs brake-specific fuel consumption (BSFC), fuel density ( $\rho$ ) and fuel economy (FE).

$\frac{g}{\text { mile }}=\frac{g}{b h p-h r} \times \frac{\rho\left(\frac{l b}{g a l}\right)}{\left(B S F C\left(\frac{l b}{b h p-h r}\right) \times F E\left(\frac{\text { miles }}{\text { gal }}\right)\right)}$

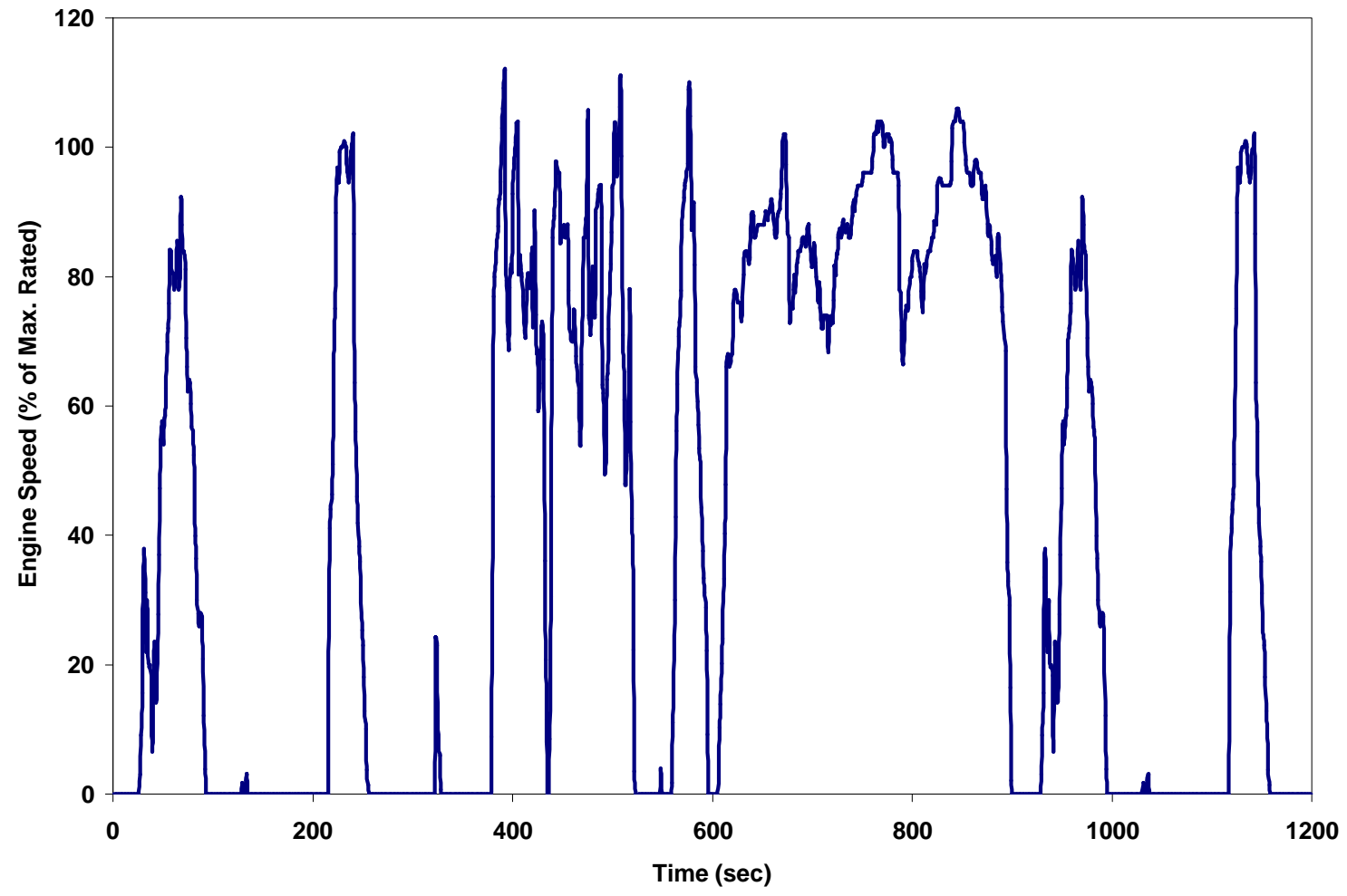

Figure 2-2: EPA Heavy Duty Engine Transient Cycle Federal Test Procedure (FTP) 


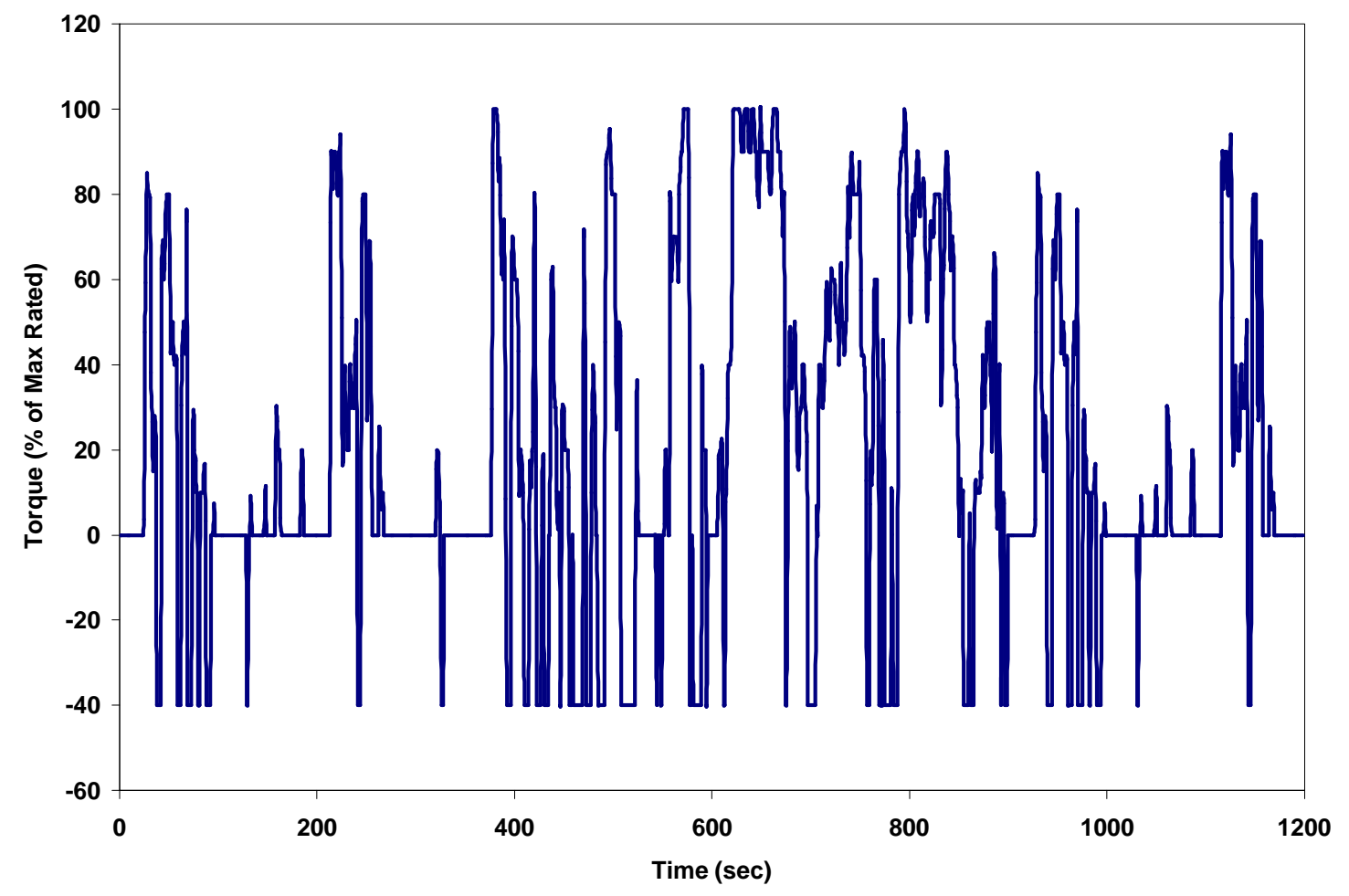

Figure 2-3: EPA Heavy Duty Engine Transient Cycle Federal Test Cycle Procedure (FTP) 


\subsection{Heavy Duty Vehicle Emissions Testing}

Heavy duty vehicles like trucks and buses are tested for emissions through an engine or chassis based test cycle. The test cycles are designed to test the vehicle for its emissions under various conditions such as acceleration; cruise, deceleration and idling which are done to simulate the on-road conditions. In general, engine test cycles are schedules of speed and loads, whereas chassis test cycles consist of speed versus time traces with power absorbers used to simulate road load, aerodynamic drag and gradients on the vehicle and flywheels for simulating the inertia of the vehicle [Plint et al., 1995]. A review of chassis and engine test cycles follows [Bata et al., 1994].

In the early 1970's, the EPA initiated the CAPE-21 study to address vehicle emissions by collecting data from in-use heavy duty vehicles. Fifty-five trucks and five buses from New York City and Los Angeles were monitored and data were collected in both freeway and urban driving conditions. The database was supplemented with the traffic count data taken at approximately 275 cordon points in the three states from 6 a.m. to 8 p.m. for a typical weekday in 1962-63 [Cosby, 1973]. The goal was to understand the behavior of trucks in urban and freeway conditions and characterize the pattern and functions of these trucks under these conditions.

The final CAPE-21 database consisted of the operating data for forty-four trucks and four buses in New York and forty-four trucks and three buses in Los Angeles. The vehicles monitored included gasoline/diesel, two-axle, three-axle and tractor- trailer configurations. The data were recorded and reduced to a "power tape" form. The power tape form lists engine speed and load factors as percentages of engine speed and power 
respectively. This set of power tape data is the CAPE-21 database in its final form [EPA, 1978b].

In 1974, EPA awarded the Olson Laboratories the " Heavy Duty Vehicle Cycle Development" contract to process the database of CAPE-21 and develop chassis and engine dynamometer cycles that are representative of the CAPE-21 database [EPA, 1978b]. Monte Carlo simulations were run for the NY non-freeway, LA freeway and LA non-freeway from the collected data and these sub cycles were combined to form a whole cycle representative of the real life driving conditions [EPA, 1978a].

\subsubsection{Actual Driving Cycles}

These are the cycles developed from the day-to-day driving schedules on the road such as the Federal Testing Procedure. The observed data are represented statiscally by using a probability density function on joint speed-acceleration axes and weighting each of the route aggregate data by the density of traffic flow [Bata et al., 1994]. The individual micro-trips are combined to form a driving cycle that is the best representative of the collected data i.e., the actual driving conditions. The statiscally derived cycles are the Federal Test Procedure (FTP), figures 2-2, 2-3 for engine testing and the EPA Urban Dynamometer Testing Schedule for Heavy Duty Vehicles (Test D), figure 2-4, for Chassis testing, both listed in CFR 40, Pt. 86, 1996. The latter is highly transient and is very difficult to follow closely for the vehicles with unsynchronized manual transmissions. Since 1984, the EPA have required emissions certifications testing using the FTP mandatory for all the heavy duty on road engines sold in the United States [SwRI, 1997]. 


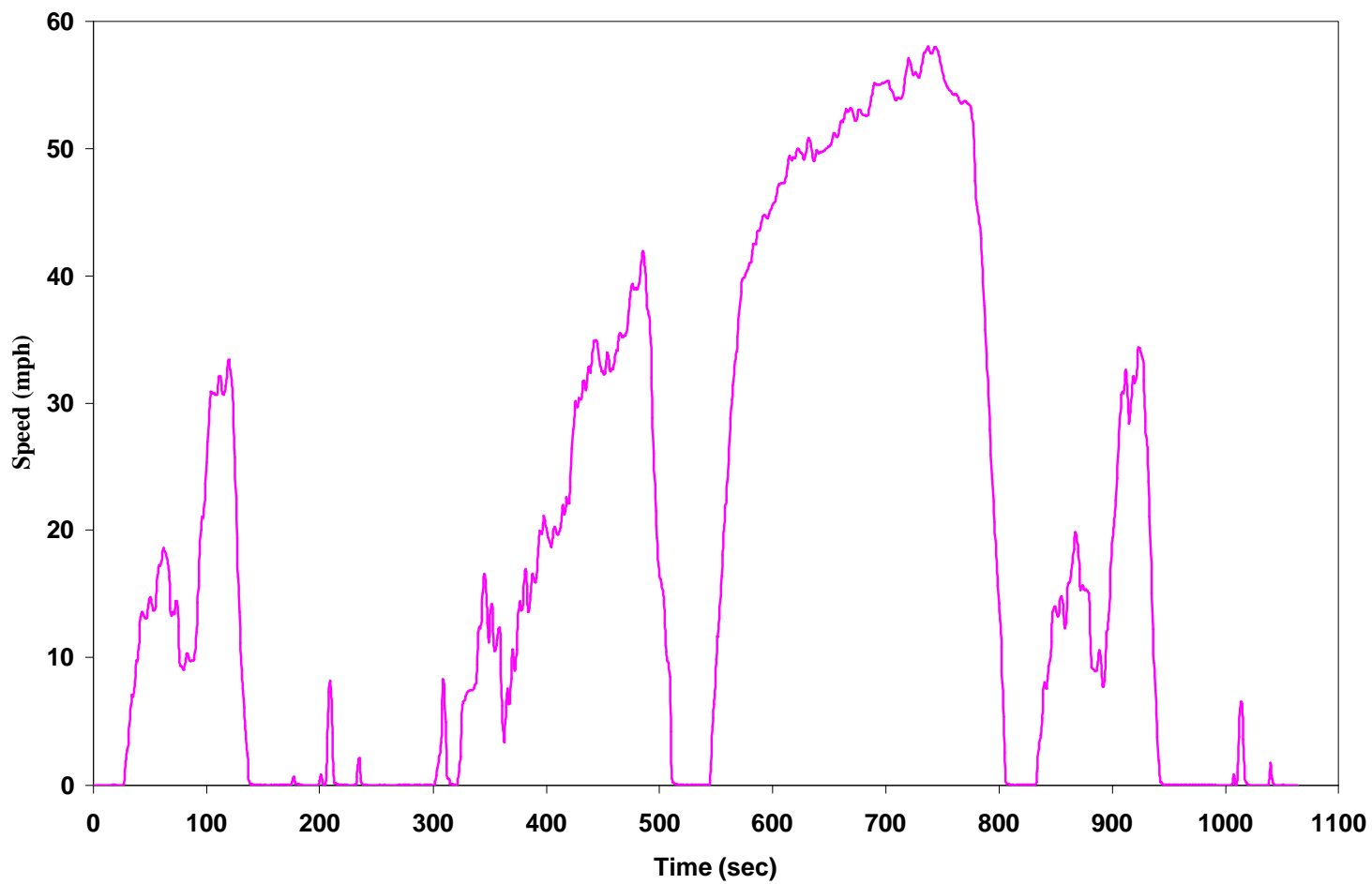

Figure 2-4: EPA Urban Dynamometer Driving Schedule for Heavy Duty Vehicles

\section{(Test D)}


Other tests derived from actual vehicle data were the New York Bus cycle and New York Composite cycle as shown in figures 2-5, 2-7 [EPA, 1978b]. These tests along with the Test D were used in Canada to compare diesel and ethanol bus emissions [King et al., 1992]. It was observed that the New York Bus cycle intended to simulate very low average speed driving operations in congested urban traffic produced fuel consumption and $\mathrm{CO}_{2}$ emissions in $\mathrm{g} /$ mile twice that of any other cycle. It is understood that the cycle is applicable only to those cities that have a high degree of traffic density such as Tokyo or New York city [King et al., 1992]. WVU researchers developed the New York Garbage Truck cycle (NYGTC), figure 2-6, representative of the in-use refuse trucks [Clark et al., 1997]. The cycle incorporates three compactions while the vehicle is not moving and has fixed acceleration rates.

The New York Composite cycle was used by the Chevron Corporation and referred to as the "Unfiltered Bus Cycle", to test emissions and fuel economy of a methanol bus with a 1988 DDC engine [Thompson et al., 1990]. The cycle has high frequency components and is not repetitious; it explores the engine performance fully. 


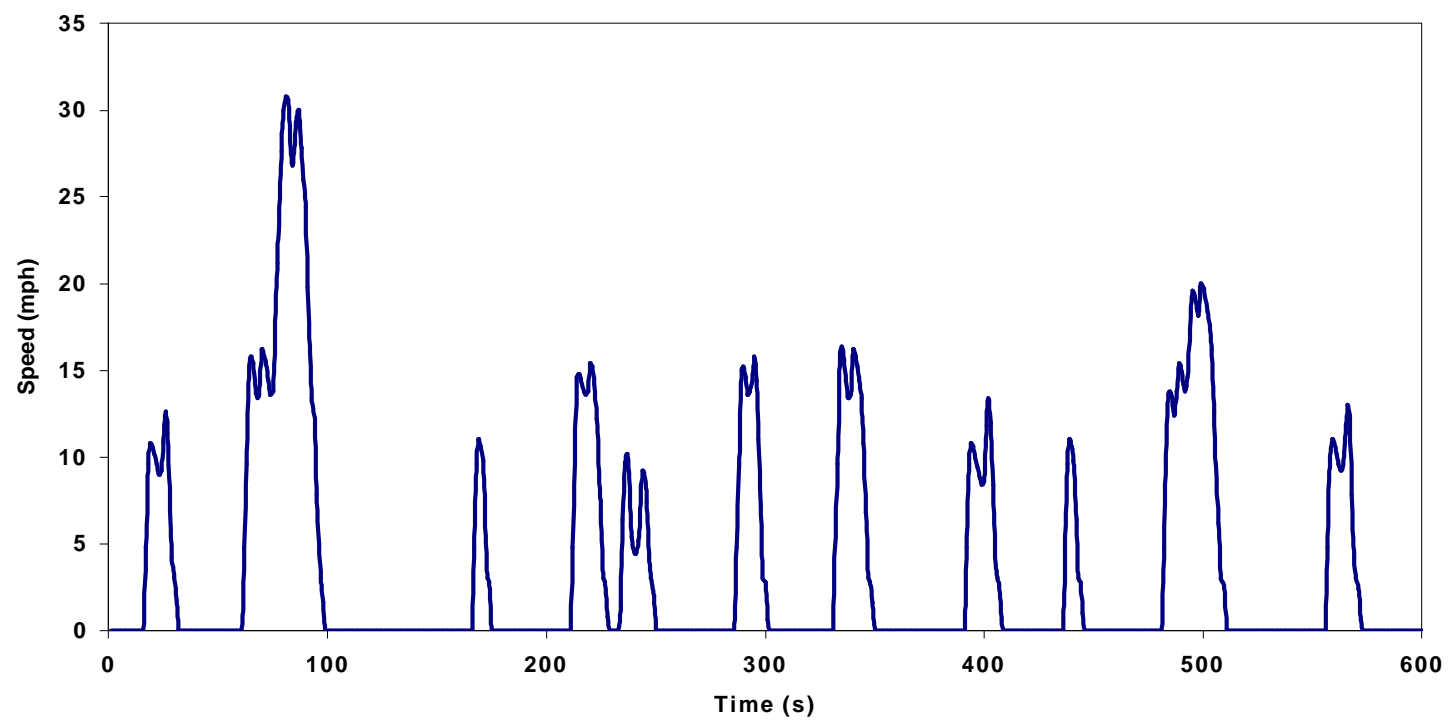

Figure 2-5: New York Bus cycle 


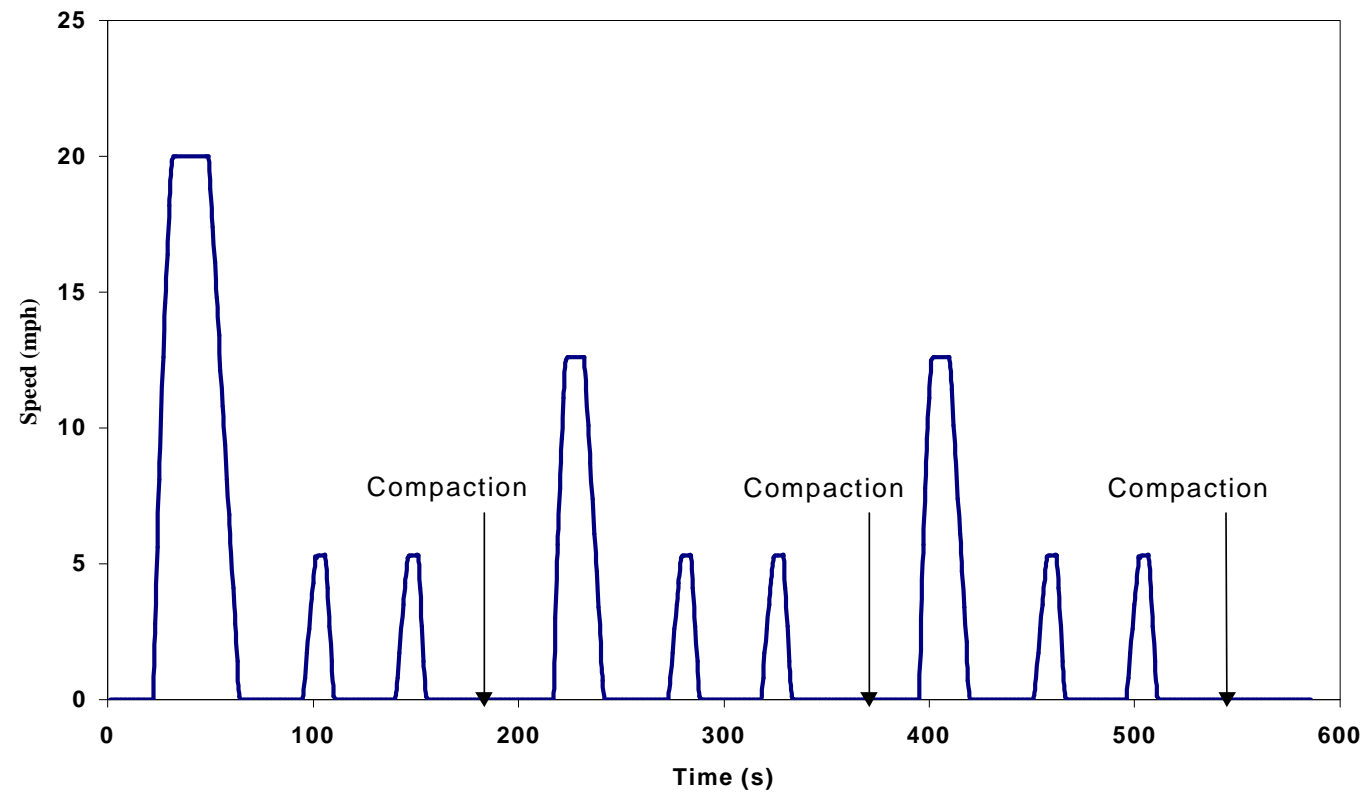

Figure 2-6: New York Garbage Truck cycle 


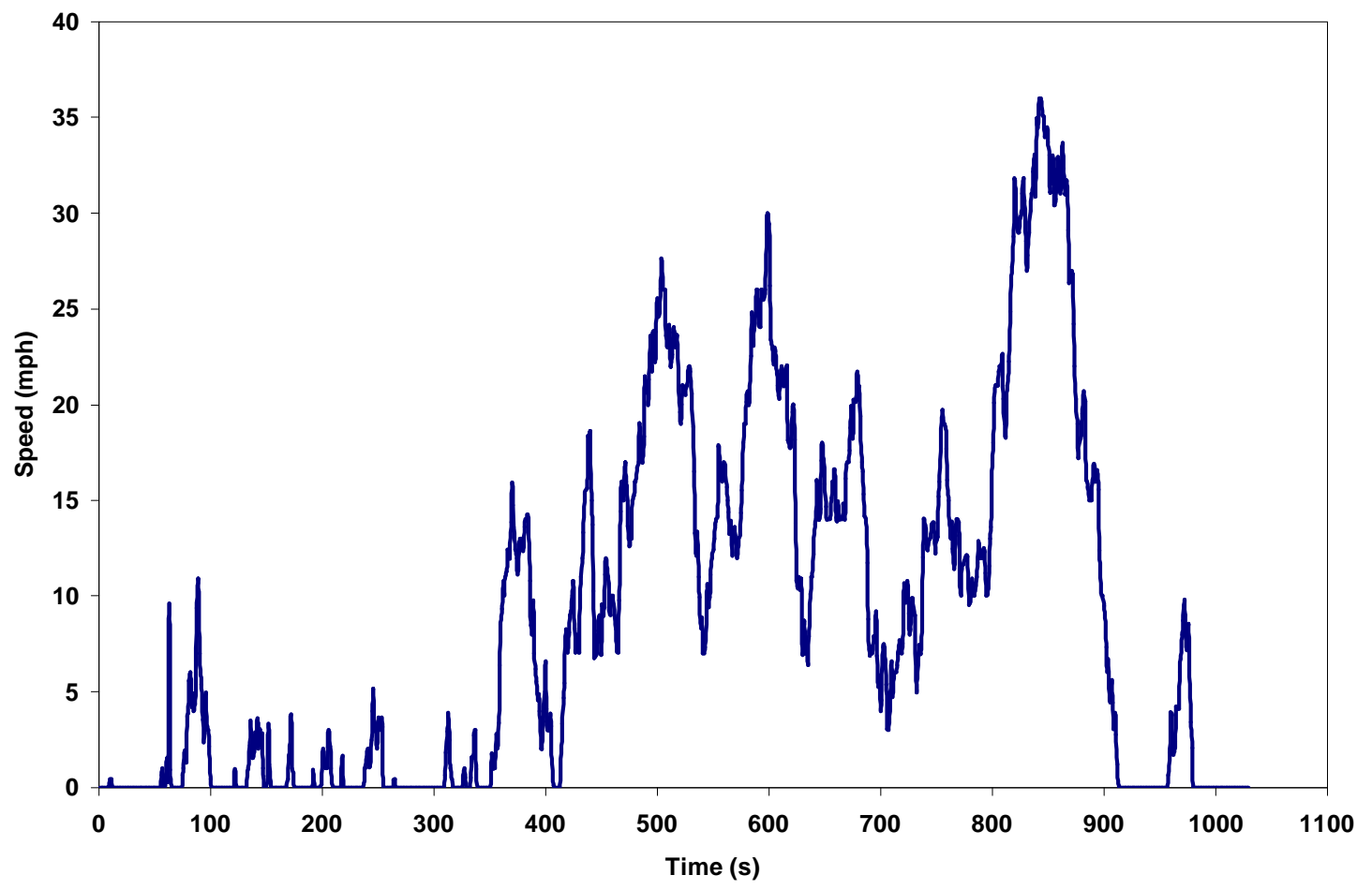

Figure 2-7: New York Composite cycle 


\subsubsection{Synthesized Driving Cycles}

Synthesized driving cycles are developed by considering different driving modes namely idling, cruise, acceleration and deceleration. These cycles eliminate the need for large banks of actual data. The synthesized driving cycles are constructed from a number of constant acceleration and speed phases. The modes identified for heavy duty testing cycles are as follows [Bata et al., 1994]

Acceleration - The vehicle's acceleration is more than $0.03 \mathrm{~m} / \mathrm{s}^{2}$

Cruise mode - The vehicle's speed is greater than $0.3 \mathrm{~m} / \mathrm{s}$ and the acceleration of the vehicle is less than $0.3 \mathrm{~m} / \mathrm{s}^{2}$

Deceleration - The vehicle's deceleration is less than $0.3 \mathrm{~m} / \mathrm{s}^{2}$

Idling - The vehicle's speed is less than $0.3 \mathrm{~m} / \mathrm{s}$

Note: The indicated acceleration and deceleration rates and speeds are prescribed, but lower values may be utilized to compensate for the low power to weight ratios of heavy duty vehicles.

The Central Business District Simulation (CBD) cycle [Clark et al., 1995], which is used for testing transit buses in the WVU Transportable Laboratories, is prescribed by Society of Automotive Engineers Recommended Practice (SAE J 1376, 1993). The CBD is composed of 14 repetitions of the basic cycle with the maximum speed of $8.9 \mathrm{~m} / \mathrm{s}$ (20mph). Each mode consists of idle, acceleration to $8.9 \mathrm{~m} / \mathrm{s}(20 \mathrm{mph})$, steady state operation and deceleration as shown in figure 2-8. The entire test simulates $3.2 \mathrm{~km}(2$ miles) traveled. The transit coach design operating profile duty cycle (SAE J 1376, 1993) 
suitable for determining the fuel consumption, consists of the arterial operation and commuter operation in addition to the CBD phase of the cycle. The arterial operation is composed of speeds up to $17.9 \mathrm{~m} / \mathrm{s}(40 \mathrm{mph})$, while the commuter phase is up to $24.6 \mathrm{~m} / \mathrm{s}$ (55mph). The commuter phase is a single $6.4 \mathrm{~km} \mathrm{(4} \mathrm{mile)} \mathrm{mode} \mathrm{that} \mathrm{possesses}$ acceleration, deceleration and steady state.

To test over the road tractors, the WVU Transportable Laboratories have previously employed a truck CBD cycle [Wang et al., 1993] similar to the CBD phase of the transit coach cycle. This truck CBD cycle as shown in figure 2-9 is similar to the original CBD but acceleration and braking rates are reduced to be more attainable by heavy duty vehicles. The CBD fails to utilize the full power of the engine and it is concentrated over the 0 to $8.94 \mathrm{~m} / \mathrm{s}$ ( 0 to $20 \mathrm{mph}$ ) region making emission variations at higher speeds unknown. Testing of the vehicle at different speeds is necessary since CO and PM are known to be highly sensitive to load and transients.

WVU has developed several transient chassis test cycles including the 5-peak WVU test cycle as shown in figure 2-10 [Clark et al., 1994]. The 5-peak WVU test cycle is geometric in nature and the acceleration rates it employs are low enough for any truck to follow. The 5 different acceleration ramps employ different speeds, namely 20, 25, 30, 35 and $40 \mathrm{mph}$ during the steady states and avoid favoring any particular gear in the transmission. The total distance traveled is $8 \mathrm{~km}$ (5miles). However, the cycle fails to utilize the full power of the vehicle during the course of the cycle, while the 5 mile route (figure 2-11) calls for maximum acceleration of the truck or bus at each peak, also covers 5 miles, but it is completed in less time by a more powerful or faster shifting vehicle. The 
5 mile route is considered to represent the real use more closely in this regard than the 5 peak WVU test cycle. 


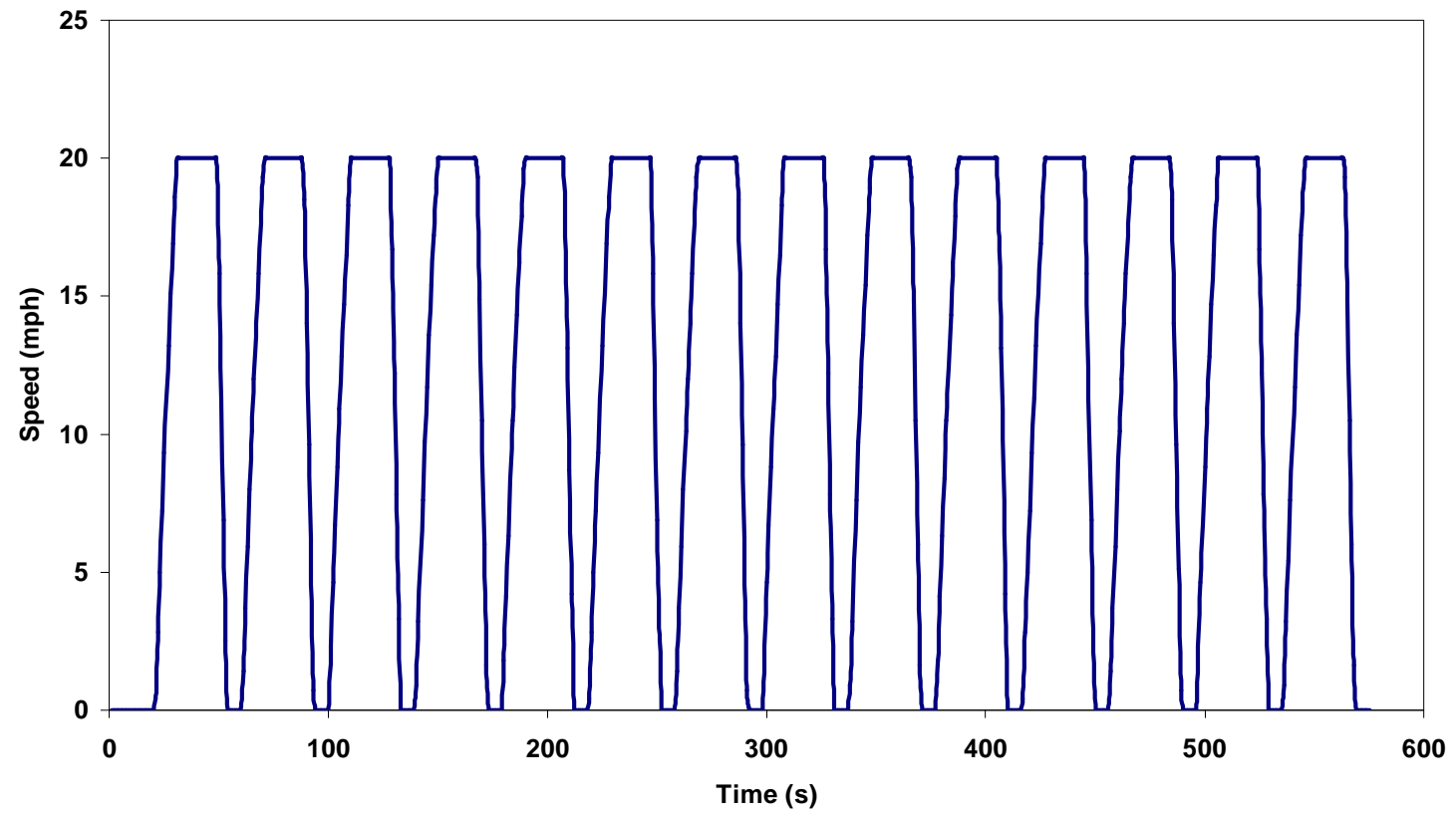

Figure 2-8: Central Business District cycle 


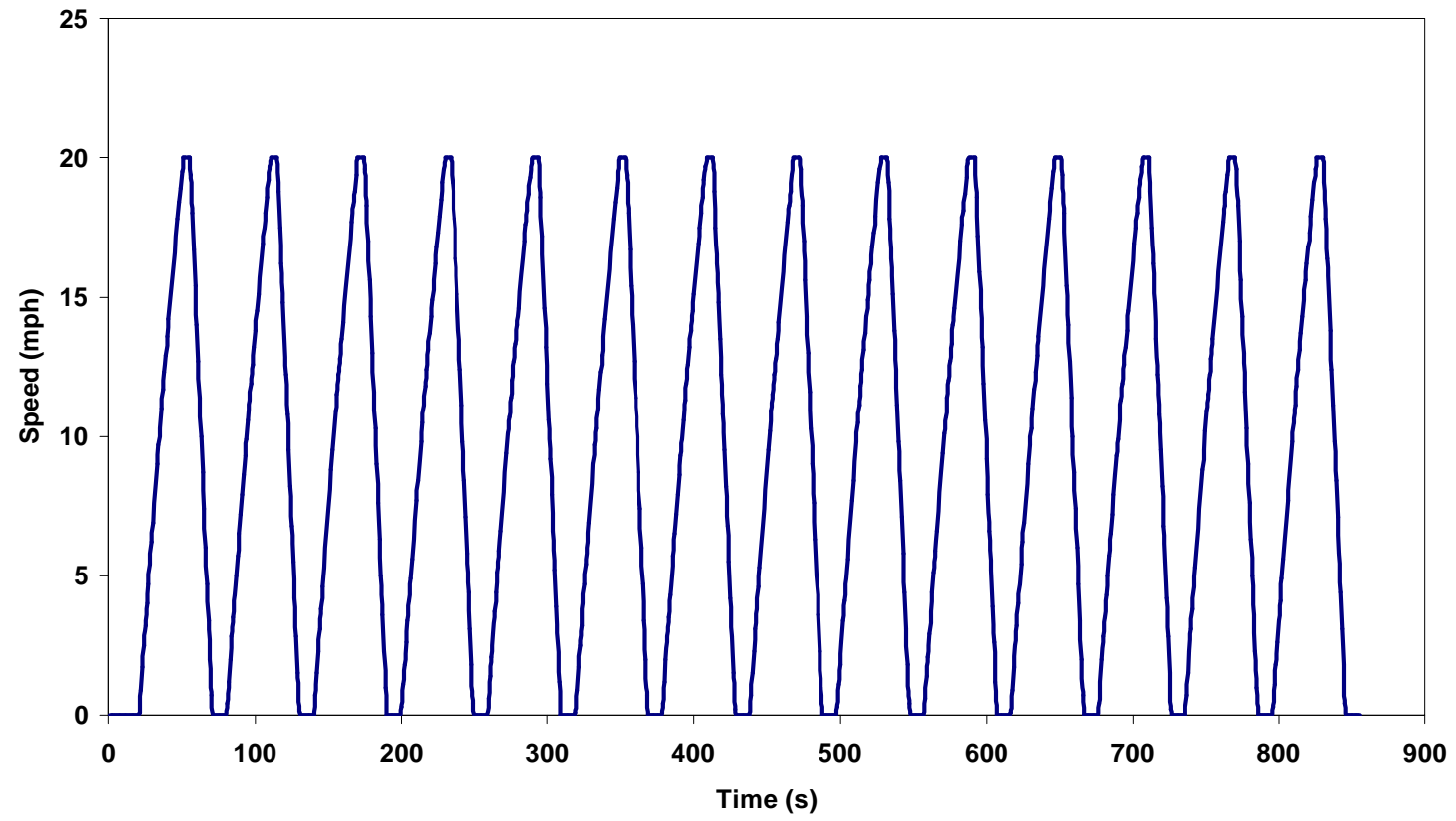

Figure 2-9: Truck CBD cycle 


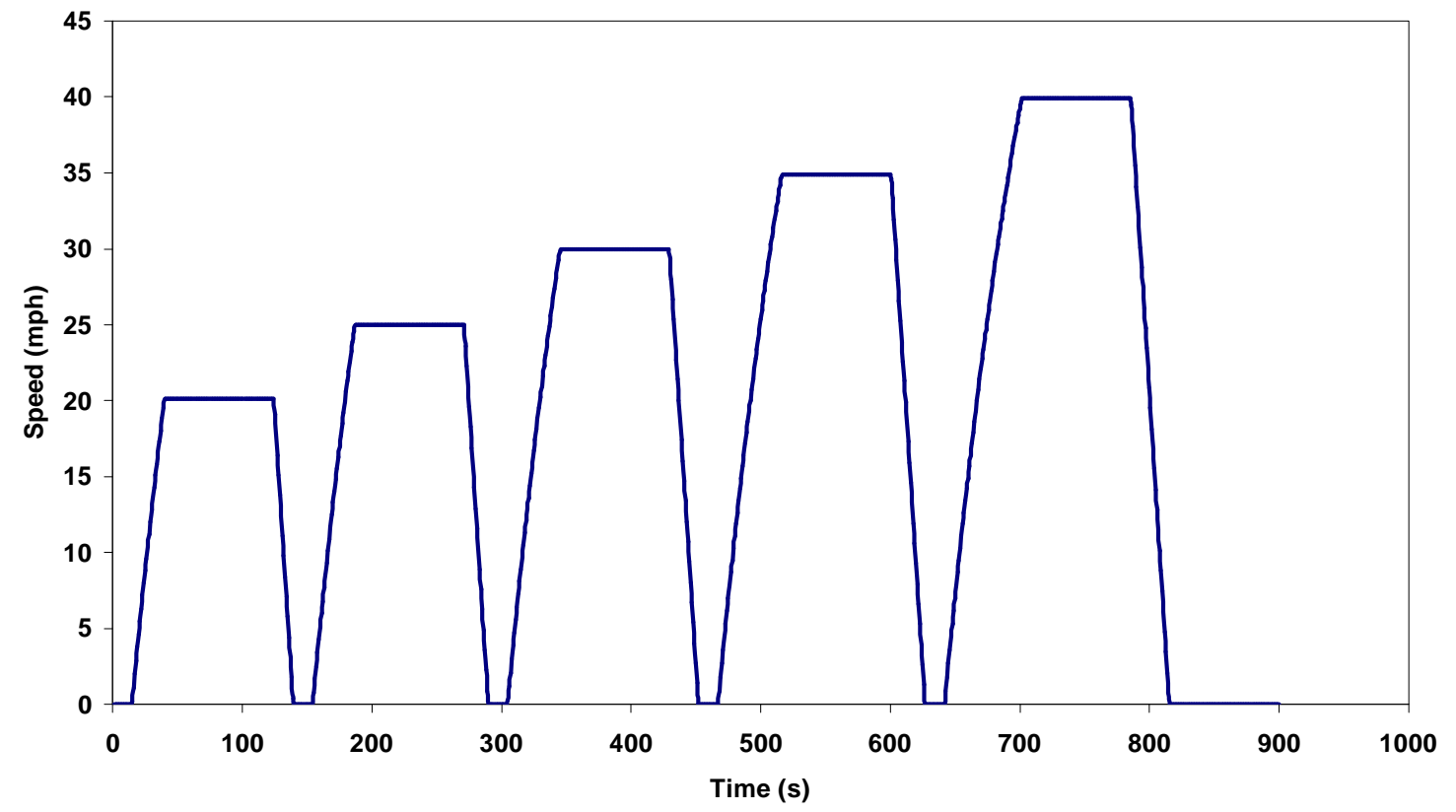

Figure 2-10: Speed- Time plot of the WVU 5 Peak cycle

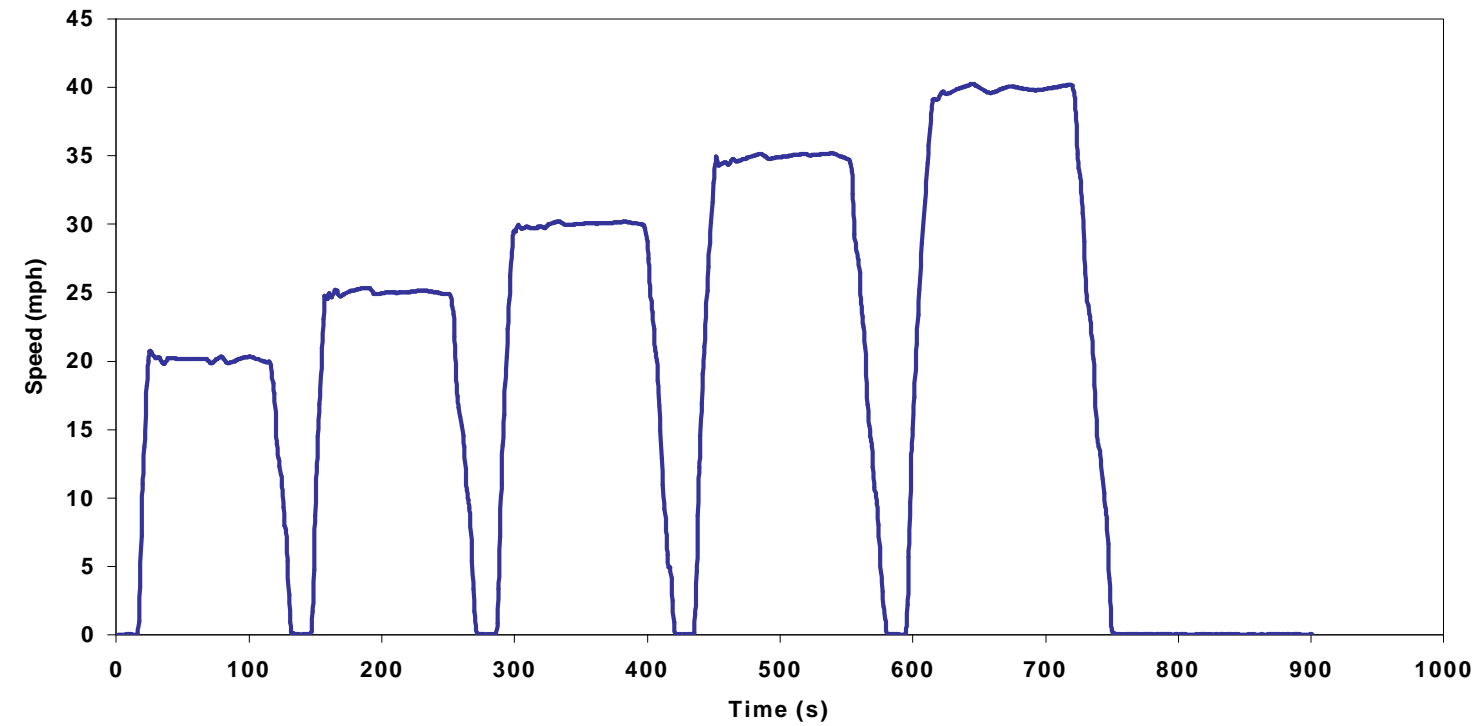

Figure 2-11: Speed -Time plot of a vehicle following a 5 mile route 


\subsubsection{Modal Cycles}

The Japanese government uses a synthesized 6-mode cycle for heavy duty diesel vehicles that weigh more than $2500 \mathrm{~kg}$ or transport 10 or more passengers. Total emissions measured during the cycle are multiplied by the weighting factor to yield emissions reflecting real road conditions. Table 2-2 gives the details of the Japanese 6 mode cycle [Degobert, 1995].

\begin{tabular}{|l|l|l|l|}
\hline Mode number & \% of nominal speed & \% loading rate & Weighting factor \\
\hline 1 & Idling & idling & 35.5 \\
\hline 2 & 40 & 100 & 7.1 \\
\hline 3 & 40 & 25 & 5.9 \\
\hline 4 & 60 & 100 & 10.7 \\
\hline 5 & 60 & 25 & 12.2 \\
\hline 6 & 80 & 75 & 28.6 \\
\hline
\end{tabular}

Table 2-2 gives the details of the Japanese 6 mode cycle

The Economic Commission for Europe (ECE) R49 13 mode engine test cycle is used to test diesel engines in Europe. This 13 mode cycle weight high temperature modes heavily and is modified to measure the efficiency of particulate filters [Brown et al., 1996]. Table 2-3 shows the speed, load, weighting factors for the ECE R49 13 mode cycle [Degobert, 1995]. 


\begin{tabular}{|l|l|l|l|}
\hline Mode number & Speed & Loading rate (\%) & Weighting factor \\
\hline 1 & Idle & -- & $0.25 / 3$ \\
\hline 2 & Maximum Torque & 10 & 0.08 \\
\hline 3 & & 25 & 0.08 \\
\hline 4 & & 50 & 0.08 \\
\hline 5 & & 75 & 0.08 \\
\hline 6 & & 100 & $0.25 / 3$ \\
\hline 7 & Idle & -- & 0.10 \\
\hline 8 & Maximum Power & 100 & 0.02 \\
\hline 9 & & 75 & 0.02 \\
\hline 10 & & 50 & 0.02 \\
\hline 11 & & 25 & 0.02 \\
\hline 12 & & 10 & 0.02 \\
\hline 13 & & -- & $0.25 / 3$ \\
\hline
\end{tabular}

Table 2-3 shows the speed, load, weighting factors for the ECE R49 13 mode cycle

Degobert [1995] mentioned the 8-mode cycle to simulate the FTP cycle and found that it had good correlation with the FTP for $\mathrm{NO}_{\mathrm{x}}$ and particulate emissions, though it did not have the transient operation of the vehicle. 


\subsection{Clean Air Act 1990}

The Clean Air Act 1990 (CAA) was formulated to protect and enhance the quality of nation's air resources so as to promote the public health and welfare. The CAA 1990 specified the emission standards for gasoline and diesel vehicles [EPA, 1994]. The CAA 1990 reduced the amount of emissions allowed from urban buses and heavy duty trucks.

For the model years 1987-2003 the Environmental Protection Agency (EPA) and the California Air Resources Board (CARB) formulated emissions standards for trucks and buses and they are summarized below in tables $2-4 \& 2-5$. The emissions are based upon testing the vehicle through the FTP test cycle and the emissions are expressed in g/bhp-hr. 


\subsubsection{Heavy Duty Emissions Standards}

Table 2-4 EPA emission standards for heavy duty diesel engines, g/bhp-hr

\begin{tabular}{|l|l|l|l|l|}
\hline \multicolumn{5}{|c|}{ Heavy Duty Diesel Truck Engines } \\
\hline Year & HC & CO & NO $_{\mathrm{x}}$ & PM \\
\hline 1990 & 1.3 & 15.5 & 6 & 0.6 \\
\hline 1991 & 1.3 & 15.5 & 5 & 0.25 \\
\hline 1994 & 1.3 & 15.5 & 5 & 0.1 \\
\hline 1998 & 1.3 & 15.5 & 4 & 0.1 \\
\hline
\end{tabular}

\begin{tabular}{|c|c|c|c|c|}
\hline \multicolumn{5}{|c|}{ Urban Bus Engines } \\
\hline Year & $\mathrm{HC}$ & $\mathrm{CO}$ & $\mathrm{NO}_{\mathrm{x}}$ & $\mathrm{PM}$ \\
\hline 1991 & 1.3 & 15.5 & 5 & 0.25 \\
\hline 1993 & 1.3 & 15.5 & 5 & 0.1 \\
\hline 1994 & 1.3 & 15.5 & 5 & 0.07 \\
\hline 1996 & 1.3 & 15.5 & 5 & 0.05 \\
\hline 1998 & 1.3 & 15.5 & 4 & 0.05 \\
\hline
\end{tabular}


Table 2-5: California Emission Standards for heavy duty diesel engines, g/bhp-hr

\begin{tabular}{|l|l|l|l|l|l|}
\hline \multicolumn{6}{|c|}{ Heavy Duty Diesel Truck Engines } \\
\hline Year & NMHC & THC & CO & $\mathrm{NO}_{\mathrm{x}}$ & PM \\
\hline 1987 & - & 1.3 & 15.5 & 6 & 0.6 \\
\hline 1991 & 1.2 & 1.3 & 15.5 & 5 & 0.25 \\
\hline 1994 & 1.2 & 1.3 & 15.5 & 4 & 0.1 \\
\hline & 1.2 & 1.3 & 15.5 & 5 & 0.1 \\
\hline 1991 & 1.2 & 1.3 & 15.5 & 5 & 0.07 \\
\hline 1994 & 1.2 & 1.3 & 15.5 & 4 & 0.05 \\
\hline 1996 & & & & & \\
\hline
\end{tabular}

From the emissions standards it is clear that the $\mathrm{NO}_{\mathrm{x}}$ and $\mathrm{PM}$ emissions are reduced year by year and the march towards the Zero Emissions Vehicle has begun. California has lower emissions standards compared to the rest of the country.

In October 1997, EPA adopted a new emission standard for the model year 2004 and later heavy duty diesel engines used in trucks and buses. The standard reflects the provisions of the Statement of Principles (SOP) signed in 1995 by the EPA, CARB and the leading manufacturers of heavy duty diesel engines. The goal is to reduce highway heavy duty diesel engines to levels approximately 2 g/bhp-hr beginning in 2004 . Manufacturers are allowed to certify the engines to one of the two options as specified in Table 2-6 
Table 2-6 EPA Emission Standards for model year 2004 and later heavy duty diesel engines, g/bhp-hr

\begin{tabular}{|l|l|l|}
\hline Option & $\mathrm{NMHC} \mathrm{NO}_{\mathrm{x}}$ & NMHC \\
\hline 1 & 2.4 & - \\
\hline 2 & 2.5 & 0.5 \\
\hline
\end{tabular}

All emission standards other than $\mathrm{NMHC}$ and $\mathrm{NO}_{\mathrm{x}}$ applying to 1998 and later model year heavy duty engines will continue at their 1998 levels. The EPA has reviewed the standard in 1999 and has revised the useful life of the heavy duty diesel engine service class of 435, 000 miles, 22, 000 hours, or 10 years, whichever occurs first, for all pollutants beginning in model year 2004 .

It is known that the engine manufacturers have configured some engine maps so that injection timing may vary according to the engine operation. This would mean that the emissions would no longer relate to certification values. The recent consent decree between the federal government and the engine manufacturers requires that this practice cease and the 2004 standards have been advanced to 2002 . 


\section{Laboratory Description}

West Virginia University currently possesses facilities capable of running transient and steady state testing on either heavy duty vehicles or engines: two transportable heavy duty vehicle emissions laboratories and one stationary engine emissions laboratory [Lyons et al., 1991; Clark et al., 1994]. The chassis dynamometer laboratories collect emissions from vehicles while simulating road conditions, without removing the engine from the chassis of the vehicle. The engine dynamometer gathers the emissions produced from an engine independent of the vehicle. The following section gives a brief description of the laboratories.

\subsection{Transportable Laboratory}

West Virginia University Transportable Heavy Duty Vehicle Emissions Testing Laboratories \#1 and \#2 are capable of performing transient and steady state tests on vehicles for emissions at any location depending only on the weather conditions. The transportable laboratories consist of three vehicle combinations when moved from site to site. A tractor-trailer with the dynamometer section, an emissions trailer with the gas analyzers and a straight truck commute from one site to another. The major components of the laboratory consist of the following: chassis dynamometer test bed, load simulating devices, exhaust gas analyzers, a dilution tunnel, a blower with critical flow venturi, a generator and an extensive data acquisition system. The transportable laboratories are capable of testing the vehicle over steady state and transient testing cycles.

The dynamometer test bed is a flat bed trailer, specially designed and built so that heavy duty trucks and buses can be driven on it simulating actual speed driving. Vehicles 
are tested with the drive wheels running on $32 \mathrm{~cm}$ diameter twin rollers, but power is extracted from the vehicle hubs (wheel lug nuts) rather than through rollers as slippage between the tires and rollers can render tests inaccurate and generate heat. The rollers served only to cause the left and right drive wheels to maintain the same linear speed. The load simulating devices mounted on the test bed consists of two sets of power absorbers, one side for each side of the vehicle, to simulate the on road driving conditions and flywheels to simulate the inertial load of the vehicle.

The power absorbers simulate the aerodynamic drag and friction losses on the vehicle as if it were driven on the road. The Mustang 300hp power absorbers are air cooled, eddy current dynamometers controlled by the main computer with feedback from a load cell to measure the torque at the power absorbers. The torque produced by the vehicle is translated to the sensors and load simulating devices via shafts and gearboxes. Lebow manufactured strain gage shaft torque sensors and speed transducers were installed in the dynamometer drive train to measure the vehicle torque and speed at rear axle continuously during a test cycle. The readings obtained from the torque sensor on each side are summed together to obtain the axle torque of the vehicle.

The flywheels simulate the inertial load of the vehicle from 15,000 to 60,000 pounds in gross vehicle weight. Individual flywheels are engaged to or disengaged from driven discs to mimic inertia in 250-pound increments, depending on tire size.

To monitor the emissions from the vehicle, the exhaust gas from the exhaust system of the vehicle is channeled to a dilution tunnel through a 5-inch $(7.5 \mathrm{~cm})$ diameter insulated transfer tube. The exhaust gas is mixed with the fresh air in an 18 inch $(45 \mathrm{~cm})$ 
primary dilution tunnel. The flow rate in the tunnel is maintained by a critical flow venturi. There are three available venturi settings namely 1000, 1500, 2000 standard cubic feet per minute (scfm). The venturi is designed to have the exhaust gas concentration within the available ranges of the analyzers. A Tedlar bag is installed to obtain a sample of the outside air that is used to dilute the exhaust stream. This is the background data that is subtracted from the diluted exhaust data in order to know the net tailpipe emissions of the vehicle. A blower situated at the far end of the tunnel draws the flow through the tunnel and the venturi.

Near the end of the primary dilution tunnel, a sample is drawn at 2 to $5 \mathrm{scfm}$ into the secondary dilution tunnel. The sample flow rate is proportional to the flow rate in the primary dilution tunnel within $5 \%$ through out all the tests. Flow rate in the secondary dilution tunnel is maintained in proportion to the primary tunnel through a mass flow controller [CFR40, Pt. 86, 1996]. The secondary stream used for particulate matter analysis may again be diluted with the outside air to bring the temperature at filter face to less than $125^{\circ} \mathrm{F}$. The particulate matter is sampled on a $70 \mathrm{~mm}$ fluorocarbon coated fiber glass filters that have been preconditioned in an environmental chamber to $70 \mathrm{~F}$ and $50 \%$ relative humidity and weighed using a microbalance before testing. The filters are weighed again with a microbalance after the test in the environmental chamber to determine the amount of particulate matter in the diluted exhaust [Chasey, 1992]. The microbalance used for weighing the particulate matter has a sensitivity of 0.1 micrograms.

The exhaust gas analyzers, calibration gases, dilution tunnel, environmental chamber, and data acquisition and control system are transported in a box trailer when 
moving from one test site to another. A full calibration is done prior to the start of the test and any incongruities are corrected before the commencement of the test.

The gas analysis equipment in the trailer measures the emissions in the exhaust sample. The sample probes at the far end of the tunnel sample a portion of the diluted exhaust for analysis. Heated sample lines transport the exhaust gas to the analyzers. The gas analyzers detect the concentration of each emission gas in parts per million and relay a signal to a computer that records the data on a continuous basis at a frequency of $10 \mathrm{~Hz}$. The laboratories are capable of testing the following emission gases: carbon dioxide $\left(\mathrm{CO}_{2}\right)$, carbon monoxide $(\mathrm{CO})$, hydrocarbons, and oxides of nitrogen $\left(\mathrm{NO}_{\mathrm{x}}\right)$ as well as other exhaust gases such as formaldehyde ( $\mathrm{HCHO})$, methane $\left(\mathrm{CH}_{4}\right)$ and methanol $\left(\mathrm{CH}_{3} \mathrm{OH}\right)$. HC concentrations are measured with a heated flame ionization detector. $\mathrm{NO}_{\mathrm{x}}$ concentrations are measured using a chemiluminescent detector. $\mathrm{CO}$ and $\mathrm{CO}_{2}$ concentrations are found using non-dispersive infrared analyzers. 
Table 3-1 gives the manufacturers and model numbers of the specific analyzers used by the transportable laboratories.

\begin{tabular}{|l|l|l|}
\hline Gas & Analyzer & Method of Detection \\
\hline $\mathrm{HC}$ & Rosemount Analytical Model 402 High- & Heated Flame Ionization Detector \\
& Temperature & \\
\hline $\mathrm{CO}$ & Rosemount Industrial Model 880A and 868 & Non-dispersive Infrared Detector \\
\hline $\mathrm{CO}_{2}$ & Rosemount Industrial Model 880A & Non-dispersive Infrared Detector \\
\hline $\mathrm{NO}_{\mathrm{x}}$ & Rosemount Analytical Model 955 NO/NO & Chemiluminescent Detector \\
\hline
\end{tabular}

The data acquisition and control system that makes all of this testing possible has six major components [Chasey, 1992]:

- Control System Computer

- Driver's Interface Computer

- Data Acquisition Boards and Signal Conditioners

- Dynamometer Controllers

- Sensors, Cabling and Interconnections

- Calibration and Test Software 
These six components together acquire, process and store data. The data acquisition and control assembly is also where instrument errors are introduced and accounted for in the system.

\subsection{Stationary Laboratory}

The stationary engine laboratory is similar to the transportable laboratories, except that it is permanently installed at the Engine and Emissions Research Laboratory located on the Evansdale campus of West Virginia University. The primary difference is that the engine is tested separately from the vehicle. The engine is connected to an aircooled, direct current (DC) dynamometer and other components of the laboratory include computer control system, primary and secondary dilution tunnels and exhaust gas analyzers. The nature of the engine testing allows much more control over the engine and measurement of data as compared to the chassis tests conducted in the transportable laboratories.

The DC dynamometer employed for testing is a General Electric Model DYC 243, capable of absorbing up to 550 horsepower (hp) and producing $500 \mathrm{hp}$ in motoring power. Torque is measured using a strain gage type load cell that measured force. The strain gage is attached to a load arm of known length on the dynamometer. The measured force is multiplied by this length to obtain torque. Speed is measured using a digital tachometer internally installed on the dynamometer.

The data acquisition and dynamometer control system, an Intel 80486 based computer much like that of the transportable laboratories. The system is equipped with three RTI-815 input/output boards capable of recording and scanning 96 channels at 5 
hertz. The channels read by the system are: engine speed, load cell force, engine water temperature, engine oil temperature, fuel temperature, manifold air pressure, intake air temperature, exhaust temperature and dilution tunnel pressure/temperature. All of the dynamometer and engine controls were attained using programs in Quick Basic written by G. Palmer, Pei, Atkinson and McKain.

An air conditioning system was installed at the facility to ensure that the air supply to the engine was between $68^{\circ} \mathrm{F}$ and $86^{\circ} \mathrm{F}$ as per CFR $[86.341-79,1996]$. Exhaust gas is piped into the 18-inch primary dilution tunnel and is diluted with outside air drawn in by a blower through a critical flow venturi. A 10 -inch orifice plate located three feet into the dilution tunnel assured proper mixing. The gas probes located 17 feet into the tunnel draw known flow rates of the exhaust to the analyzer bench. The secondary dilution tunnel situated just after the probes is used for particulate matter (PM) measurements. The analyzers sample the exhaust for $\mathrm{CO}, \mathrm{NO}_{\mathrm{x}}, \mathrm{HC}$ and $\mathrm{CO}_{2}$. 


\section{Data Collection}

The following section gives the details of the vehicles tested and the cycles used for testing the vehicles. The data were collected by the staff of the WVU transportable heavy duty chassis dynamometer testing laboratories. Table 4-1 gives the details of the vehicles tested. To identify the vehicles tested, the vehicles were named from A to J. The vehicles used to generate emissions inventory data were those from A to $\mathrm{H}$ as shown in Table 4-1. Vehicles A, B and C represent a transit bus (model year 1996) tested under three different Gross Vehicle Weight (GVW) and odometer reading. Vehicle D represents a transit bus (model year 1994) tested on a higher odometer reading as compared to vehicles A, B and C. Vehicle E represents a transit bus (model year 1996) with a Cummins M11 engine. Vehicle F was a refuse truck while vehicle $\mathrm{G}$ was a snow plow truck, both tested at a higher GVW compared to the transit bus. Vehicle H was a tanker truck of model year 1991. Table 4-2 gives the details of the engines tested and their transmissions. Vehicles A, B, C and D were powered by a Detroit Diesel Series 50 engine while vehicles $\mathrm{E}$ and $\mathrm{F}$ were powered by a Cummins M11 and Caterpillar 3306 engine respectively. Vehicles G and $\mathrm{H}$ were powered by Detroit Diesel 6V-92 and Caterpillar 3176 engines respectively. Table 4-3 shows the cycles used for testing and the emission results of the vehicles tested. Vehicle A was tested on three different cycles namely the Central Business District cycle (CBD), the 5 peak WVU test cycle and the 5 mile route.

Vehicles B, C, D, E, F and G were tested on the CBD cycle while the vehicle G was tested on the Truck CBD cycle and the emission results from these tests were compared. The CBD and the 5 peak WVU test cycle do not exploit the full power of the vehicle while the 5 mile route does. Table 4-4 shows the details of the vehicles tested for 
prediction purpose. Vehicle I represent a transit bus (model year 1989) powered by a Detroit Diesel 6V-92 engine tested on two different cycles namely the CBD and the New York Composite cycle. Vehicle J was a tractor truck (model year 1992) powered by a Detroit Diesel 6V-92 engine tested on the Truck CBD and the 5 peak WVU test cycle. The effect of vehicle types and cycles on emissions of heavy duty vehicles was analyzed. The emissions rate as a function of axle power was analyzed for each component tested and the prediction models were developed on basis of axle power for a given vehicle type. 
Table 4-1: Details of the vehicles tested.

\begin{tabular}{|c|c|c|c|c|c|c|c|}
\hline $\begin{array}{l}\text { Vehicle } \\
\text { Identity }\end{array}$ & $\begin{array}{l}\text { Vehicle } \\
\text { Type }\end{array}$ & Engine & $\begin{array}{l}\text { Model } \\
\text { Year }\end{array}$ & $\begin{array}{l}\text { Year } \\
\text { Tested }\end{array}$ & $\begin{array}{l}\text { Odometer } \\
\text { Reading } \\
\text { (miles) }\end{array}$ & $\begin{array}{l}\text { Gross Vehicle } \\
\text { Weight (lbs.) }\end{array}$ & $\begin{array}{l}\text { Test } \\
\text { Weight } \\
\text { (lbs.) }\end{array}$ \\
\hline A & $\begin{array}{l}\text { Transit } \\
\text { bus }\end{array}$ & $\begin{array}{l}\text { Detroit Diesel } \\
\text { Series } 50\end{array}$ & 1996 & 1997 & 40900 & 37920 & 32843 \\
\hline B & $\begin{array}{l}\text { Transit } \\
\text { bus }\end{array}$ & $\begin{array}{l}\text { Detroit Diesel } \\
\text { Series } 50\end{array}$ & 1996 & 1997 & 34300 & 37920 & 32843 \\
\hline $\mathrm{C}$ & $\begin{array}{l}\text { Transit } \\
\text { bus }\end{array}$ & $\begin{array}{l}\text { Detroit Diesel } \\
\text { Series } 50\end{array}$ & 1996 & 1997 & 27500 & 37920 & 32843 \\
\hline $\mathrm{D}$ & $\begin{array}{l}\text { Transit } \\
\text { bus }\end{array}$ & $\begin{array}{l}\text { Detroit Diesel } \\
\text { Series } 50\end{array}$ & 1994 & 1997 & 132500 & 37920 & 31900 \\
\hline $\mathrm{E}$ & $\begin{array}{l}\text { Transit } \\
\text { bus }\end{array}$ & $\begin{array}{l}\text { Cummins } \\
\text { M11 }\end{array}$ & 1996 & 1997 & 53500 & 39600 & 33449 \\
\hline $\mathrm{F}$ & $\begin{array}{l}\text { Refuse } \\
\text { truck }\end{array}$ & $\begin{array}{l}\text { Caterpillar } \\
3306\end{array}$ & 1994 & 1996 & 13400 & 69897 & 41987 \\
\hline G & $\begin{array}{l}\text { Snow } \\
\text { plow } \\
\text { truck }\end{array}$ & $\begin{array}{l}\text { Detroit Diesel } \\
6 \mathrm{~V}-92 \mathrm{TA}\end{array}$ & 1993 & 1995 & 43806 & 55020 & 38575 \\
\hline $\mathrm{H}$ & $\begin{array}{l}\text { Tanker } \\
\text { truck }\end{array}$ & $\begin{array}{l}\text { Caterpillar } \\
3176\end{array}$ & 1991 & 1993 & --------- & 50000 & 34963 \\
\hline
\end{tabular}


Table 4-2: Details of the engines tested

\begin{tabular}{|c|c|c|c|c|c|}
\hline $\begin{array}{l}\text { Vehicle } \\
\text { Identity }\end{array}$ & Engine Type & $\begin{array}{l}\text { Engine } \\
\text { Power } \\
\text { (hp) }\end{array}$ & $\begin{array}{l}\text { Engine } \\
\text { Displacement } \\
\text { (liters) }\end{array}$ & $\begin{array}{l}\text { Number of } \\
\text { Cylinders }\end{array}$ & $\begin{array}{l}\text { Vehicle } \\
\text { Transmission and } \\
\text { Configuration }\end{array}$ \\
\hline $\mathrm{A}, \mathrm{B}, \mathrm{C}$ & $\begin{array}{l}\text { Detroit Diesel } \\
\text { Series } 50\end{array}$ & 275 & 8.5 & 4 & $\begin{array}{l}\text { Automatic } \\
5 \text { speed }\end{array}$ \\
\hline $\mathrm{D}$ & $\begin{array}{l}\text { Detroit Diesel } \\
\text { Series } 50\end{array}$ & 275 & 8.5 & 4 & $\begin{array}{l}\text { Automatic } \\
3 \text { speed }\end{array}$ \\
\hline $\mathrm{E}$ & Cummins M11 & 280 & 10.8 & 6 & $\begin{array}{l}\text { Automatic } \\
5 \text { speed }\end{array}$ \\
\hline $\mathrm{F}$ & $\begin{array}{l}\text { Caterpillar } \\
3306\end{array}$ & 300 & 10.5 & 6 & $\begin{array}{l}\text { Automatic } \\
4 \text { speed }\end{array}$ \\
\hline$G$ & $\begin{array}{l}\text { Detroit Diesel } \\
6 \mathrm{~V}-92 \mathrm{TA}\end{array}$ & 277 & 9.05 & 6 & $\begin{array}{l}\text { Manual } \\
9 \text { speed }\end{array}$ \\
\hline $\mathrm{H}$ & $\begin{array}{l}\text { Caterpillar } \\
3176\end{array}$ & 325 & 10.3 & 6 & $\begin{array}{l}\text { Manual } \\
5 \text { speed }\end{array}$ \\
\hline
\end{tabular}


Table 4-3: Vehicles and cycles used for testing and emissions measured.

\begin{tabular}{|c|c|c|c|c|c|}
\hline \multirow{2}{*}{$\begin{array}{l}\text { Vehicle } \\
\text { Identity }\end{array}$} & \multirow[t]{2}{*}{ Cycles Used } & \multicolumn{4}{|c|}{ Emissions (g/mile) } \\
\hline & & $\mathrm{CO}$ & $\mathrm{NO}_{\mathrm{x}}$ & $\mathrm{HC}$ & PM \\
\hline \multirow[t]{3}{*}{ A } & $\begin{array}{l}\text { Central } \\
\text { Business } \\
\text { District } \\
\text { cycle (CBD) }\end{array}$ & 4.56 & 28.1 & 0.120 & 0.210 \\
\hline & $\begin{array}{l}5 \text { peak } \\
\text { WVU test } \\
\text { cycle }\end{array}$ & 1.30 & 29.3 & 0.0500 & 0.0700 \\
\hline & 5 mile route & 2.47 & 24.9 & \begin{tabular}{|l|}
0.0400 \\
\end{tabular} & 0.190 \\
\hline B & CBD & 4.32 & 30.8 & 0.150 & 0.270 \\
\hline $\mathrm{C}$ & CBD & 4.14 & 32.3 & 0.0800 & 0.360 \\
\hline $\mathrm{D}$ & CBD & 6.48 & 31.0 & 0.0900 & 0.900 \\
\hline $\mathrm{E}$ & CBD & 3.99 & 27.2 & 1.61 & 0.340 \\
\hline $\mathrm{F}$ & CBD & 3.00 & 34.4 & 1.93 & 0.450 \\
\hline $\bar{G}$ & Truck CBD & 11.0 & 21.9 & 2.56 & 1.92 \\
\hline $\mathrm{H}$ & CBD & 30.4 & 26.3 & 2.85 & 1.39 \\
\hline
\end{tabular}


Table 4-4: Details of the vehicles tested for prediction purpose.

\begin{tabular}{|c|c|c|c|c|c|c|c|}
\hline $\begin{array}{l}\text { Type of } \\
\text { Vehicle }\end{array}$ & $\begin{array}{l}\text { Model } \\
\text { Year }\end{array}$ & $\begin{array}{l}\text { Gross } \\
\text { Vehicle } \\
\text { Weight } \\
\text { (lbs.) }\end{array}$ & $\begin{array}{c}\text { Test } \\
\text { Weight } \\
\text { (lbs.) }\end{array}$ & $\begin{array}{c}\text { Vehicle } \\
\text { Manufacturer }\end{array}$ & $\begin{array}{l}\text { Engine } \\
\text { Type }\end{array}$ & $\begin{array}{c}\text { Engine Power } \\
\text { (hp) }\end{array}$ & Cycles Tested \\
\hline \multirow[t]{2}{*}{$\begin{array}{l}\text { Transit bus } \\
\text { (Vehicle I) }\end{array}$} & 1989 & 36900 & 19249 & $\begin{array}{c}\text { General } \\
\text { Motors Corp }\end{array}$ & $\begin{array}{l}\text { Detroit } \\
\text { Diesel } \\
6 \mathrm{~V}-92\end{array}$ & 253 & CBD cycle \\
\hline & & 36900 & 19249 & & & & $\begin{array}{c}\text { New York } \\
\text { Composite } \\
\text { cycle }\end{array}$ \\
\hline \multirow[t]{2}{*}{$\begin{array}{c}\text { Tractor truck } \\
(\text { Vehicle J) }\end{array}$} & 1992 & 80000 & 41953 & \begin{tabular}{|c|} 
General \\
Motors Corp
\end{tabular} & $\begin{array}{l}\text { Detroit } \\
\text { Diesel } \\
6 \mathrm{~V}-92\end{array}$ & 300 & $\begin{array}{c}\text { Truck CBD } \\
\text { cycle }\end{array}$ \\
\hline & & 80000 & 41953 & & & & $\begin{array}{c}\text { 5-peak WVU } \\
\text { test cycle }\end{array}$ \\
\hline
\end{tabular}




\section{Time Delays}

\subsection{Theory of Delays}

The measurement delay time caused by the exhaust collection network will vary due to the type of the vehicle being tested and the design of its exhaust network. On similar lines, the response time of the analyzer is not identical. The response of the analyzer is a combination of physical response due to the changes in sample gas concentration and a variable electronic response which can be set by the operator [Messer et al., 1995]

The measurement delay associated with the tailpipe exhaust from the exhaust collection network depends on the velocity of flow down the connecting lengths of the pipe. The flow rate of the exhaust depends on the engine speed, turbocharger boost (if equipped), fuel flow and ambient air conditions. Measurement delay depends on the vehicle exhaust configuration because identical engines tested on different vehicles produce different vehicle exhaust flow velocities. The combination of one or more of these factors produces different delay times. However the delay caused by the analyzer transport time and analyzer response are larger than the delay due to the other factors.

A theoretical measurement delay associated with gas transfer within gas sampling and measurement system may be calculated by modeling the exhaust collection system using basic fluid flow and heat transfer equations. The overall measurement delay time for each pollutant is a combination of response time of the analyzers and the time taken by the gases to transport to travel through the tunnel and the sampling lines. $\mathrm{NO}_{\mathrm{x}}$, power 
and CO signals that are unshifted and tested on a modified truck CBD cycle are shown in figure 5-1.

\subsection{Cross-correlation for Time Delay Calculation}

Cross-correlation is comparing two sets of data against a common variable and calculating the best time shift, if any, that best matches the two sets of data assuming that there exist a correlation between them. Cross-correlation is done in order to calculate the measurement time delays involved in the gas sampling lines and due to the analyzer response times by comparing the power and emissions data. For the process of crosscorrelation it is assumed that the emissions would lag behind power. Correlation coefficients for each of the time shift are calculated through a basic program (appendix B) and the highest correlation coefficient corresponds to the lag of one signal to the other. Results that show little change between correlation coefficients indicates that two sets of data do not have similar trends.

Correlation coefficients involving two sets of data can be calculated using the following correlation equation

$$
\Pi_{\Delta t}=\frac{\sum_{\Delta t=-t \max }^{t \max -\Delta t}\left[P(t) \cdot C\left(t+\Delta t_{\text {average }}\right)\right]}{\sum_{\Delta t=-t \max }^{t \max -\Delta t}[P(t) \cdot C(t)]}
$$

where $\Pi_{\Delta t}$ is the correlation coefficient, $\mathrm{P}(\mathrm{t})$ is the power, $\mathrm{C}(\mathrm{t})$ is the emission rate of the gas and $\Delta \mathrm{t}$ average is the time shift between signals. 
For the cross-correlation method to be successful it is necessary that the emission components increase with power. It is obvious that $\mathrm{CO}_{2}$ increases with the power consumed as $\mathrm{CO}_{2}$ represents the fuel consumed during the operation. Generally, $\mathrm{NO}_{\mathrm{x}}$ behave in sympathy with power, although a high speed, low load set-point may produce more $\mathrm{NO}_{\mathrm{x}}$ than low speed, high power for the same engine power rating. Emissions of $\mathrm{NO}_{\mathrm{x}}$ also depend on the manufacturer's timing maps. [Messer et al., 1995].

Cross correlating emissions data to power yields the time shift $\left(\Delta \mathrm{t}_{\text {average }}\right)$, which is the average response time for the exhaust collection system to detect a change in emission gas levels. The time shift depends on the power output from the engine. An increase in the power output from the engine results in an increase in exhaust flow rate and exhaust temperature, which decreases the exhaust transport time of the exhaust collection system. Thus $\Delta \mathrm{t}_{\text {average }}$ should lie between the extremes of idle power and maximum power exhibited during any testing cycle.

This window of delay time is thus a function of the power level output from the engine that can be represented as:

$$
\Delta \mathrm{t}=\Delta \mathrm{tmax}-\mathrm{A}^{*} \mathrm{P}
$$

where the delay time decreases with an increase of power, P. From the previous discussion, the value for $\Delta \mathrm{tmax}$ must be larger than $\Delta \mathrm{t}_{\text {average }}$ by some additional duration, say M. Thus,

$$
\Delta \mathrm{tmax}=\Delta \mathrm{t}_{\text {average }}+\mathrm{M}
$$

and correlation coefficients will take on the form: 


$$
\Pi_{\Delta t}=\frac{\sum_{\Delta t=-t \max }^{t \max x \Delta t}\left[P(t) \cdot C\left(t+\left(\Delta t \max -A^{*} P(t)\right)\right)\right]}{\sum_{\Delta t=-t \max }^{t \max }[P(t) \cdot C(t)]}
$$

The task becomes finding the combination of values for $\mathrm{A}$ and $\Delta$ tmax that maximizes the equation(5).

Before building simple correlation models it is necessary to align $\mathrm{NO}_{\mathrm{x}}$ or $\mathrm{CO}$ and power data with respect to time. Cross-correlation of instantaneous $\mathrm{NO}_{\mathrm{x}}$ or $\mathrm{CO}$ and axle power data with respect to time over the cycle yields the time shift of the emission component with respect to power. Figure 5-2 shows the variations of the shifted $\mathrm{NO}_{\mathrm{x}}$ and smoothed axle power over a truck CBD cycle for a tractor truck. Axle power is smoothed to reduce high fluctuations using a 7-point moving average filter. It is seen that $\mathrm{NO}_{\mathrm{x}}$ and axle power correlate better after time shifting than when analyzed on the $\mathrm{NO}_{\mathrm{x}}$ and axle power data without time shifting. 7-point moving average filter for a variable $\mathrm{X}_{\mathrm{i}}$ (axle power) is given by

$$
\left(\mathrm{X}_{1}+3 \mathrm{X}_{2}+5 \mathrm{X}_{3}+7 \mathrm{X}_{4}+5 \mathrm{X}_{5}+3 \mathrm{X}_{6}+\mathrm{X}_{7}\right) / 25
$$

where $X_{1}$ to $X_{7}$ represent the first seven data points of the axle power data which are incremented over the course of the test. 


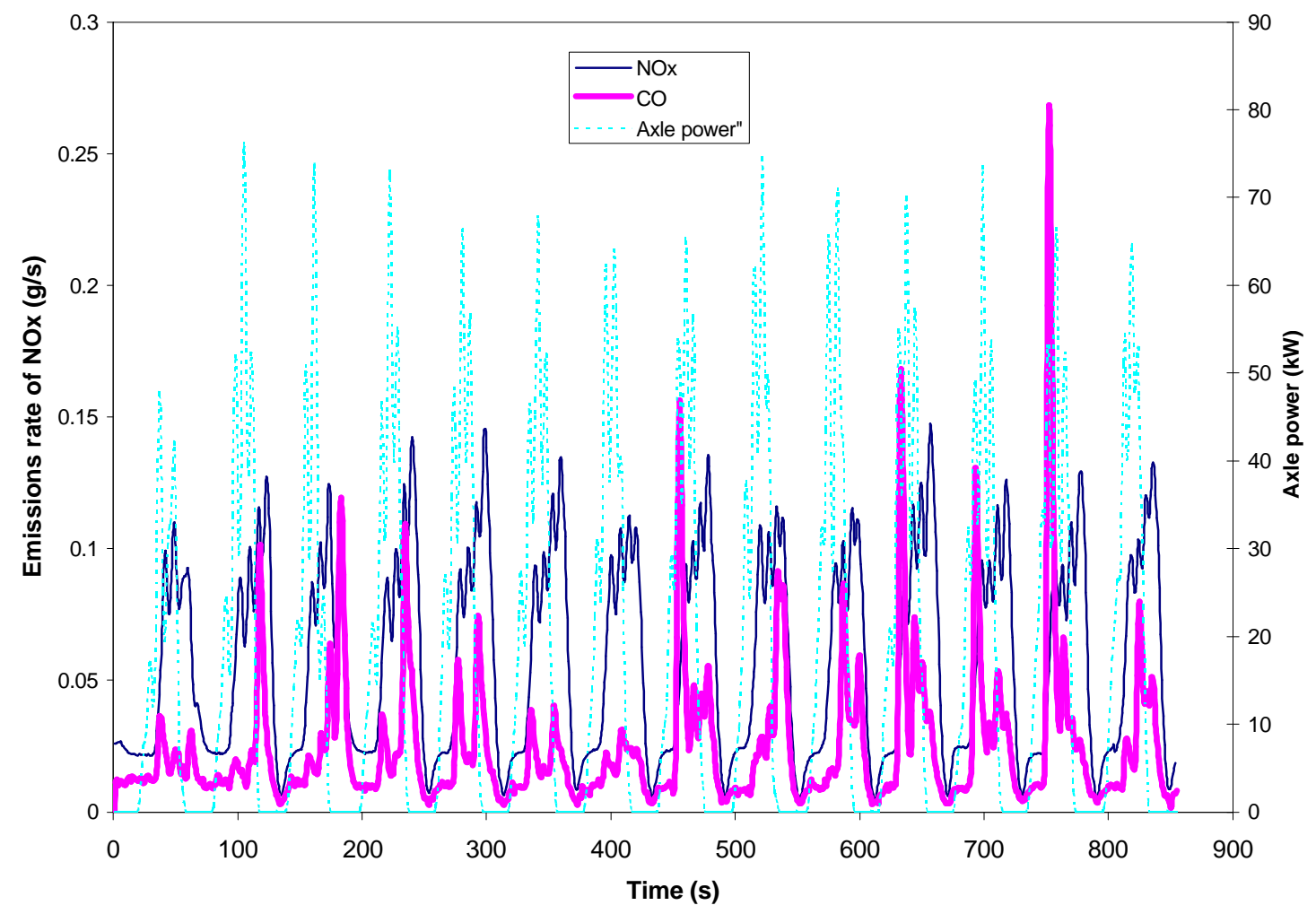

Figure 5-1: Shifted $\mathrm{NO}_{\mathrm{x}}(\mathrm{g} / \mathrm{s})$, axle power $(\mathrm{kW})$, and $\mathrm{CO}(\mathrm{g} / \mathrm{s})$ for a tractor truck (vehicle J) with a Detroit Diesel 6V-92 300hp (223kW) engine tested on the truck CBD cycle. 


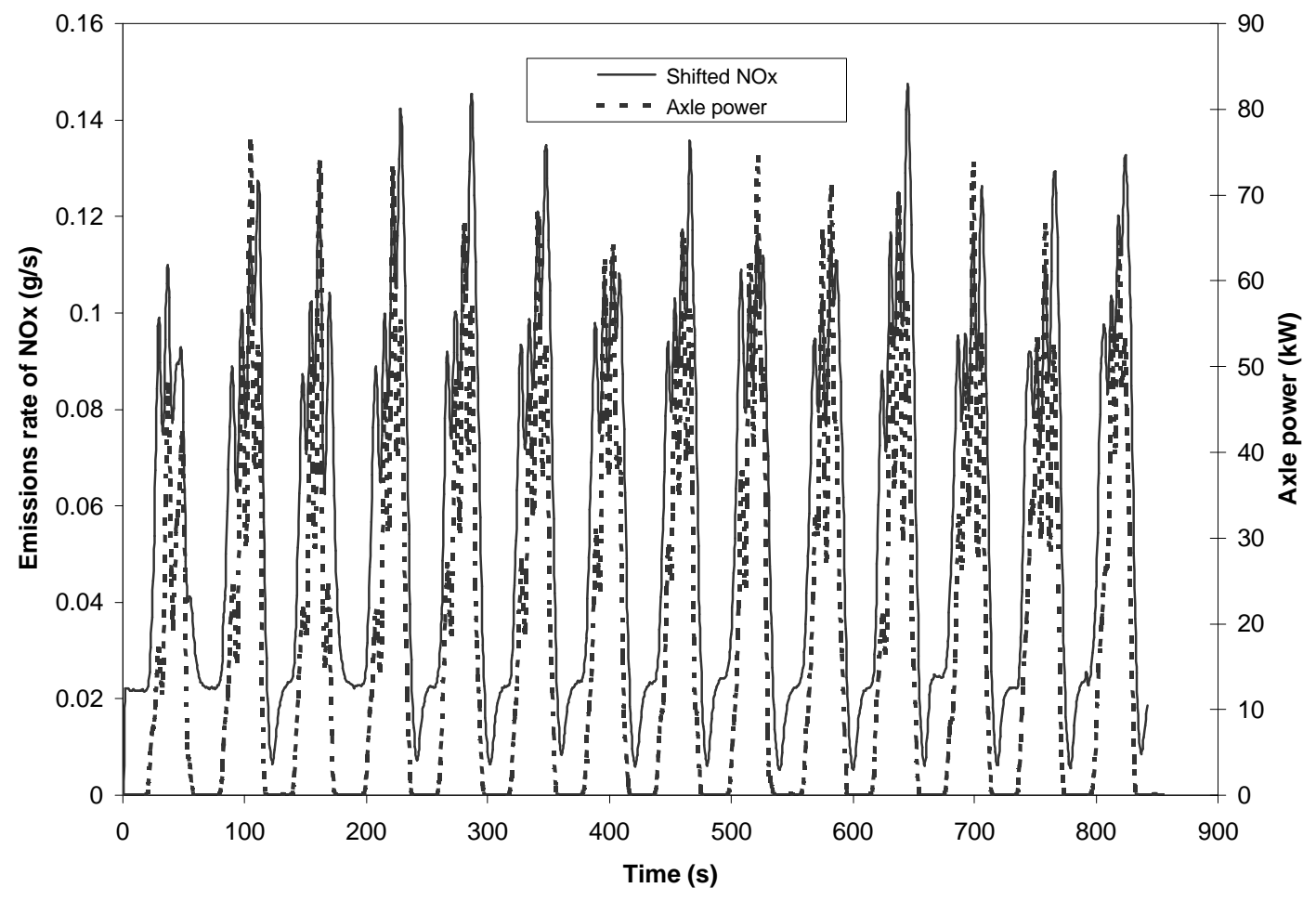

Figure 5-2: Shifted $\mathrm{NO}_{\mathrm{x}}$ and smoothed axle power for a tractor truck (Vehicle J) with a Detroit Diesel 6V-92 300hp (223kW) engine tested on truck CBD cycle. 


\subsection{Sensitivity Analysis}

Time shifting plays an important role in cycle prediction. Cross-correlation method is used for proper time alignment between emissions and axle power data. It is important that the correct time shift is used: inappropriate time shifts give rise to increased data scatter and poor correlation on emission power plots. Figures 5-3, 4, 5 show the variations of $\mathrm{NO}_{\mathrm{x}}$ with smoothed axle power when time shifts of 10 (inappropriate), 13 (appropriate), and 16 seconds (inappropriate) respectively are used. It is seen that for time shifts of either 10 or 16 seconds, the data scatter is high and there is considerable bifurcation in the data, which might mislead the analysis completely. When the time shift is 13 seconds, the data scatter is less than when the time shift is either 10 or 16 seconds. Also, figure 5-6 shows the variation of correlation coefficient with the phase lag for $\mathrm{NO}_{\mathrm{x}}$ emissions. It is seen that the phase lag of 13 seconds has the highest value of correlation coefficient, which confirms that the time shift is 13 seconds. So, it is important that the time shifting is done properly before analyzing the data. 


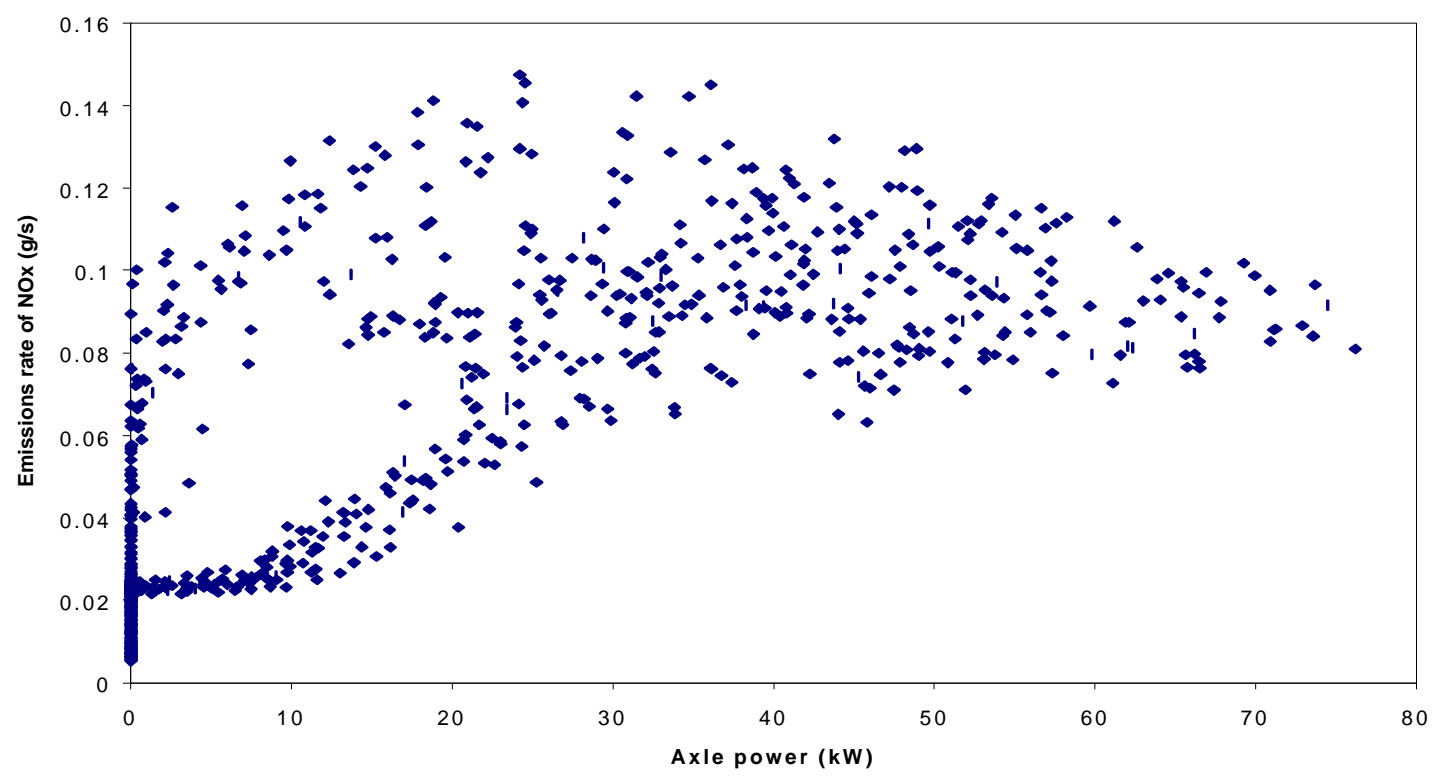

Figure 5-3: $\mathrm{NO}_{\mathrm{x}}$ vs. smoothed axle power with a time shift of $10 \mathrm{sec}$ for a tractor truck (vehicle J) with a Detroit Diesel 6V-92 300hp (223kW) engine tested on the truck CBD cycle.

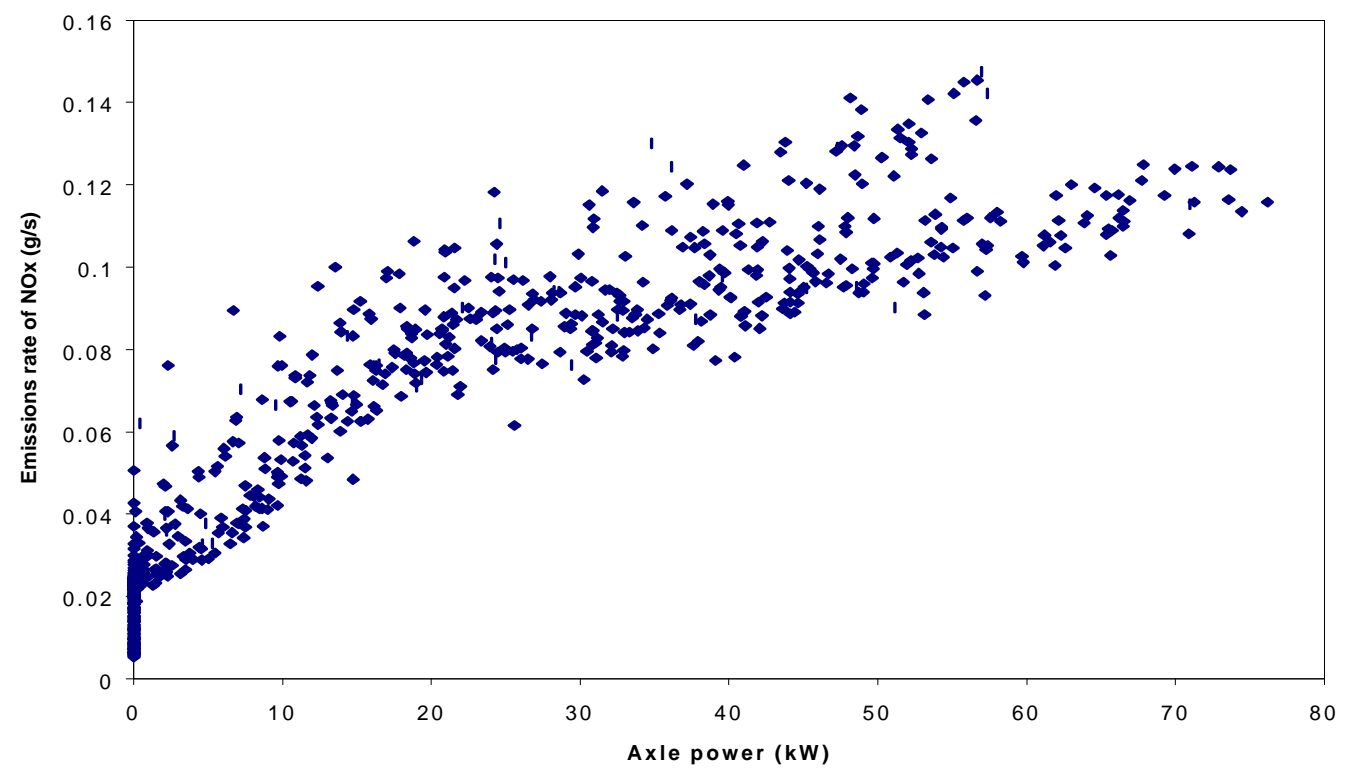

Figure 5-4: $\mathrm{NO}_{\mathrm{x}}$ vs. smoothed axle power with a time shift of $13 \mathrm{sec}$ for a tractor truck (vehicle J) with a Detroit Diesel 6V-92 300hp (223kW) engine tested on the truck CBD 
cycle. This time shift proves optimal, and the $10 \mathrm{sec}$ and $16 \mathrm{sec}$ shifts (Figures 3 and 5) show scatter arising from improper time alignment.

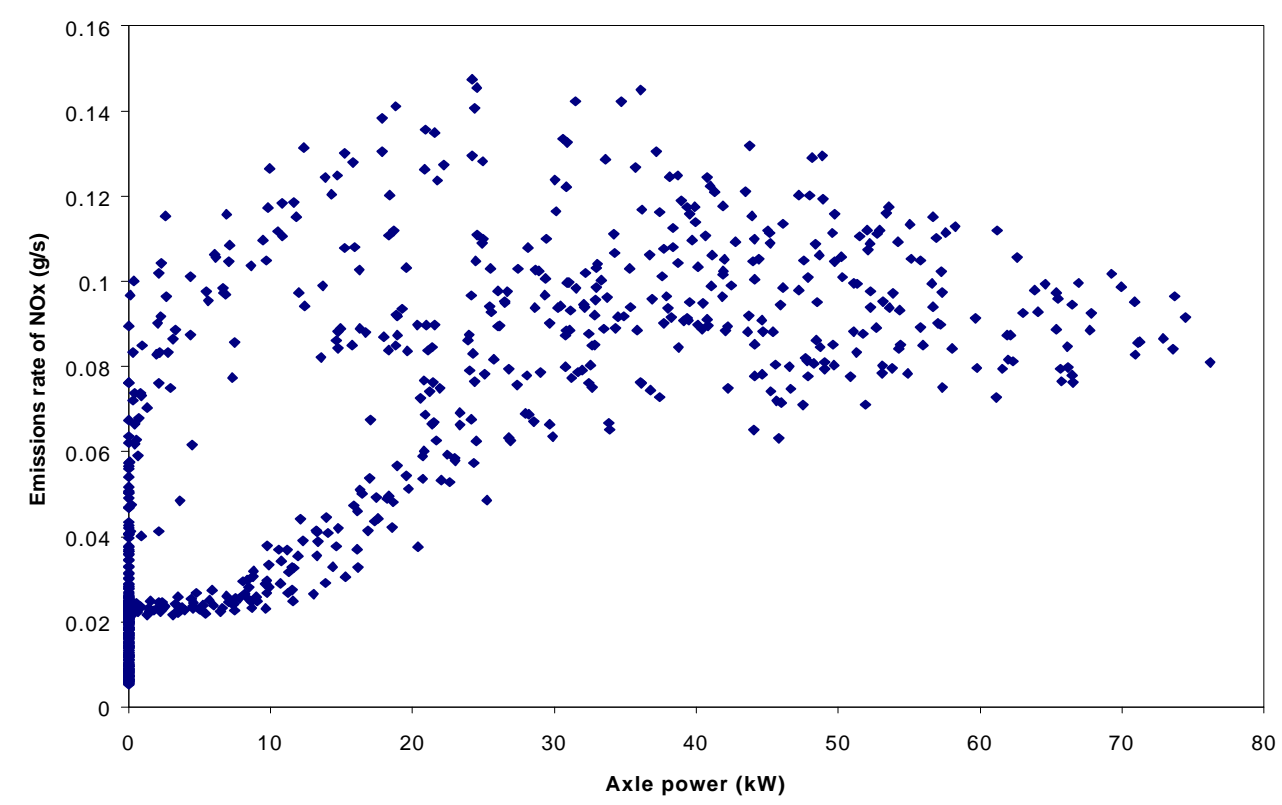

Figure 5-5: $\mathrm{NO}_{\mathrm{x}}$ vs. smoothed axle power with a time shift of $16 \mathrm{sec}$ for a tractor truck (vehicle J) with a Detroit Diesel 6V-92 300hp (223kW) engine tested on the truck CBD cycle. 


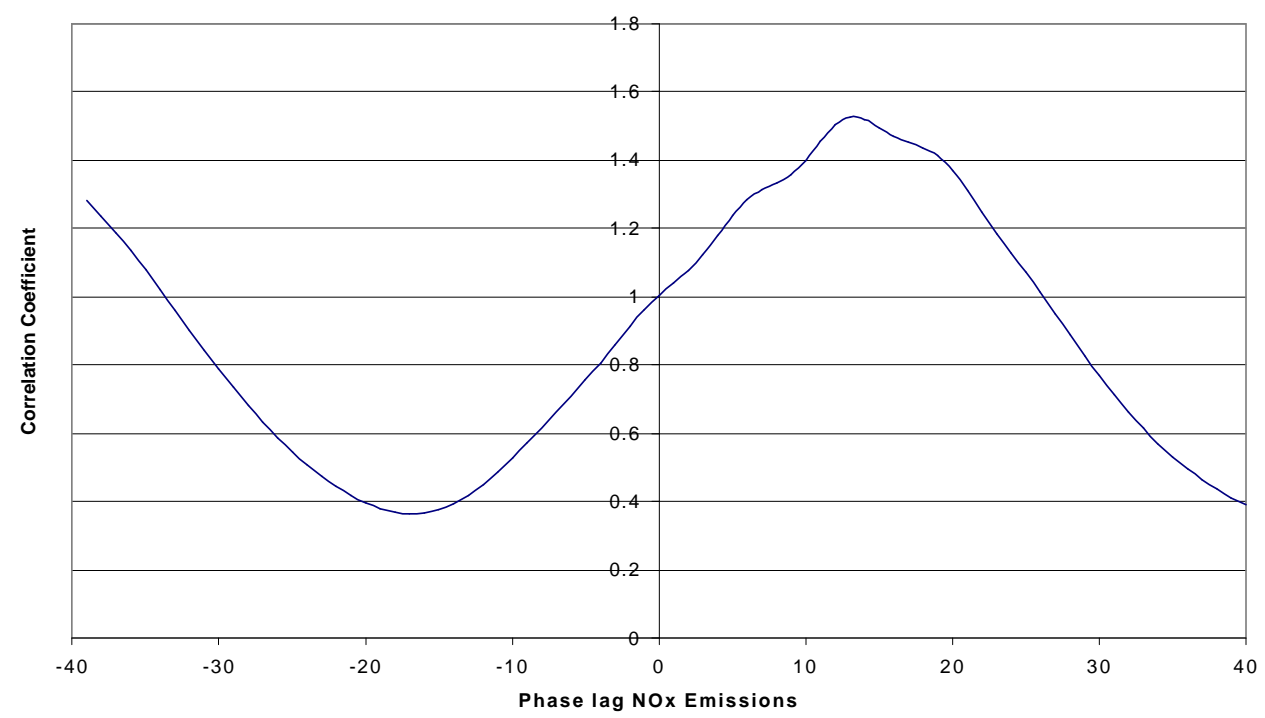

Figure 5-6: Correlation Coefficient vs. phase lag of $\mathrm{NO}_{\mathrm{x}}$ emissions for a tractor truck (vehicle J) with a Detroit Diesel 6V-92 300hp(223kW) engine tested on the truck CBD cycle. The correlation coefficient is seen to be maximum at 13 seconds. 


\section{Dispersion}

\subsection{Theory of Dispersion}

The Residence Time Distribution (RTD) approach to non ideal flow of fluids through the reactors, developed by Levenspiel et al. [1972] states that elements of fluid taking different routes through the reactor may require different lengths of time to pass through the vessel. The distribution of these times for the stream of leaving the vessel is called the exit age distribution or the Residence Time Distribution (RTD) of the fluid. An analogy is drawn between mixing in actual flow and a diffusion process and is called the dispersion model.

The mixing process involves a shuffling or redistribution of material either by slippage or eddies, and since this is repeated a considerable number of times during flow of liquid through a vessel we can consider these disturbances to be statistical in nature, just as in molecular diffusion. For molecular dispersion in the $\mathrm{x}$ direction the governing differential equation is given by Fick's Law

$$
\frac{\partial C}{\partial t}=d \frac{\partial^{2} C}{\partial x^{2}}
$$

where $\mathrm{d}$, the coefficient of molecular diffusion, is a parameter which uniquely characterizes the process. In an analogous manner we may consider all the contributions to backmixing of fluid flowing in the $\mathrm{x}$ direction to be described by a similar expression,

$$
\frac{\partial C}{\partial t}=D \frac{\partial^{2} C}{\partial x^{2}}
$$


where the parameter $\mathrm{D}$ refers to the longitudinal or axial dispersion coefficient, characterizing the backmixing during the flow. The terms axial and longitudinal distinguish the mixing in the direction of flow such as lateral and radial direction.

\subsection{Dispersion Model}

In dimensionless form where $\mathrm{z}=(\mathrm{ut}+\mathrm{x}) / \mathrm{L}$ and $\theta=\mathrm{tu} / \mathrm{L}$ the differential equation representing the dispersion model becomes

$$
\frac{\partial C}{\partial \theta}=\left(\frac{\partial^{2} C}{\partial z^{2}}\right) \frac{D}{u L}-\frac{\partial C}{\partial z}
$$

where $\mathrm{D}$ is the diameter of the vessel with the fluid flowing in an average velocity $\mathrm{u}$ at any arbitrary distance $\mathrm{x}$ through the tunnel of length $\mathrm{L}$. $\mathrm{D} / \mathrm{uL}$ is called the vessel dispersion number and it measures the extent of axial dispersion. Thus $\mathrm{D} / \mathrm{uL}$ tends to 0 for negligible dispersion (plug flow) and tends to infinite value for large dispersion or mixed flow.

If we impose a pulse input into the flowing fluid then dispersion modifies the pulse and can be modeled as

$$
C_{i}=\frac{1}{\left.2 \sqrt{\pi \theta_{i}(D / u L}\right)} \exp \left[-\frac{\left(1-\theta_{\mathrm{i}}\right)^{2}}{4 \theta_{\mathrm{i}}(D / u L}\right]
$$

where $C_{i}$ is the concentration of the dispersion model at a time $t_{i}$ and $\theta_{i}$ is the ratio of $u t / L$ 
The dispersion model developed was applied to the transient emission component signals like $\mathrm{NO}_{\mathrm{x}}$ or $\mathrm{CO}$ to improve the correlation with axle power. Axial dispersion occurs in the $\mathrm{NO}_{\mathrm{x}}$ or $\mathrm{CO}$ signal as it travels through the tunnel and the sampling lines. In contrast, power was measured directly at the drive-wheels and has no diffusion effects associated with it. In order to compare $\mathrm{NO}_{\mathrm{x}}$ or $\mathrm{CO}$ with axle power, the dispersed signal needs to be back transformed to yield instantaneous tailpipe emissions as if measured with no delay at the engine exhaust manifold. A simpler alternative to back transforms was to disperse axle power axially (though incorrect physically) as if it were to have traveled through the tunnel and the sampling lines. The spreading effect of the tunnel, sampling lines and analyzer measurements on a pulse input (power) was modeled by a Gaussian curve. The dispersion model developed by Levenspiel et al. [1972] was applied to predict the axial dispersion of power at the downstream point where the $\mathrm{NO}_{\mathrm{x}}$ or $\mathrm{CO}$ analyzer was situated. This model was used successfully in previous work relating opacity and CO [Jarrett et al., 1998], although it was acknowledged that the precise nature of dispersion of the $\mathrm{NO}_{\mathrm{x}}$ or $\mathrm{CO}$ signal due to the flow and the analyzer response was unknown. Defining the parameters of the dispersion model to our conditions we have,

$$
\left.\mathrm{C}_{\mathrm{i}}=\frac{1}{\left.2 \sqrt{\pi \theta_{i}(D / u L}\right)} \exp \left[-\frac{\left(1-\theta_{\mathrm{i}}\right)^{2}}{4 \theta_{\mathrm{i}}(D / u L}\right)\right]
$$

where $\theta_{\mathrm{i}}$ is the ratio of $t_{\mathrm{i}}$ to $\tau, \tau$ is the mean time shift between the power peaks and the dispersed $\mathrm{NO}_{\mathrm{x}}$ or $\mathrm{CO}$ signal (which was determined using a cross-correlation method between the dispersed $\mathrm{NO}_{\mathrm{x}}$ and axle power data), $\mathrm{t}_{\mathrm{i}}$ is one second time increment 
which was centered around $\tau$ depending on the difference in the range of axle power and $\mathrm{NO}_{\mathrm{x}}$ peaks, subscript $\mathrm{i}$ denotes the instantaneous value, $\mathrm{D} / \mathrm{uL}$ is the dimensionless vessel dispersion number, a parameter that describes the extent of axial dispersion and $\mathrm{C}_{\mathrm{i}}$ is the concentration of the dispersion model at each interval of $t_{i}$.

The values of $\mathrm{C}_{\mathrm{i}}$, which denote axle power in the dispersion model, were normalized. This normalized dispersion curve was applied to each point of the axle power data, treating each reading as pulse input. The resulting curve represents the dispersed axle power. Although "dispersed axle power" has no physical meaning, power has now been made to mimic the same extent of dispersion that $\mathrm{NO}_{\mathrm{x}}$ or $\mathrm{CO}$ has, by traveling through the tunnel and sampling lines. As a result, cross-correlation needs to be applied to the dispersed axle power and $\mathrm{NO}_{\mathrm{x}}$ or $\mathrm{CO}$ data, to account for the delay in the measurement. 


\section{Heavy Duty Emissions Inventory Data}

\subsection{Carbon dioxide $\left(\mathrm{CO}_{2}\right)$}

\subsubsection{Carbon dioxide vs. Axle power}

The amount of carbon dioxide produced by an engine is directly proportional to the power consumed. Knowing the power produced during an operation, the amount of carbon dioxide emitted could be calculated. A function could be developed that relates the variation of carbon dioxide with power for any vehicle or engine. Both carbon dioxide and power could be measured from a transient testing cycle of the engine/vehicle. The power measured is either axle power or engine power depending on the nature of the test cycle (engine or chassis test). There is a delay associated with the gaseous emissions measurement compared to the power, which is directly measured from the drive wheels. The time delay associated with the measurement of carbon dioxide by the $\mathrm{CO}_{2}$ analyzer compared to the measurement of power, is due to the flow of exhaust through sampling lines, dilution tunnel and response time of the analyzer. To know the time delay, carbon dioxide and smoothed power are cross-correlated and the resulting time shift between them is calculated. The time delay in the measurement of $\mathrm{CO}_{2}$ is accounted by shifting the carbon dioxide data by the measured delay. The shifted carbon dioxide data is plotted with the axle power of the vehicle and the peak to peak matching of $\mathrm{CO}_{2}$ and power data is verified. For example figures 7-1, 7-2 show the shifted $\mathrm{CO}_{2}$ and axle power data for a transit bus (vehicle I) with a Detroit Diesel 6V-92 engine tested on the CBD and New York Composite cycle. Figures 7-3, 7-4 show the shifted $\mathrm{CO}_{2}$ and axle power data for a tractor truck (vehicle J) with a Detroit Diesel 6V-92 engine tested on the truck CBD cycle and the 5 peak WVU test cycle. It is important that the proper time shift is applied, as 
inappropriate time shifts causes scatter on emission power plots. It is seen that irrespective of the vehicle (transit bus or tractor truck), shifted $\mathrm{CO}_{2}$ and axle power follows similar trends. The time delay calculated using cross-correlation for the transit bus (vehicle I) is 13 and 14 seconds, when tested on the New York Composite cycle and the $\mathrm{CBD}$ cycle. The time delay for the tractor truck (vehicle $\mathrm{J}$ ) is found to be 12 seconds for both the truck CBD cycle and the 5 peak WVU test cycle.

\subsubsection{Carbon dioxide Prediction}

It is seen that carbon dioxide correlates with axle power as expected after applying the time shift associated with the $\mathrm{CO}_{2}$ measurement by the analyzers. It is seen that the $\mathrm{CO}_{2}$ data and axle power data match closely over the duration of the test cycle. The $\mathrm{CO}_{2}$ data are plotted as a function of axle power for the transit bus (vehicle I) and the tractor truck (vehicle J) tested on the New York Composite cycle and 5 peak WVU test cycle respectively, as shown in figures $7-5,7-7$. A polynomial curve is fitted to the data and a correlation model involving $\mathrm{CO}_{2}$ as a function of axle power for both the cases is obtained from the fit. The fit shows that axle power and $\mathrm{CO}_{2}$ correlate good. The ability of this fit to predict the $\mathrm{CO}_{2}$ data from another cycle is explored. The correlation model developed for New York Composite cycle is applied on the CBD cycle tested on the same transit bus as shown in figure 7-6. The goodness of fit of this model with the data from CBD cycle was found to be 0.9744 where goodness of fit is the ratio between the sum of square regression to total error in the model. Similarly the correlation model developed for 5 peak WVU peak cycle is applied on the truck CBD cycle tested on the same tractor truck as shown in figure 7-8. The goodness of fit of this model with the data from truck CBD cycle is found to be 0.9779 . 


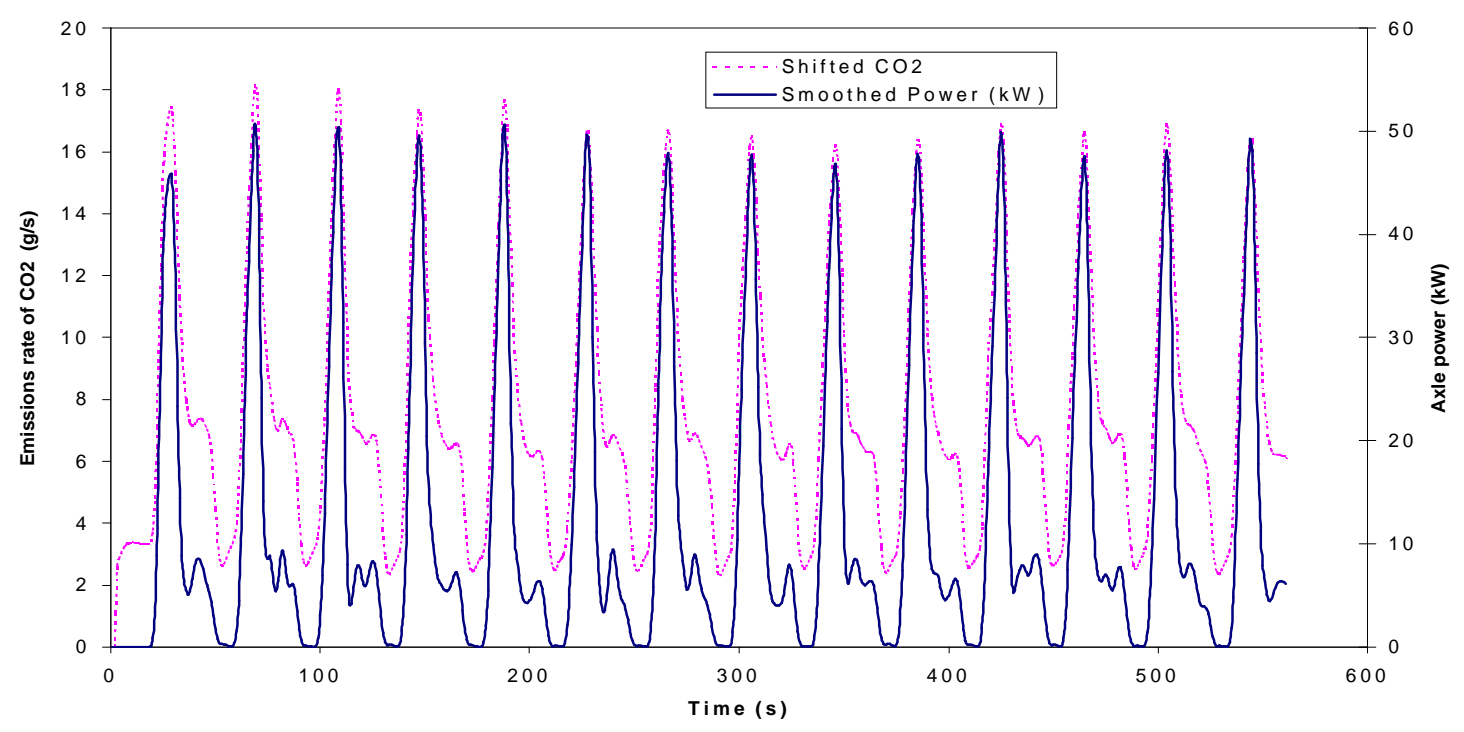

Figure 7-1: Shifted $\mathrm{CO}_{2}$ and smoothed power for a transit bus (vehicle I) with a Detroit Diesel 6V-92 253hp (188kW) engine tested on the CBD cycle.

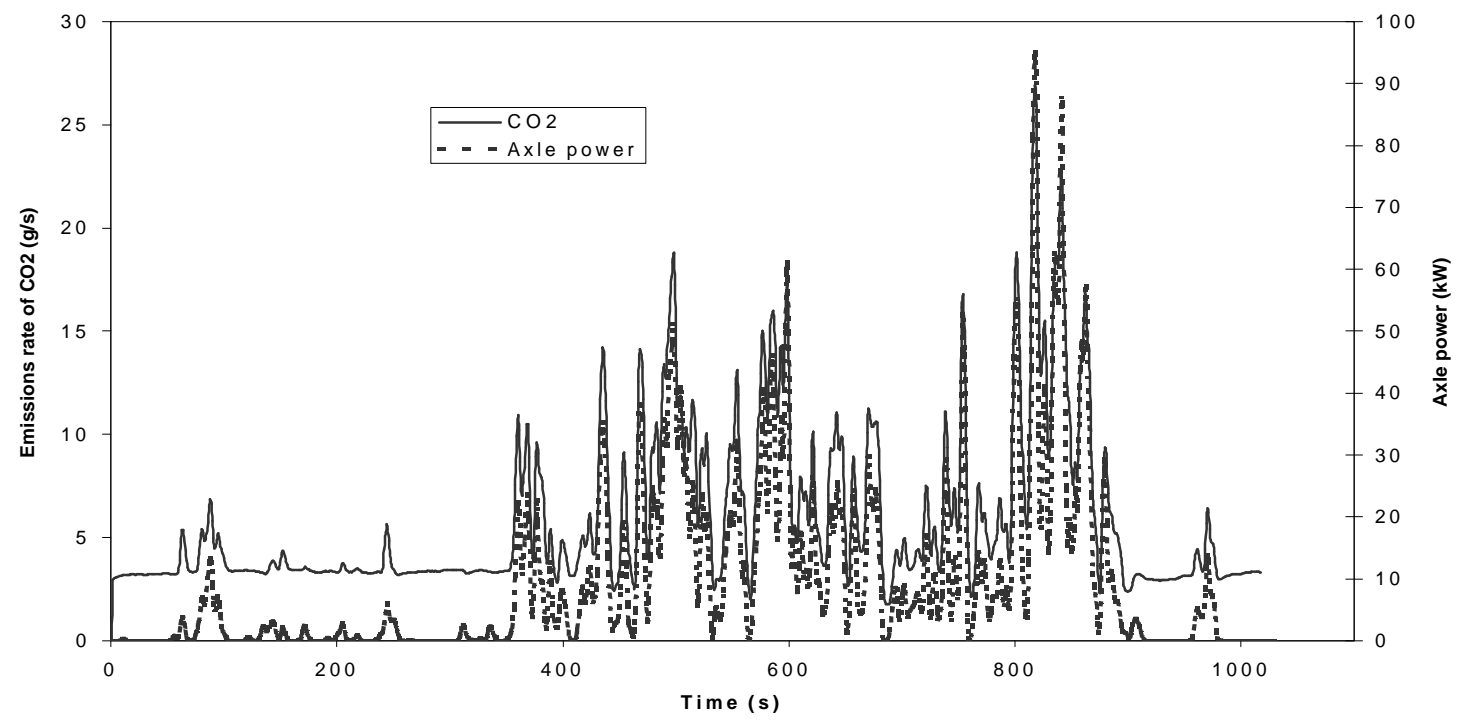

Figure 7-2: Shifted $\mathrm{CO}_{2}$ and smoothed power for a transit bus (vehicle I) with a Detroit Diesel 6V-92 253hp (188kW) engine tested on the New York Composite cycle. 


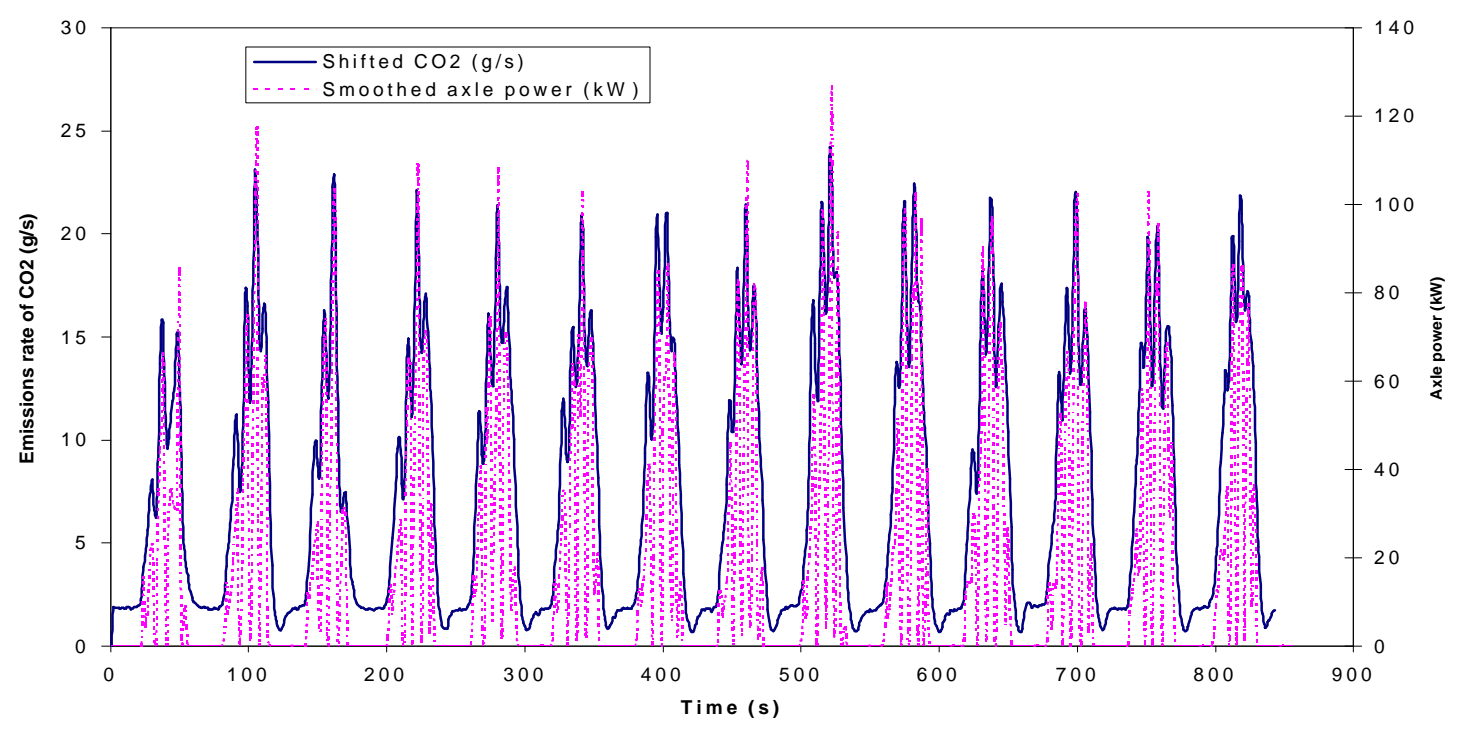

Figure 7-3: Shifted $\mathrm{CO}_{2}$ and smoothed power for a tractor truck (vehicle J) with a Detroit Diesel 6V-92 300hp (223kW) engine tested on the truck CBD cycle. The high frequency components in the plot are largely associated with gear shifting.

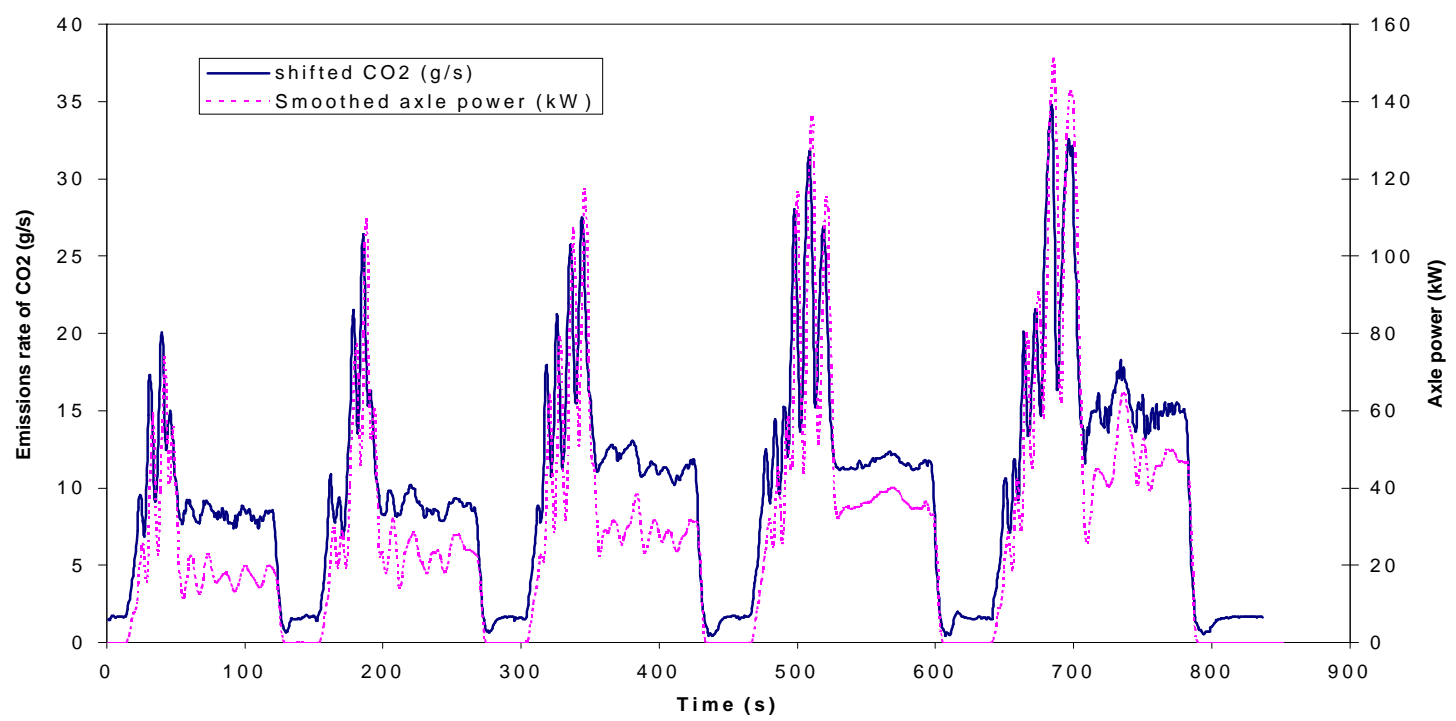

Figure 7-4: Shifted $\mathrm{CO}_{2}$ and smoothed power for a tractor truck (vehicle J) with a Detroit Diesel 6V-92 300hp (223kW) engine tested on the 5 peak WVU test cycle. 


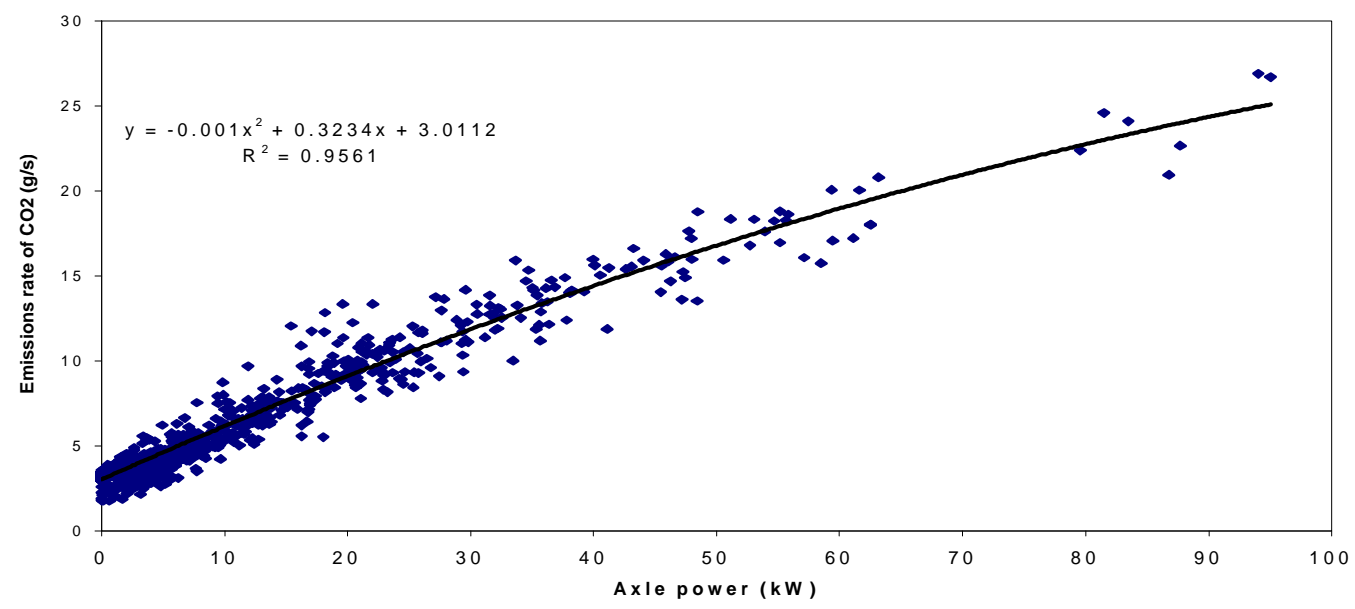

Figure 7-5: Shifted $\mathrm{CO}_{2}$ as a function of smoothed axle power for a transit bus (vehicle I) with a Detroit Diesel 6V-92 $253 \mathrm{hp} \mathrm{(188kW)} \mathrm{engine} \mathrm{tested} \mathrm{on} \mathrm{the} \mathrm{New} \mathrm{York} \mathrm{Composite}$ cycle.

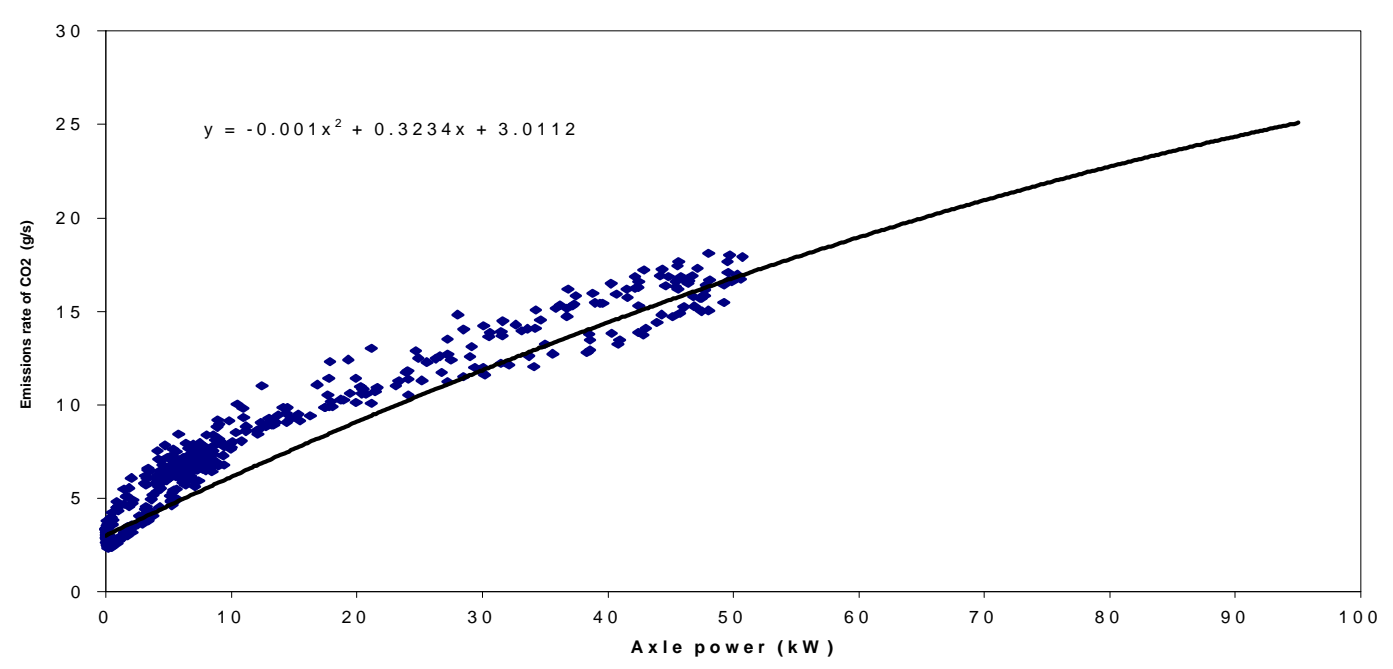

Figure 7-6: Shifted $\mathrm{CO}_{2}$ as a function of smoothed axle power for a transit bus (vehicle I) with a Detroit Diesel 6V-92 $253 \mathrm{hp}(188 \mathrm{~kW})$ engine tested on the CBD cycle. The goodness of fit for this curve vs. the data is found to be 0.9744 . 


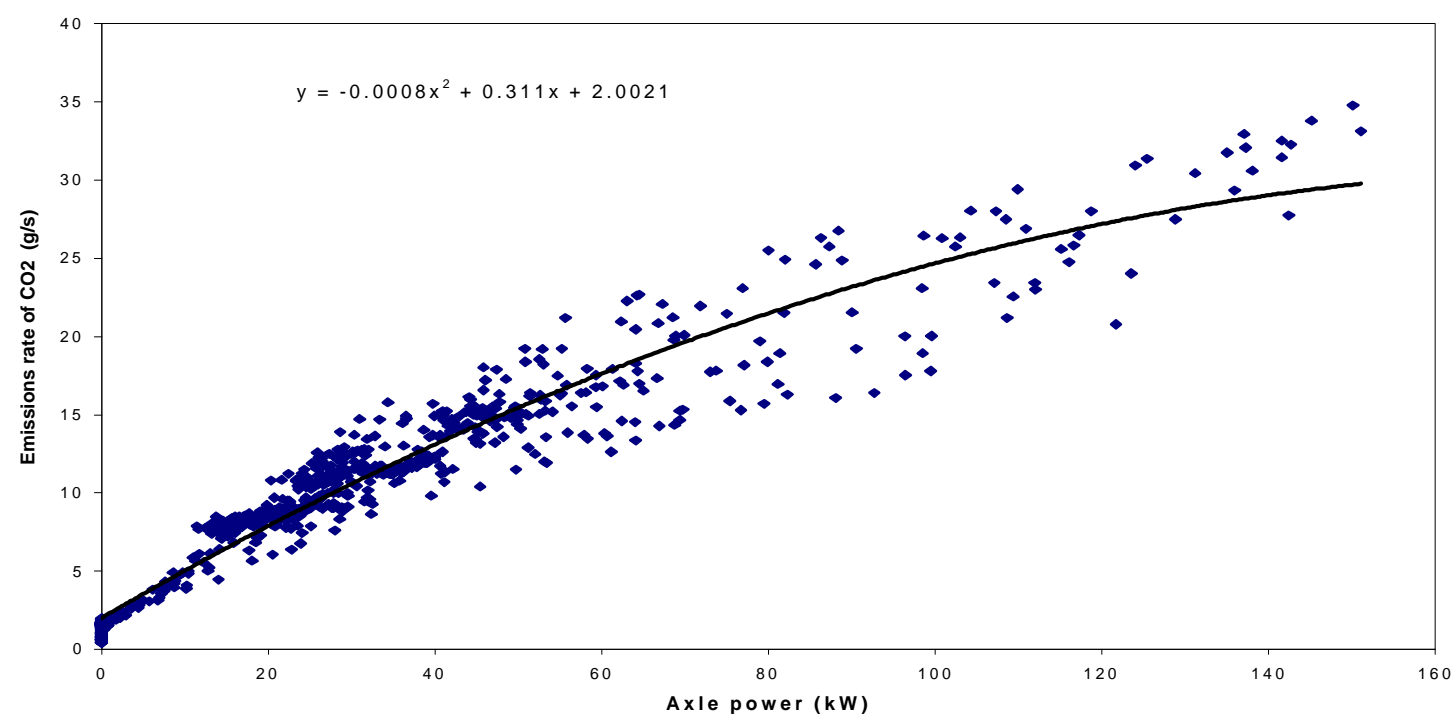

Figure 7-7: Shifted $\mathrm{CO}_{2}$ as a function of smoothed axle power for a tractor truck (vehicle J) with a Detroit Diesel 6V-92 $253 \mathrm{hp}(188 \mathrm{~kW})$ engine tested on the 5 peak WVU test cycle.

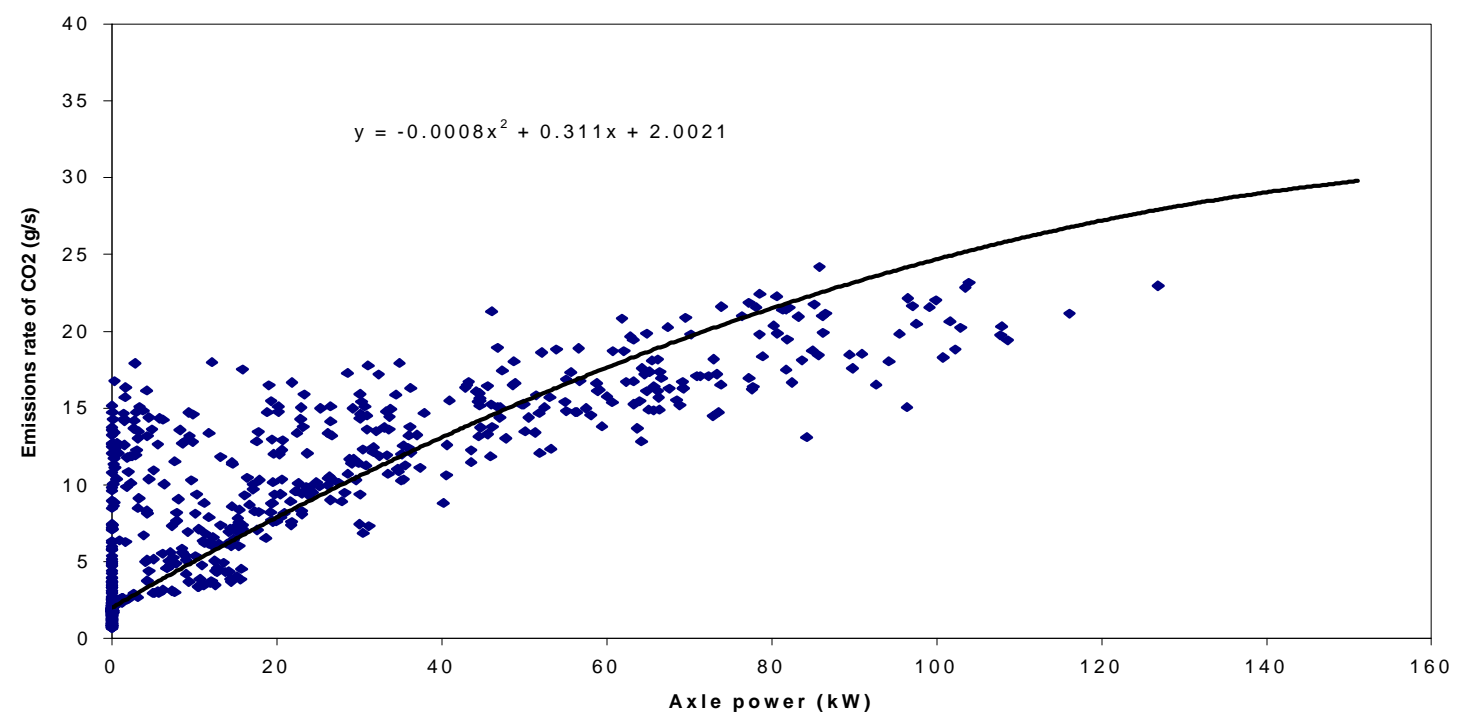

Figure 7-8: Shifted $\mathrm{CO}_{2}$ as a function of smoothed axle power for a tractor truck (vehicle J) with a Detroit Diesel 6V-92 $300 \mathrm{hp}(223 \mathrm{~kW})$ engine tested on the truck CBD cycle. The goodness of fit for this curve vs. the data is found to be 0.9779 . 


\subsection{Oxides of Nitrogen $\left(\mathrm{NO}_{\mathrm{x}}\right)$}

Oxides of nitrogen $\left(\mathrm{NO}_{\mathrm{x}}\right)$ and engine power are known to be positively correlated and the same relationship may be expected for $\mathrm{NO}_{\mathrm{x}}$ and axle power. The delay associated with the measurement of $\mathrm{NO}_{\mathrm{x}}$ by the analyzer is determined for the purpose of time shifting using cross-correlation. The lag between the $\mathrm{NO}_{\mathrm{x}}$ data and power is found to be 10 seconds. Axle power measurement is devoid of any delay as it is measured directly from the drive wheels and hence is used as a reference for time shifting. The gases from the tail-pipe of the vehicle are not transmitted to the analyzers in a plug flow fashion, but are slightly dispersed in time, having a residence time distribution. The residence time distribution is taken into consideration and $\mathrm{NO}_{\mathrm{x}}$ is correlated with dispersed power instead of performing a reverse transform on the continuous tail-pipe emissions and producing numerical instabilities. The instantaneous power is dispersed in time using a function that mimicked the emissions dispersion [Ramamurthy et al., 1998]. Dispersed power is found to correlate more closely with $\mathrm{NO}_{\mathrm{x}}$ than instantaneous undispersed power. For example the quality of fit, $\mathrm{R}^{2}$ values for $\mathrm{NO}_{\mathrm{x}}$ with dispersed and undispersed power for vehicle A are found to be 0.8409 and 0.8291 respectively.

\subsubsection{Oxides of Nitrogen vs. Axle power}

Figure 7-9 provides second by second data for vehicles A, B and C on the CBD cycle, with a best fit curve of $\mathrm{NO}_{\mathrm{x}}$ emissions, in units of $\mathrm{g} / \mathrm{sec}$, against dispersed axle power for each vehicle. These are the three transit buses with identical specifications, so that similar behavior could be expected. It is evident that the data shown in figure 7-9 bifurcate as a result of engine maps of the engine control strategy: it is the advancing of the injection timing that raises the $\mathrm{NO}_{\mathrm{x}}$ emissions. Without more detailed knowledge of 
the timing algorithms employed in the engine control, it is not possible to predict the impact of bifurcation. The bifurcation leads to a poor correlation of the data with the bestfit curve. For comparison, figure 7-10 provides data from two repeat runs on vehicle A, showing good data consistency from run to run. Data scatter arises in these plots because (i) the same power may be delivered to the rear axle with the engine operating at different speeds (due to different gear selection) or under different transient conditions, (ii) any imperfection in time alignment of data causes scatter, and (iii) variations in injection timing at similar fueling rates will lead to emission level changes. In figures 7-9 and 7-10 the few high values for $\mathrm{NO}_{\mathrm{x}}$ emissions rates correspond to high $\mathrm{NO}_{\mathrm{x}}$ "spikes" during acceleration on some of the peaks of the CBD cycle. The presence of these spikes reduces correlation coefficients for the "best-fit" lines considerably.

Concerns over cycle-specific emissions from heavy duty vehicles are well founded. Figure 7-11 shows the variations of $\mathrm{NO}_{\mathrm{x}}$ with dispersed axle power from vehicle A for a range of cycles. It is evident that there are differences, for example, between the results for the $\mathrm{CBD}$ cycle and the 5 mile route since the $\mathrm{CBD}$ cycle does not exploit full power output capability of the vehicle. The presence of these spikes reduces correlation coefficients for the "best-fit" lines considerably.

Recently manufactured diesel engines have all been certified to similar $\mathrm{NO}_{\mathrm{x}}$ emissions levels (4 to $5 \mathrm{~g} / \mathrm{bhp}$-hr) using the FTP for engines, and this is reflected in the fact that the instantaneous $\mathrm{NO}_{\mathrm{x}}$ emissions do not vary substantially with respect to dispersed axle power between vehicle types. Figure 7-12 presents data for vehicles A, D, E and F, all for the Central Business District Cycle. Vehicles A and D differ in vehicle age, while A and E employ engines from different manufacturers. Vehicles $\mathrm{F}$ is a refuse 
truck, rather than a transit bus, like A, D and E, and so is tested at a higher weight with correspondingly higher engine power demand. However, it is evident that CBD does not demand full engine power from these vehicles, so that the resulting data cannot be used for holistic inventory source modeling without extrapolation.

Vehicles $\mathrm{G}$ and $\mathrm{H}$ are both trucks with unsynchronized transmissions, and these have difficulty in following a cycle such as the CBD and the truck CBD cycle [Clark et al., 1995] with higher acceleration rates. Figure 7-13 provides data for vehicles $\mathrm{G}$ and $\mathrm{H}$ on the truck $\mathrm{CBD}$ and the $\mathrm{CBD}$ cycle respectively.

\section{Comparison with Certification Data}

Although the cycles used in this case are quite distinct from the engine operation experienced in the FTP, it is of interest to see how well the data agree with the current certification $\mathrm{NO}_{\mathrm{x}}$ levels which vary from 4 to $5 \mathrm{~g} / \mathrm{bhp}$-hr for these test vehicles. Figure 714 presents data of the vehicle $A$ in previous figure in units of axle power-hr/g (ahp-hr/g) at varying levels of axle power. Since during idling power requirements do not exist, the emissions in g/ahp-hr are not always defined. In consequence, the inverse of this ratio is taken for analysis. Axle and engine (brake) power can be compared if the transmission efficiency is known. This issue has been discussed for manual transmissions in Hoppie [1997] and McKain et al. [1998], and it is known that automatic transmission, except during lockup, will be less efficient than manual over a transient cycle. Considering that transmission efficiencies might vary from $60 \%$ to $85 \%$, the certification values should correspond to a range from 4.7 to $8.3 \mathrm{~g} / \mathrm{ahp}-\mathrm{hr}(0.12$ to $0.21 \mathrm{ahp}-\mathrm{hr} / \mathrm{g})$ of $\mathrm{NO}_{\mathrm{x}}$ during chassis testing although off-cycle timing strategies will yield higher levels. The majority of the chassis emissions data corresponding in the 60 to $80 \mathrm{~kW}$ range agree with these 
values, as shown in figure 7-14. However, the reader is cautioned not to translate the data between different cycles without careful consideration, and to note that this comparison does not include the vehicle fuel consumption data that are usually employed in heavy duty vehicle inventory estimation.

\subsubsection{Oxides of Nitrogen Prediction}

$\mathrm{NO}_{\mathrm{x}}$ is seen to have good correlation with axle power and it matches with axle power for the full cycle after the time shifting is applied to the data to account for the delay associated with the measurement of the $\mathrm{NO}_{\mathrm{x}}$ data by the analyzers. Figures 7-15 and 7-16 represents the final shifted $\mathrm{NO}_{\mathrm{x}}$ variations with dispersed axle power for the transit bus (vehicle I) with a Detroit Diesel 6V-92 engine tested on the New York Composite cycle and the CBD cycle respectively. The residence time distribution is considered by applying the dispersion function to axle power. The dispersed power and the $\mathrm{NO}_{\mathrm{x}}$ data are subjected to time alignment and the $\mathrm{NO}_{\mathrm{x}}$ data are shifted, using the time shift obtained from the cross-correlation method. The correlation (model) of $\mathrm{NO}_{\mathrm{x}}$ as a function of dispersed axle power is obtained for the New York Composite cycle by fitting a polynomial curve to the data and the model is used to predict $\mathrm{NO}_{\mathrm{x}}$ for the $\mathrm{CBD}$ cycle. The goodness of fit of this model with the data from the CBD cycle is found to be 0.9014 . The predicted average emissions in units of $\mathrm{g} / \mathrm{mile}$ are compared with the measured average emissions also in (g/mile) for the whole cycle as shown in Table 7-1. Figures 717 and 7-18 show similar analysis of shifted $\mathrm{NO}_{\mathrm{x}}$ and dispersed axle power variations on a tractor truck (vehicle J) with a Detroit Diesel 6V-92 engine for the 5-peak WVU test cycle and the truck CBD cycle respectively. The model obtained from the correlation between $\mathrm{NO}_{\mathrm{x}}$ and dispersed axle power for the 5-peak WVU test cycle is then used to 
predict the $\mathrm{NO}_{\mathrm{x}}$ emissions in the truck CBD cycle. The goodness of fit of this model with the data from the truck CBD cycle is found to be 0.3567 . The average predicted and measured emissions in $\mathrm{g} / \mathrm{mile}$ are compared. Table 7-1 shows the accuracy of the $\mathrm{NO}_{\mathrm{x}}$ prediction model, developed on a single cycle, in estimating the overall emissions on a completely different cycle.

From the table it is seen that $\mathrm{NO}_{\mathrm{x}}$ is predicted suitably for the transit bus (vehicle I) but not for the tractor truck (vehicle J). This is attributed to cycle specific effects. The 5-peak WVU test cycle has a unique speed-acceleration envelope, exploring emissions at different speeds compared to the truck CBD cycle, which concentrates only on the 8.92 $\mathrm{m} / \mathrm{s}$ (20mph) region for cruise conditions. Also, the "off-cycle" injection timing produces different effects for different cycles, which makes prediction difficult.

In the prediction models developed for $\mathrm{NO}_{\mathrm{x}}$, it is seen that $\mathrm{NO}_{\mathrm{x}}$ is expressed as

$$
\mathrm{NO}_{\mathrm{x}}=\mathrm{a} *(\text { axle power })+\mathrm{b}
$$

where $\mathrm{a}$ and $\mathrm{b}$ are constants having units of $\mathrm{g} /(\mathrm{kW}-\mathrm{s})$ and $\mathrm{g} / \mathrm{s}$ respectively. Axle power could be substituted with engine power by assuming a constant drive train efficiency of $80 \%$. Eighty percent is the best estimate of the drive train efficiency used so far [Hoppie, 1997]. It is seen that both axle and engine power have a common time shift since their ratio is the drive train efficiency. In order to validate this model and check if splitting of axle power as engine/vehicle speed and engine torque would improve the prediction, $\mathrm{NO}_{\mathrm{x}} /\left(\mathrm{a}^{*}\right.$ power $\left.+\mathrm{b}\right)$ is plotted as a function of engine speed as shown in figure 7-19. Figure 7-19 is expected to be a straight line if engine speed has an influence on the model and is compared with $\mathrm{NO}_{\mathrm{x}}$ as function of power (figure 7-20) for a tractor truck tested on a 5 mile route in Riverside, CA. It is seen that engine speed alone has no say in 
prediction and it reinforces the consideration of taking power consolidated as a function to predict $\mathrm{NO}_{\mathrm{x}}$.

\subsubsection{Bifurcation of Data}

Engine manufacturers advance the injection timing of the engine which result in elevated $\mathrm{NO}_{\mathrm{x}}$ levels, so that the engine automatically slips into high $\mathrm{NO}_{\mathrm{x}}$ mode during cruise mode and improves the fuel consumption of the vehicle. This high $\mathrm{NO}_{\mathrm{x}}$ mode goes largely undetected in federal testing as FTP tests are transient and do not contain cruise sections. However, the bifurcation is clearly seen on a Cummins M11 tractor truck tested on a 5 mile route (1061-01) as shown in figure 7-21. Since the bifurcation occurs as a result of non-linear algorithms in the engine control strategy, it is not possible to predict the impact of bifurcation with-out detailed knowledge of the timing algorithms employed in engine control. The chance of slipping into the high or low $\mathrm{NO}_{\mathrm{x}}$ mode depends on the driver behavior and vehicle operation history. So, depending on the nature of the driver behavior, $\mathrm{NO}_{\mathrm{x}}$ emissions may be high or low. The bifurcation leads to poor correlation of data with the best-fit curve. 


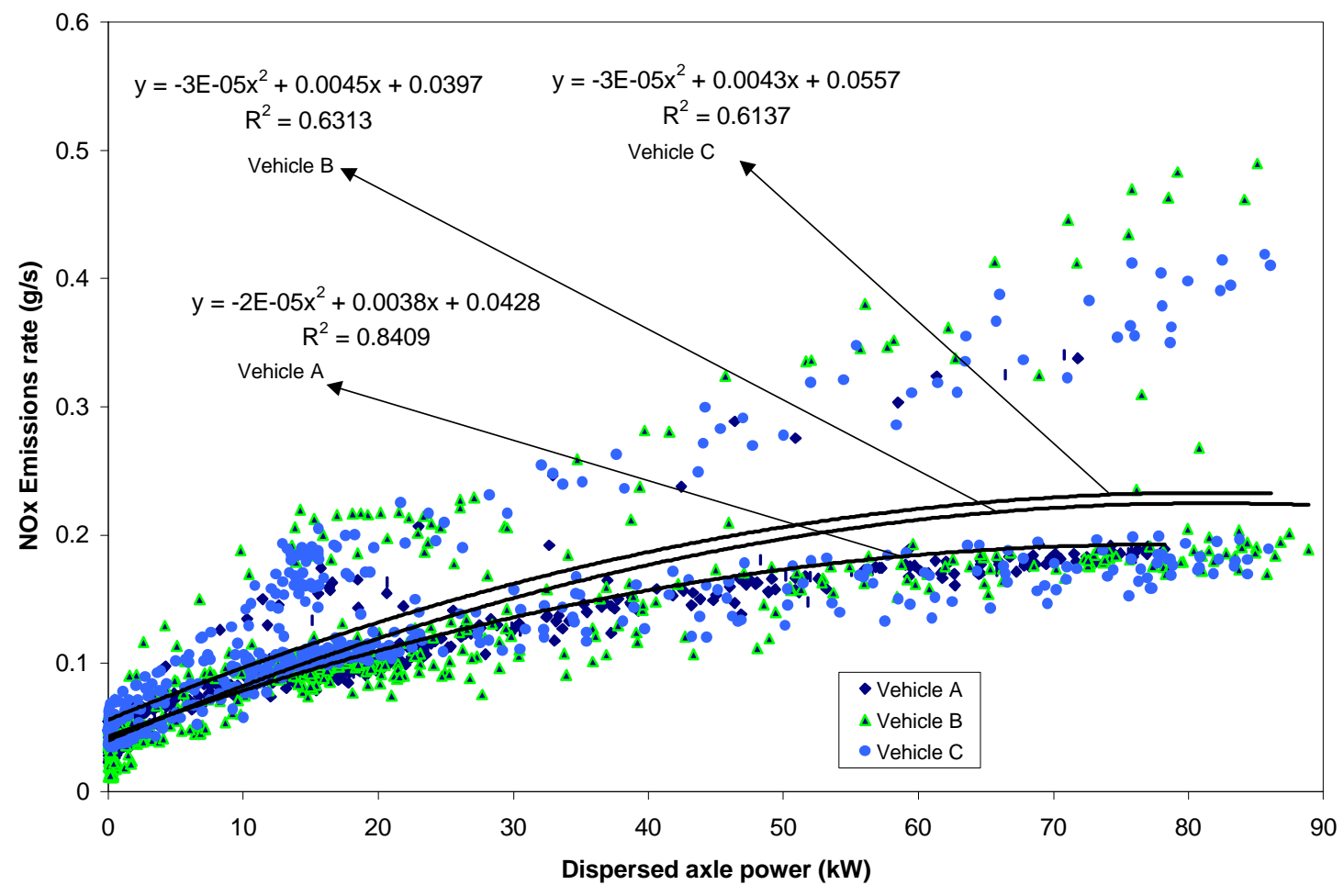

Figure 7-9: Three different buses (Vehicles A, B and C) with similar specifications tested on a CBD cycle. Bifurcation due to injection timing variations can cause poor best fit curve because the curve must seek a compromise between high and low $\mathrm{NO}_{\mathrm{x}}$ modes. 


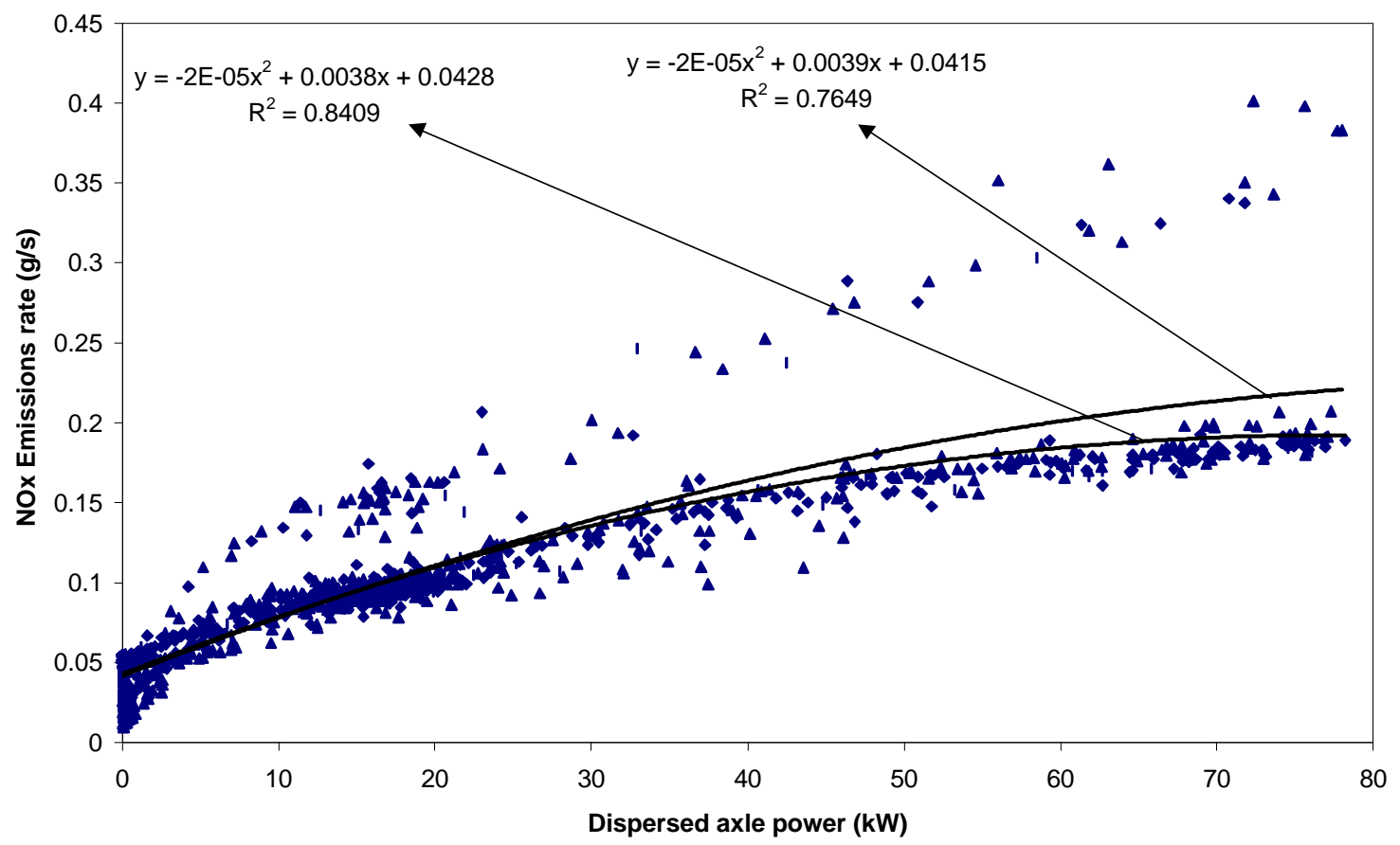

Figure 7-10: Vehicle A (transit bus, MY 96) on two consecutive runs tested on the CBD cycle. 


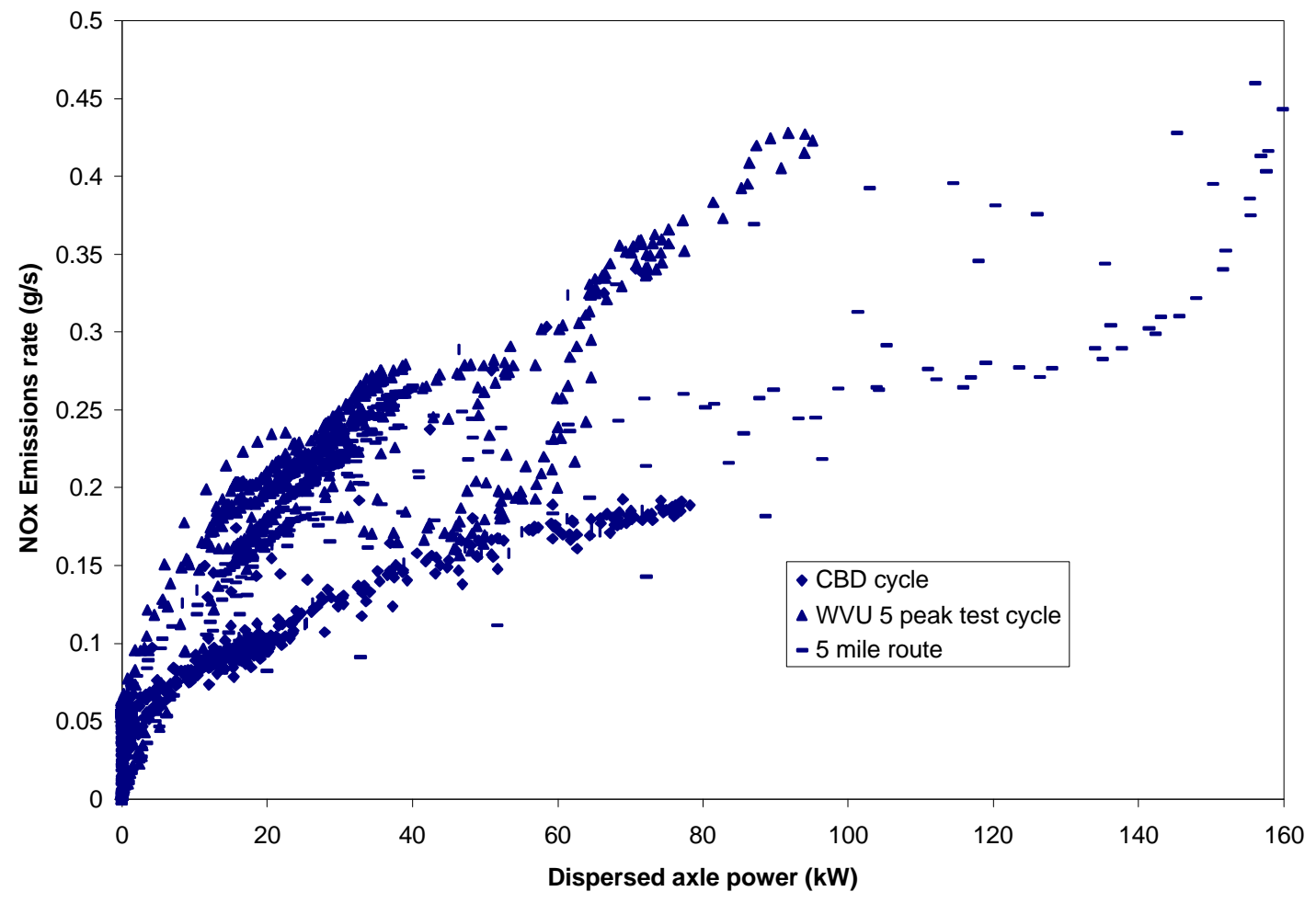

Figure 7-11: Comparison of emissions from vehicle A tested on different cycles. 


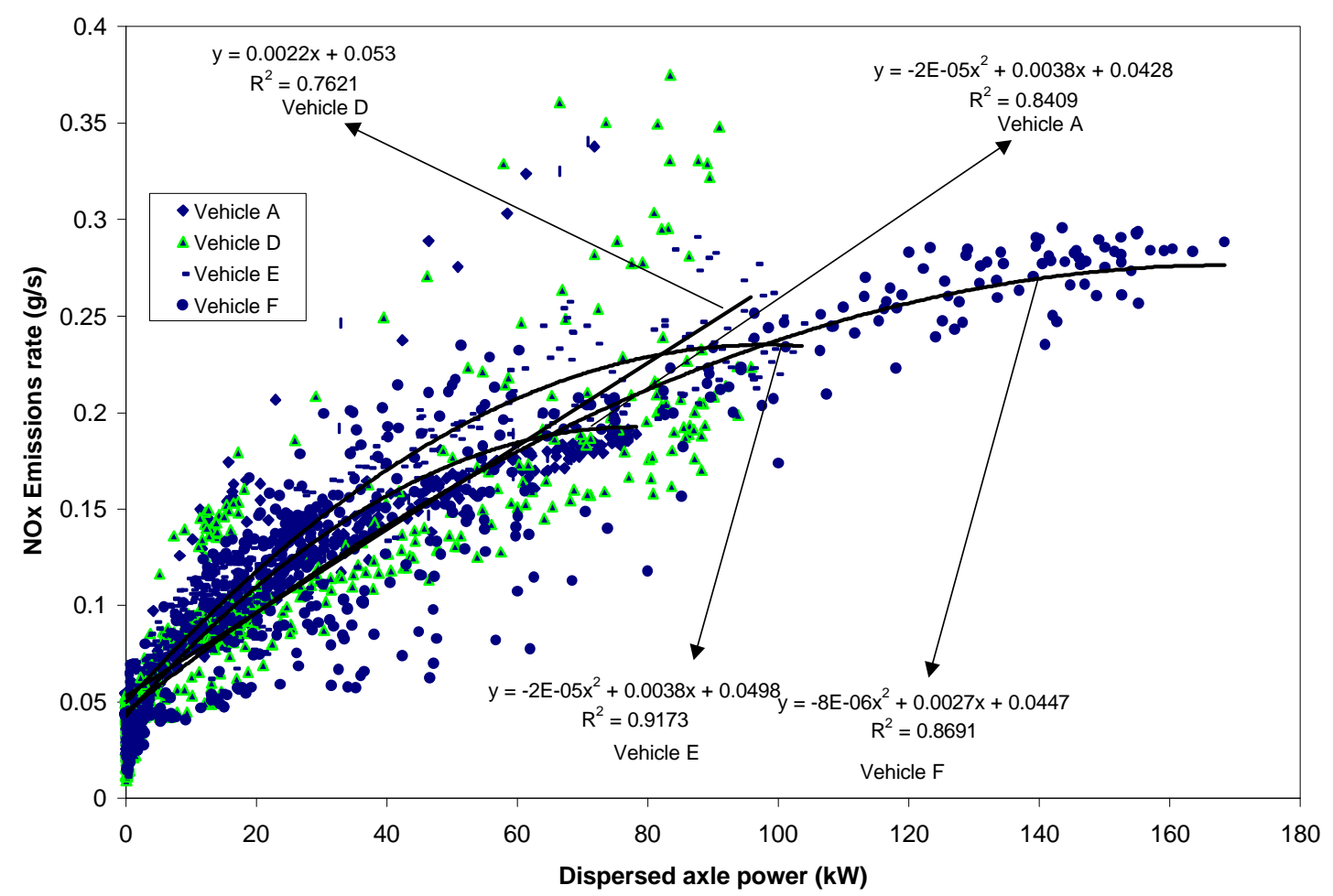

Figure 7-12: Emissions rate vs. Dispersed axle power for vehicles A, D, E and F tested on the CBD cycle. 


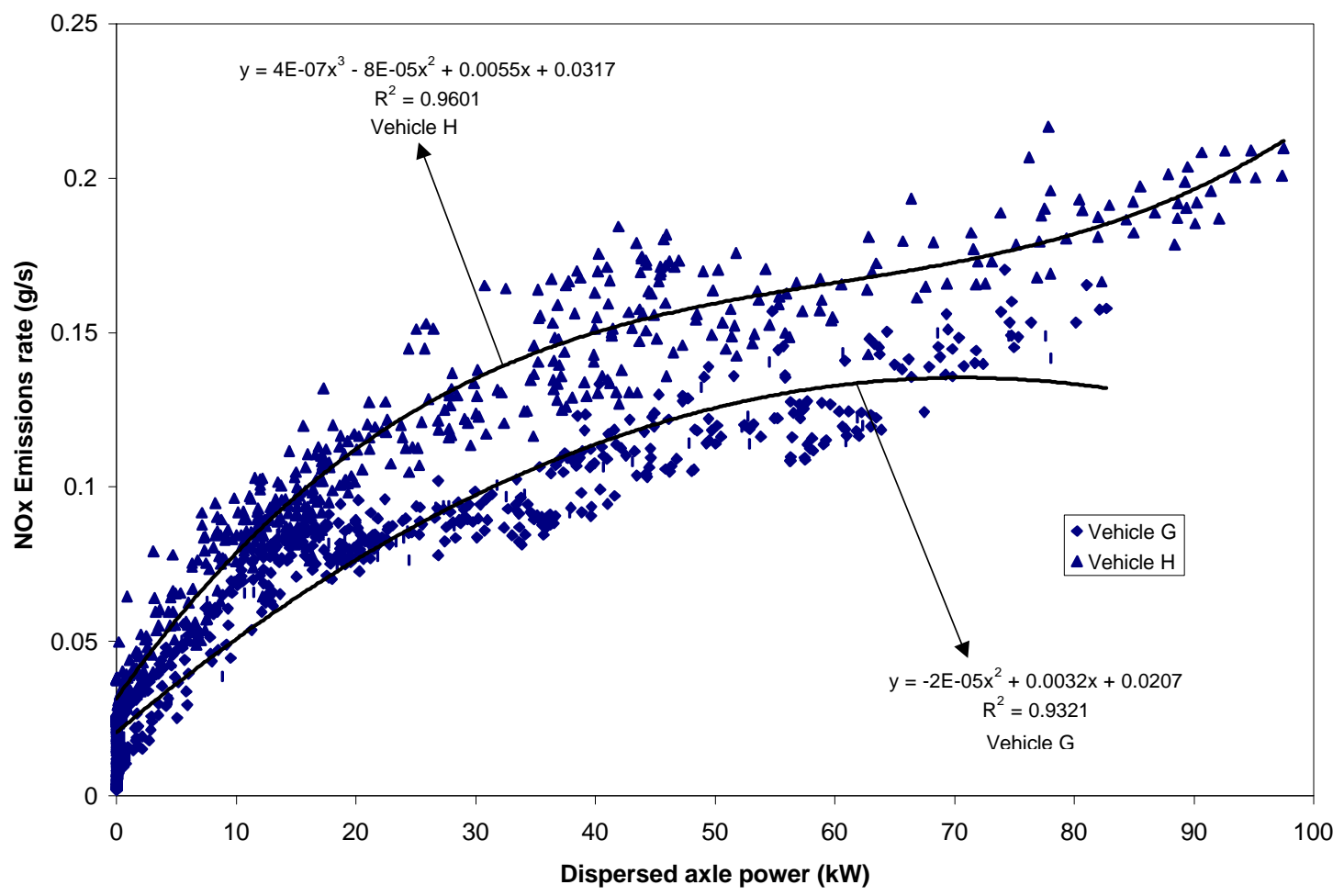

Figure 7-13: Emissions rate vs. Dispersed axle power for vehicles $\mathrm{G}$ and $\mathrm{H}$ with manual transmissions tested on the truck $\mathrm{CBD}$ and $\mathrm{CBD}$ cycles respectively. 


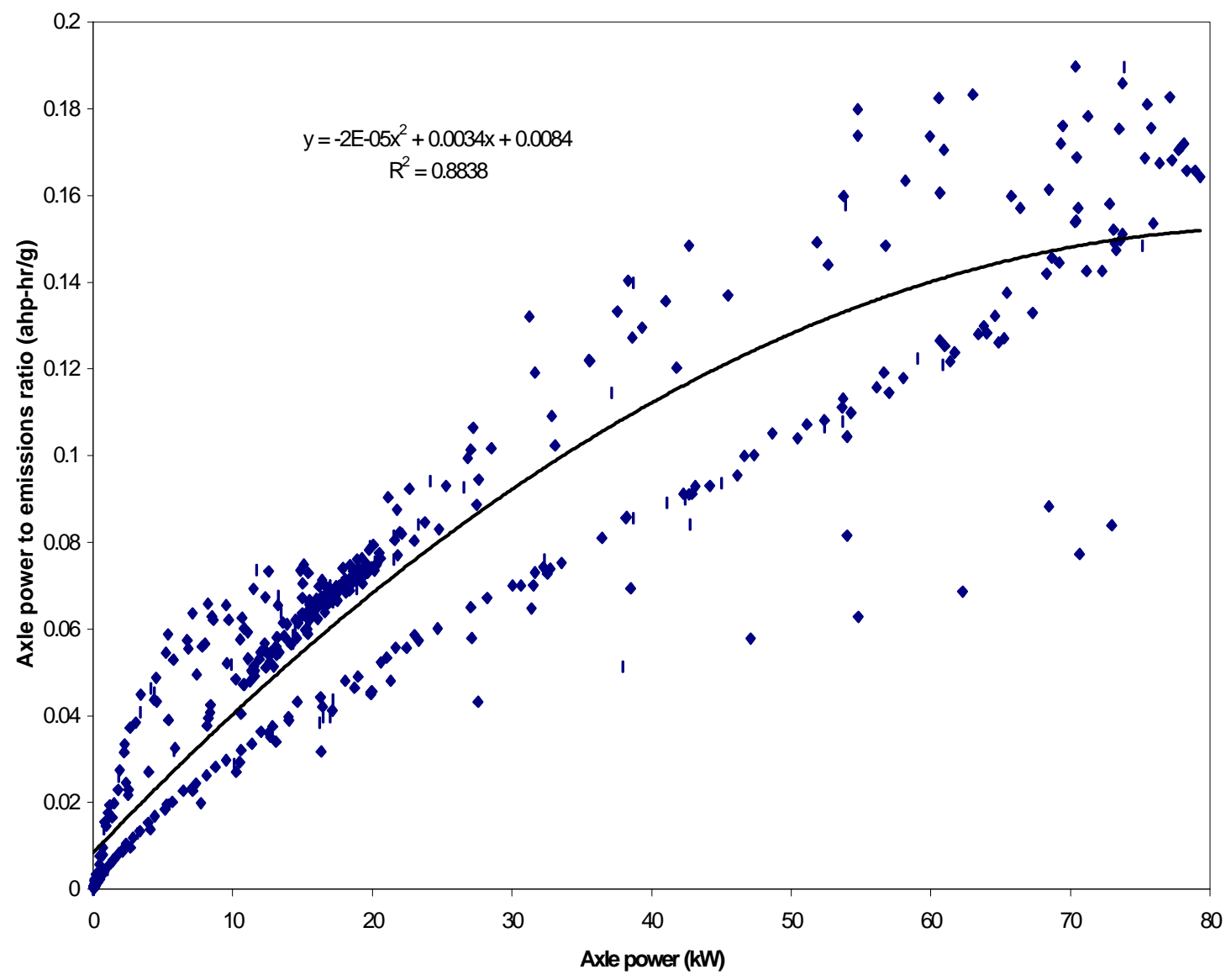

Figure 7-14: Data from vehicle A tested on a CBD cycle. The inverse of the customary emissions units has been used because $\mathrm{g} / \mathrm{bhp}$-hr is undefined at zero power output. 


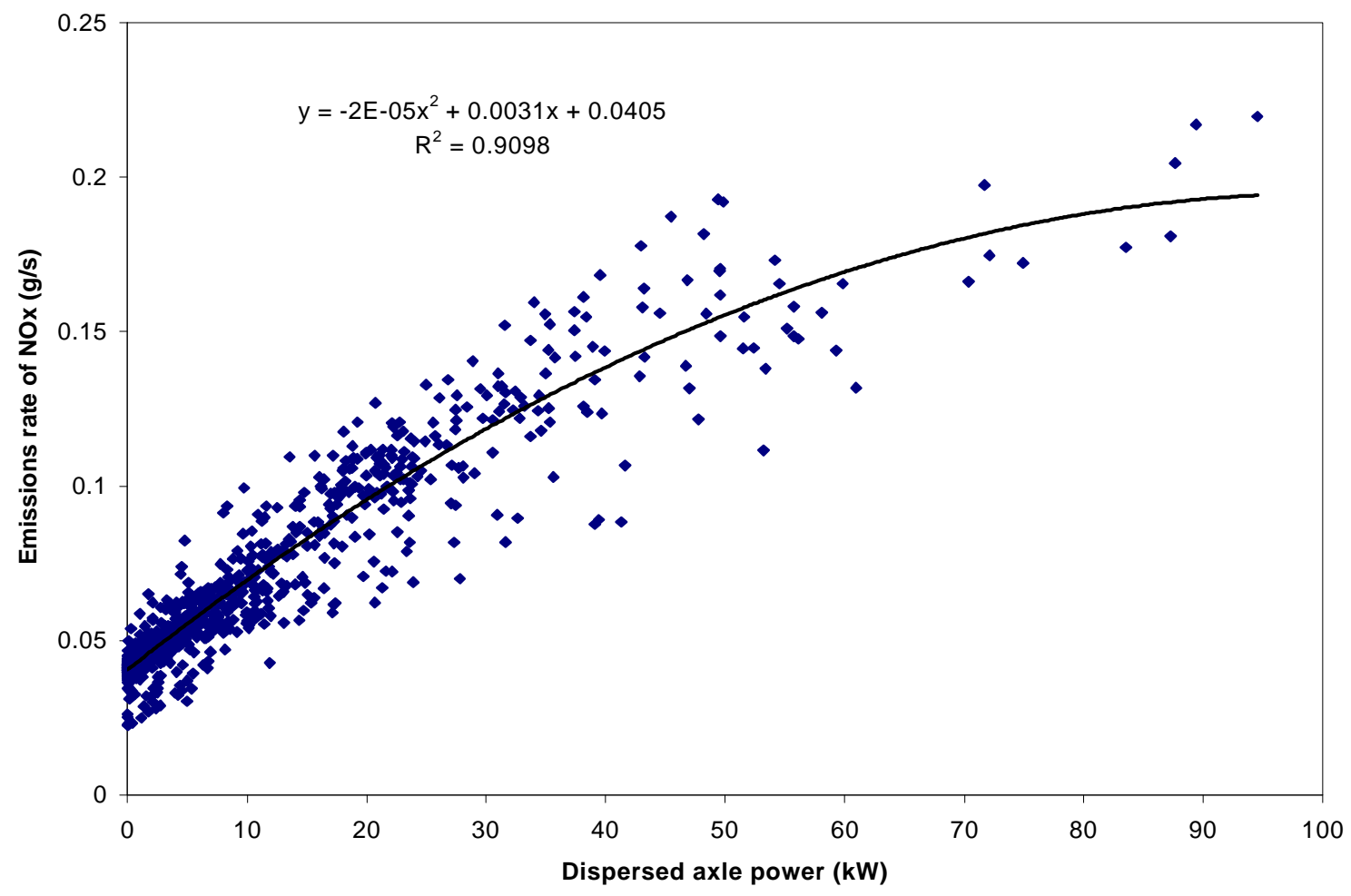

Figure 7-15: Shifted $\mathrm{NO}_{\mathrm{x}}$ vs. Dispersed power for a transit bus (vehicle I) with a Detroit Diesel 6V-92 $253 \mathrm{hp}(188 \mathrm{~kW})$ engine tested on the New York Composite cycle. 


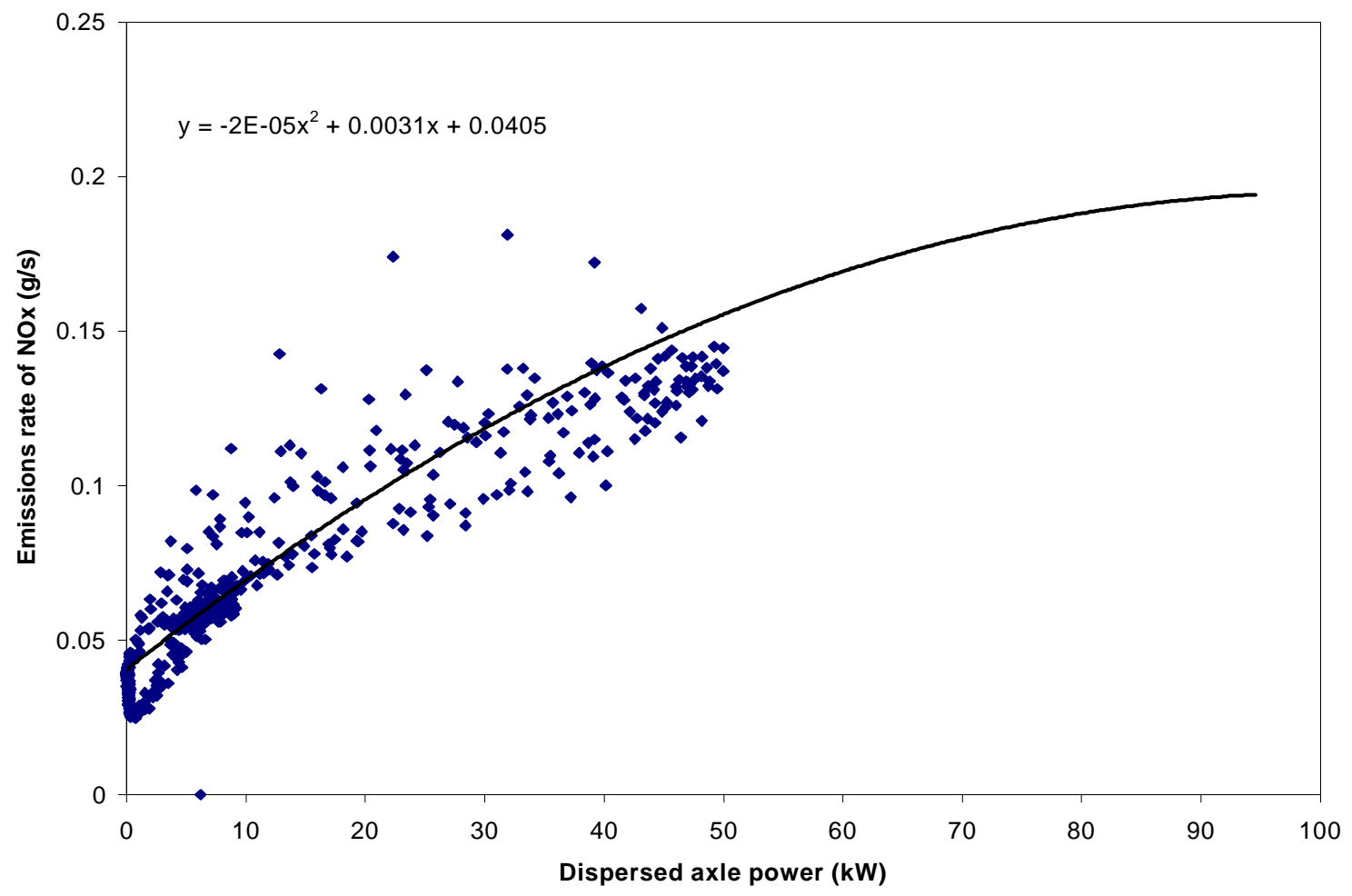

Figure 7-16: Shifted $\mathrm{NO}_{\mathrm{x}}$ vs. Dispersed power for a transit bus (vehicle I) with a Detroit Diesel 6V-92 $253 \mathrm{hp}(188 \mathrm{~kW})$ engine tested on the CBD cycle. The correlation curve is the same as those shown in figure $7-15 . \mathrm{R}^{2}$ for this curve vs. the data is 0.9014 . 


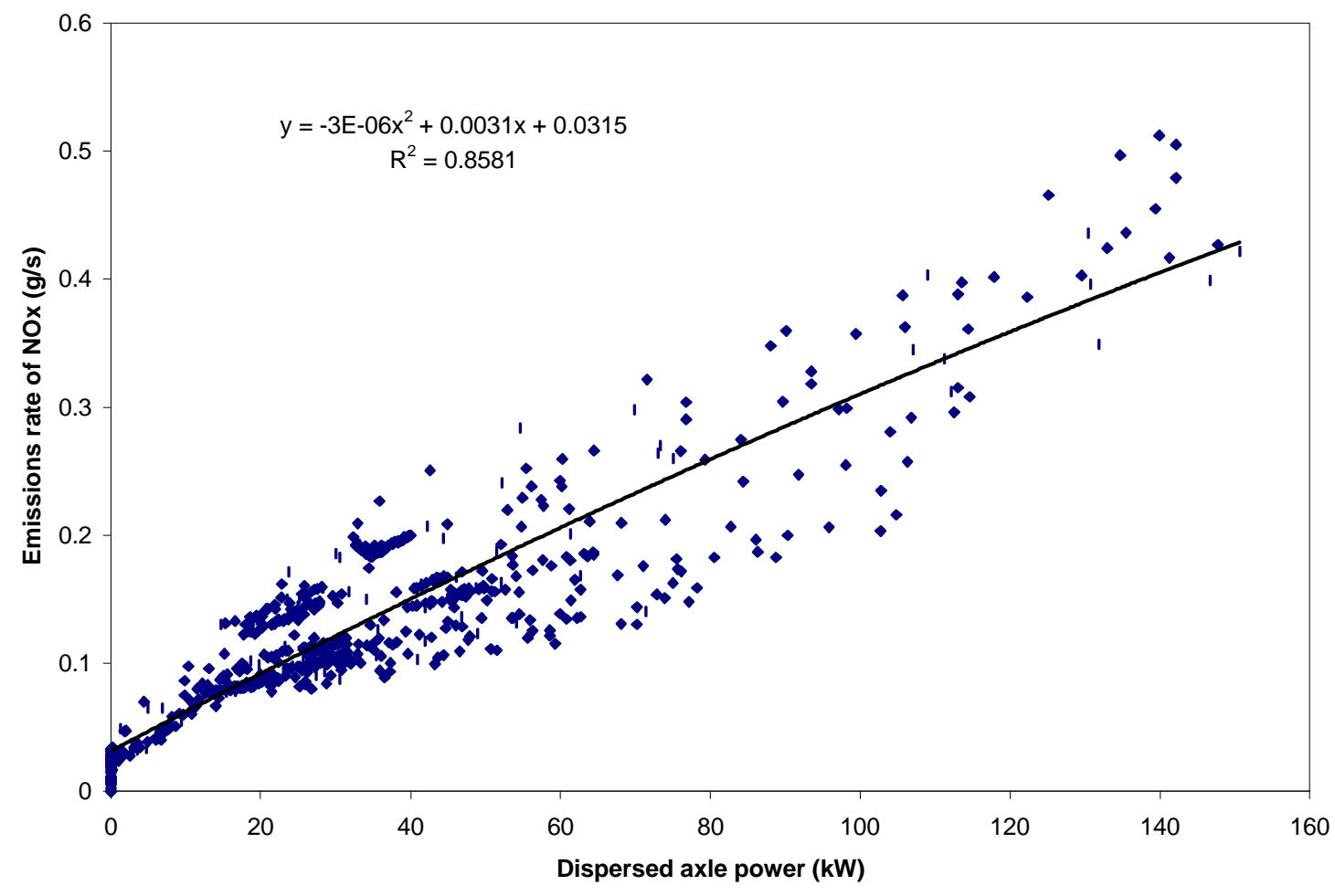

Figure 7-17: Shifted $\mathrm{NO}_{\mathrm{x}}$ vs. Dispersed power for a tractor truck (vehicle J) with a Detroit Diesel 6V-92 $300 \mathrm{hp}(223 \mathrm{~kW})$ engine tested on the 5-peak WVU test cycle. 


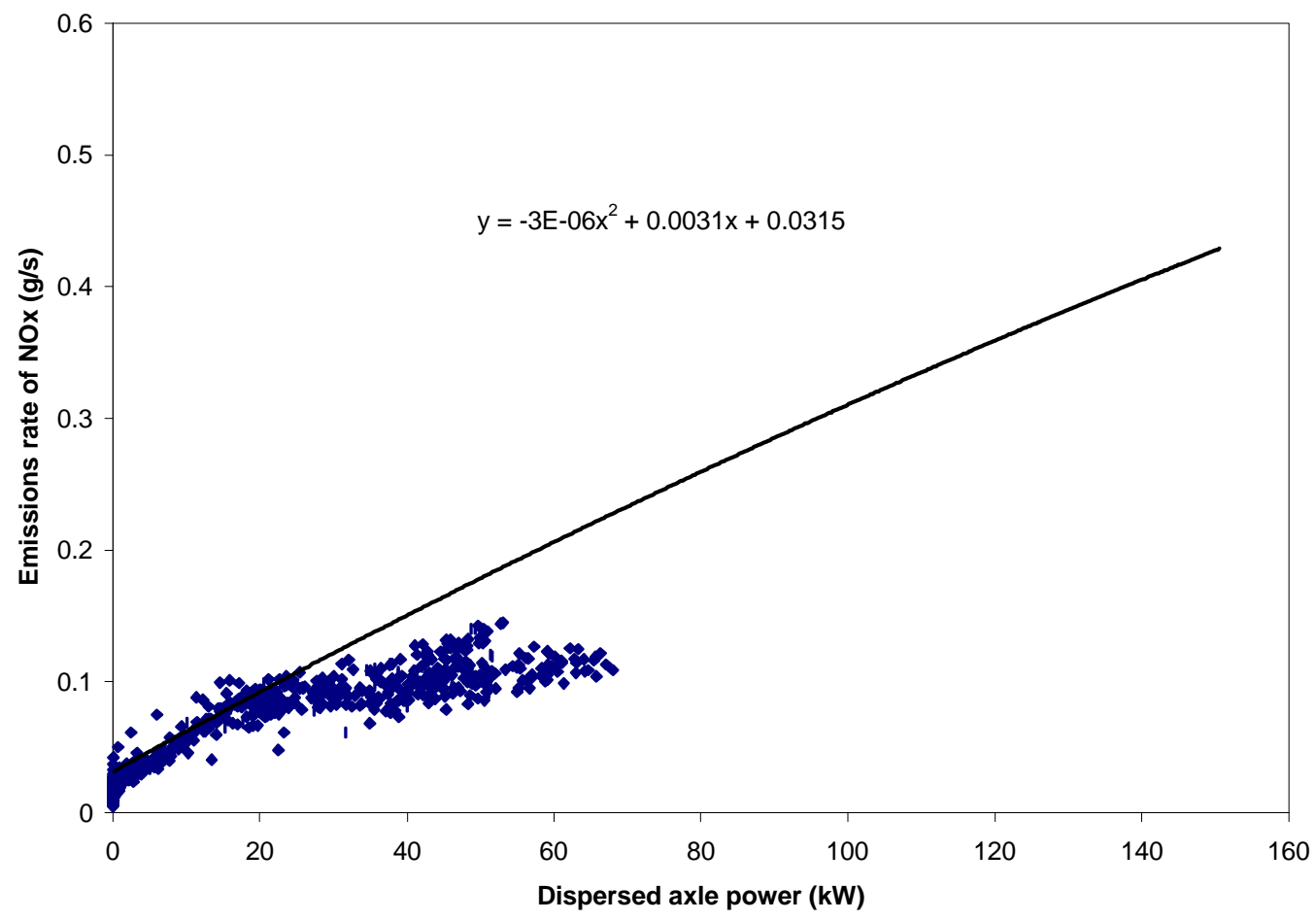

Figure 7-18: Shifted $\mathrm{NO}_{\mathrm{x}}$ vs. Dispersed power for a tractor truck (vehicle J) with a Detroit Diesel 6V-92 $300 \mathrm{hp}(223 \mathrm{~kW})$ engine tested on the truck CBD cycle. The correlation curve is the same as those shown in figure $7-17 . \mathrm{R}^{2}$ for this curve vs. the data is 0.3567 . 


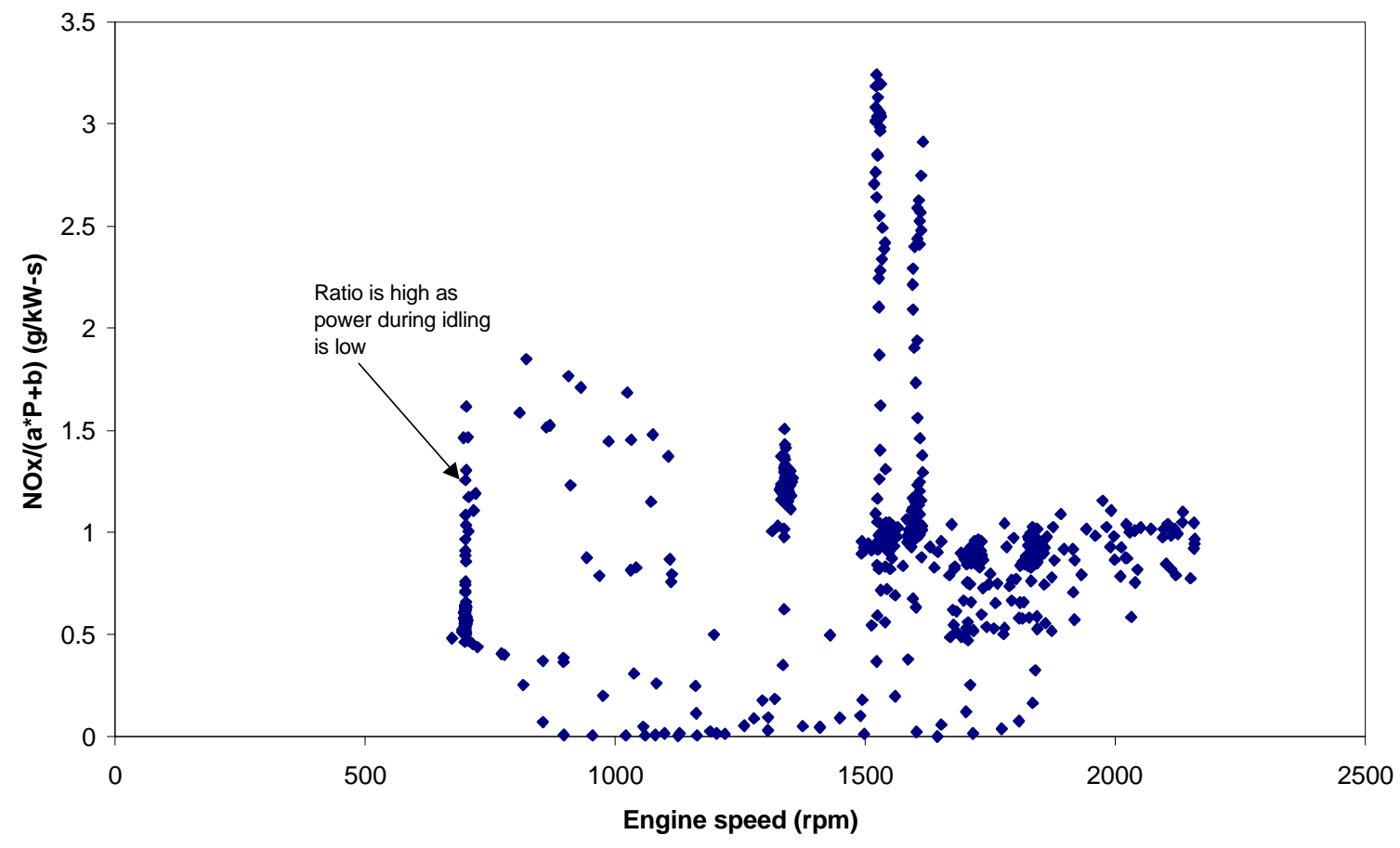

Figure 7-19: Shifted $\mathrm{NO}_{\mathrm{x}} /(\mathrm{a} * \mathrm{P}+\mathrm{b})$ vs. Engine speed for a tractor truck tested on a 5 mile route (1162-02) in Riverside, CA. 


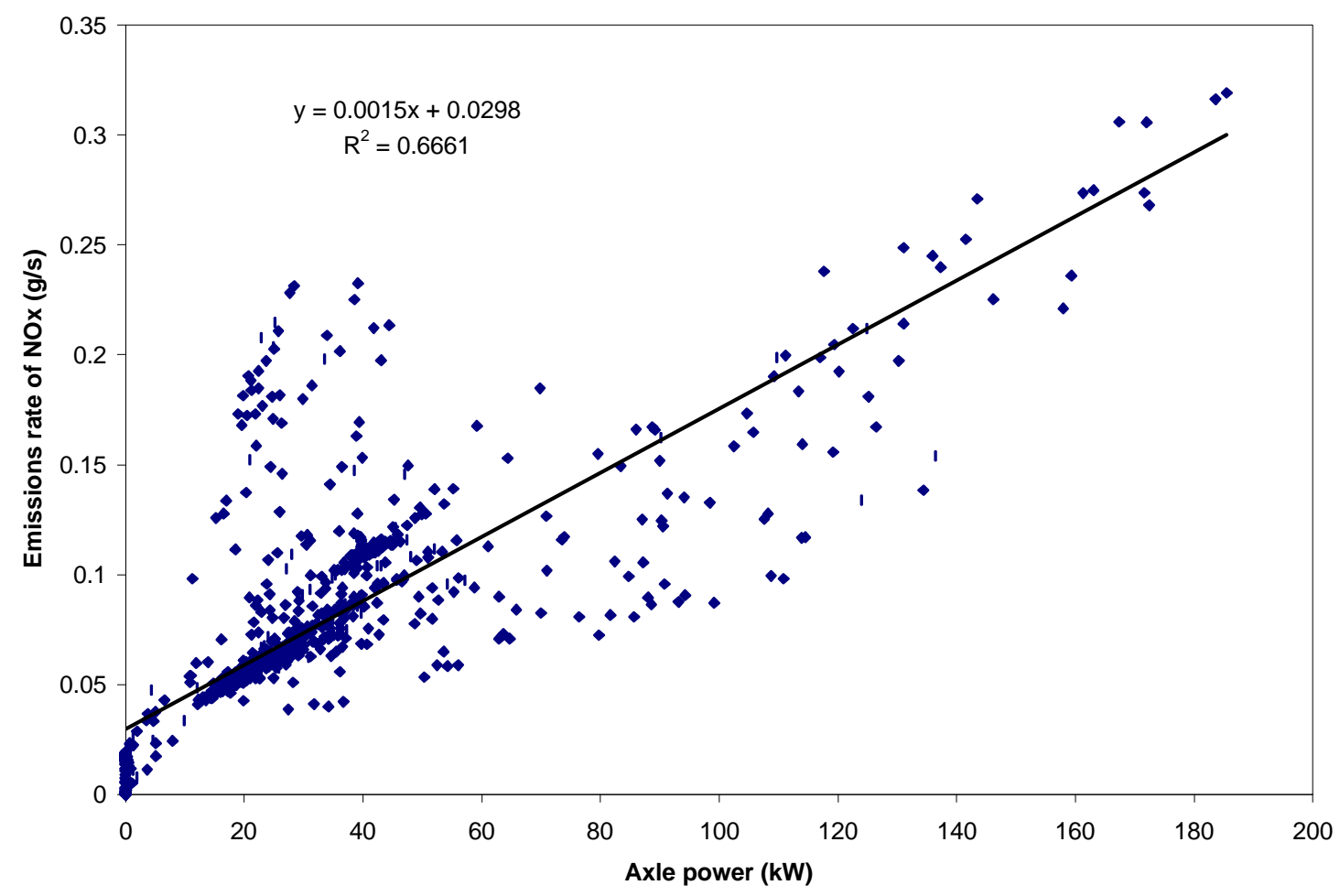

Figure 7-20: Shifted $\mathrm{NO}_{\mathrm{x}}$ vs. axle power for a tractor truck tested on a 5 mile route (1162-

02) in Riverside, CA. 


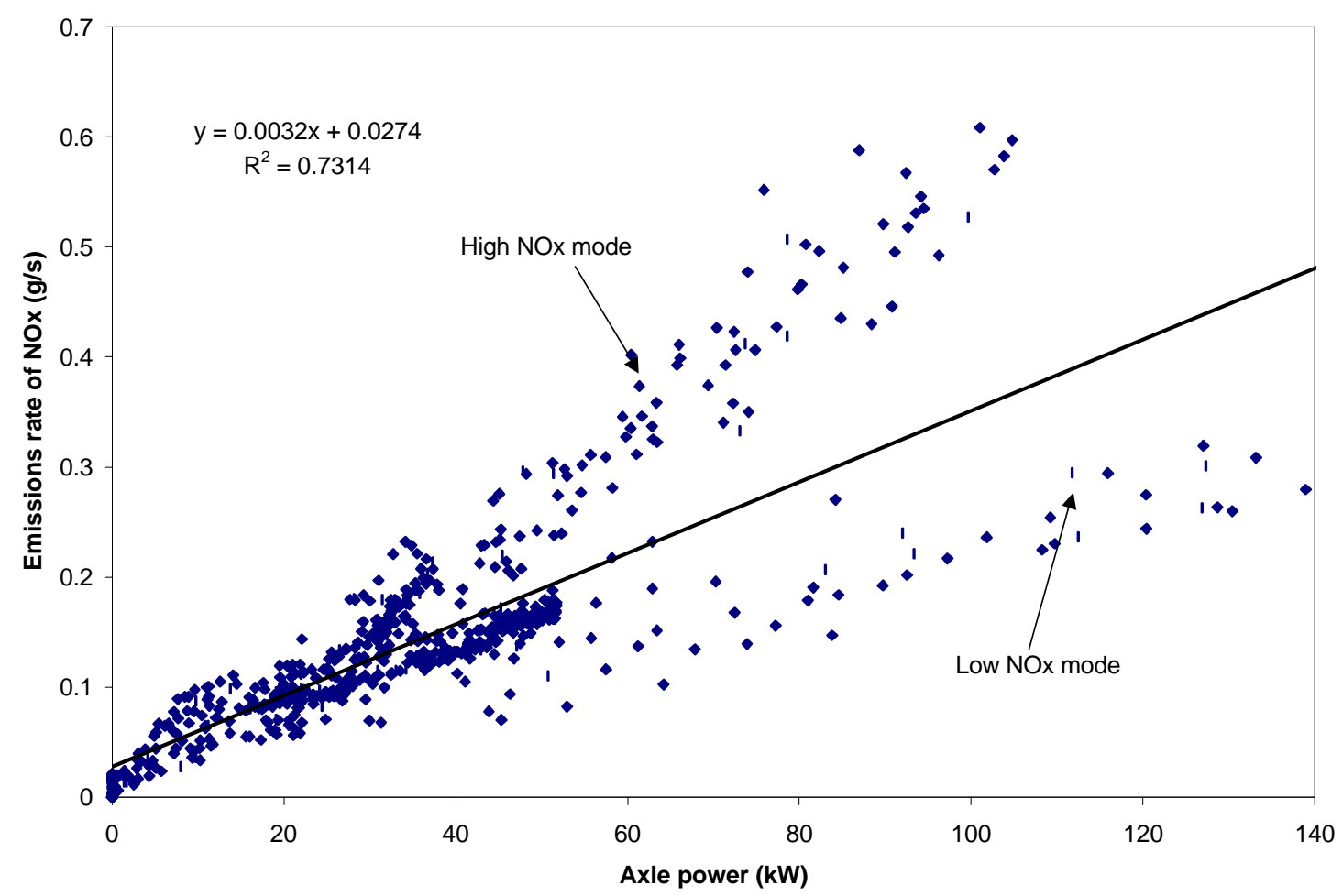

Figure 7-21: Shifted $\mathrm{NO}_{\mathrm{x}}$ vs. axle power for a Cummins M11 tractor truck tested on a 5 mile route (1061-01) in Sacramento, CA. 
Table 7-1: Comparison between measured and predicted emissions

\begin{tabular}{|l|l|l|l|l|l|}
\hline Vehicle Type & $\begin{array}{l}\text { Model } \\
\text { Basis }\end{array}$ & $\begin{array}{l}\text { Predicted } \\
\text { Cycle }\end{array}$ & $\begin{array}{l}\text { Measured } \\
\mathrm{NO}_{\mathrm{x}}(\mathrm{g} / \mathrm{mile})\end{array}$ & $\begin{array}{l}\text { Predicted } \\
\mathrm{NO}_{\mathrm{x}}(\mathrm{g} / \mathrm{mile})\end{array}$ & \% Error \\
\hline $\begin{array}{l}\text { Transit bus } \\
\text { (Vehicle I) }\end{array}$ & $\begin{array}{l}\text { New York } \\
\text { Composite } \\
\text { Cycle }\end{array}$ & $\begin{array}{l}\text { CBD } \\
\text { cycle }\end{array}$ & 20.02 & 19.60 & -2.09 \\
\hline $\begin{array}{l}\text { Tractor truck } \\
\text { (Vehicle J) }\end{array}$ & $\begin{array}{l}\text { 5-peak } \\
\text { WVU test } \\
\text { cycle }\end{array}$ & $\begin{array}{l}\text { truck } \\
\text { CBD } \\
\text { cycle }\end{array}$ & 22.62 & 33.50 & 47.0 \\
\hline
\end{tabular}




\subsection{Carbon monoxide (CO)}

\subsubsection{Carbon monoxide (CO) vs. Dispersed Axle power}

Carbon monoxide is another significant emission component in the vehicle exhaust. It is seen that $\mathrm{NO}_{\mathrm{x}}$ and $\mathrm{CO}_{2}$ have positive correlation with axle power. Similarly, $\mathrm{CO}$ correlation with axle power is attempted. When correlating $\mathrm{CO}$ with axle power, it is important to account for the delay associated with the measurement of $\mathrm{CO}$ by the $\mathrm{CO}$ analyzer, as axle power is directly measured from the drive wheels. The time delay associated with the measurement of $\mathrm{CO}$ is due to the flow of exhaust through sampling lines, dilution tunnel and response time of the analyzer. To know the time delay, carbon monoxide and smoothed power are cross-correlated and the resulting time shift between them is calculated. The time delay in the measurement of $\mathrm{CO}$ is accounted by shifting the carbon monoxide data by the measured delay. The shifted carbon monoxide data is plotted with the axle power of the vehicle and the peak-to-peak matching of $\mathrm{CO}$ and power data is verified. The gases from the tail-pipe of the vehicle are not transmitted to the analyzers in a plug flow fashion, but are dispersed in time having a residence time distribution. The residence time distribution is taken into consideration and $\mathrm{CO}$ is correlated with dispersed power instead of performing a reverse transform on the continuous tail-pipe emissions and producing numerical instabilities. The instantaneous power is dispersed in time using a function that mimics the emissions dispersion: this process is described in the dispersion section. Figure 7-22 shows the correlation of $\mathrm{CO}$ with dispersed power.

It is seen that $\mathrm{CO}$ emissions rate does not have a good correlation with power. It is understood that the rate of generation of $\mathrm{CO}$ emissions is fuel and engine specific. For a 
particular vehicle of a known type of engine, CO could be correlated with power and predicted, but control algorithms differ from engine to engine. $\mathrm{CO}$ can be emitted at a particular instant from two engines at similar conditions, with one of them having a low boost (air flow) and high engine speed and the other having a high boost and low engine speed. This suggests that $\mathrm{CO}$ cannot be correlated with axle/engine power as a combined parameter and depends on different specific engine parameters such as

- Fuel Injection Pulse Width (FIPW)

- Injection timing

- Manifold air pressure

- Engine torque and speed

\subsubsection{Carbon monoxide Prediction}

Prediction of $\mathrm{CO}$ emissions rate $(\mathrm{g} / \mathrm{s})$ is attempted initially as a function of axle power. Figures 7-23, 25, 27 and 29 show the correlation between the measured and the predicted CO $(\mathrm{g} / \mathrm{s})$ for a transit bus (vehicle I) with a Detroit Diesel 6V-92 engine tested on the New York Composite cycle and the CBD cycle, and a tractor truck (vehicle J) with the same engine, but tested on the truck CBD cycle and the 5-peak WVU test cycle. These prediction models of $\mathrm{CO}(\mathrm{g} / \mathrm{s})$ are built as a function of axle power for each of the test cycle and comparison is made with the measured CO. It is seen that transient effects influence CO production significantly, so that more sophisticated modeling is required. This might include, for example, the rate of change of axle power as an input variable. Figures 7-24, 26, 28 and 30 show the correlation of $\mathrm{CO}$ with an additional transient 
variable like rate of change of axle power for vehicles I and J. The rate of change of power is included along with power and linear multiple regression is carried out to get the prediction model.

Predicted $\mathrm{CO}=\mathrm{a}^{*}$ Power $+\mathrm{b}^{*} \mathrm{~d}($ Power $) / \mathrm{dt}+\mathrm{c}$

Where $\mathrm{a}, \mathrm{b}, \mathrm{c}$ are constants having units of $\mathrm{g} /(\mathrm{kW}-\mathrm{s}), \mathrm{g} / \mathrm{kW}$ and $\mathrm{g} / \mathrm{s}$ respectively.

The addition of rate of change of dispersed power as an input variable for prediction for the transit bus (vehicle I), and another variable, namely the square of the dispersed power for the tractor truck (vehicle J), improved the quality of prediction only marginally. 


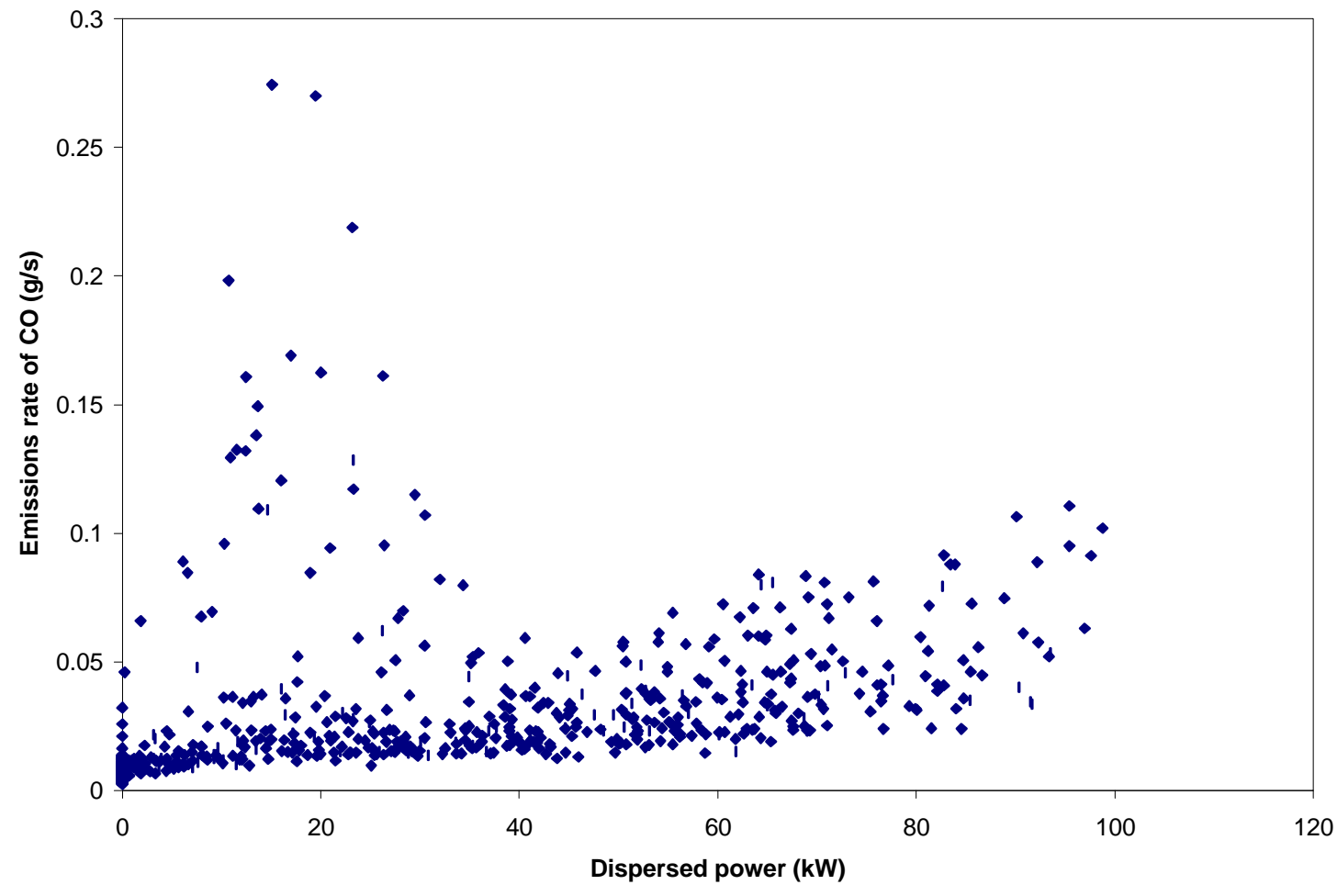

Figure 7-22: Shifted CO vs. Dispersed axle power for a tractor truck (vehicle J) with a Detroit Diesel 6V-92 300hp (223kW) engine tested on the truck CBD cycle. 


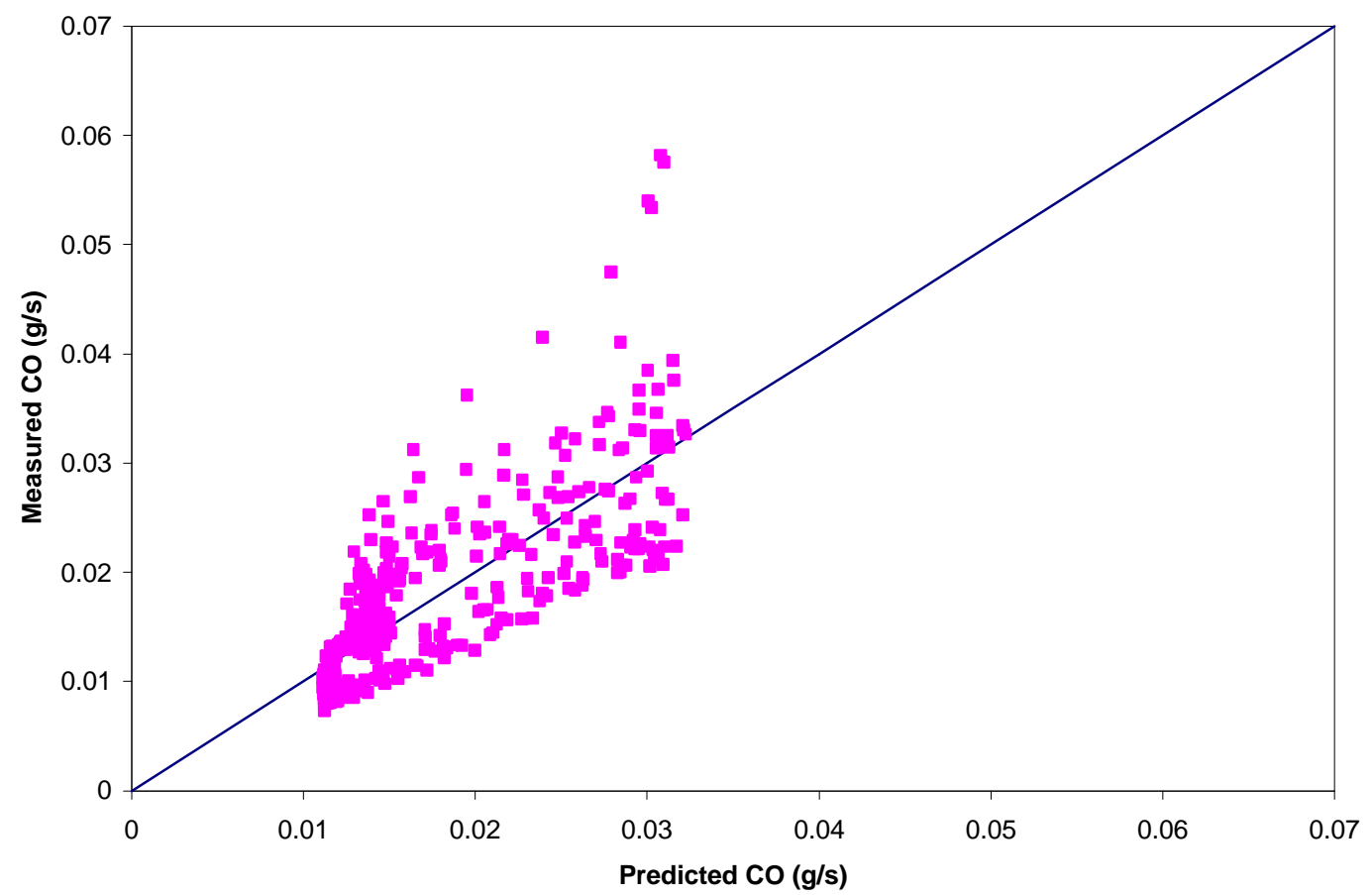

Figure 7-23: Measured vs. Predicted CO for a transit bus (vehicle I) with a Detroit Diesel 6V-92 253hp (188kW) engine tested on the CBD cycle. The correlation model based on the dispersed power data of the cycle is used to predict $\mathrm{CO}$. 


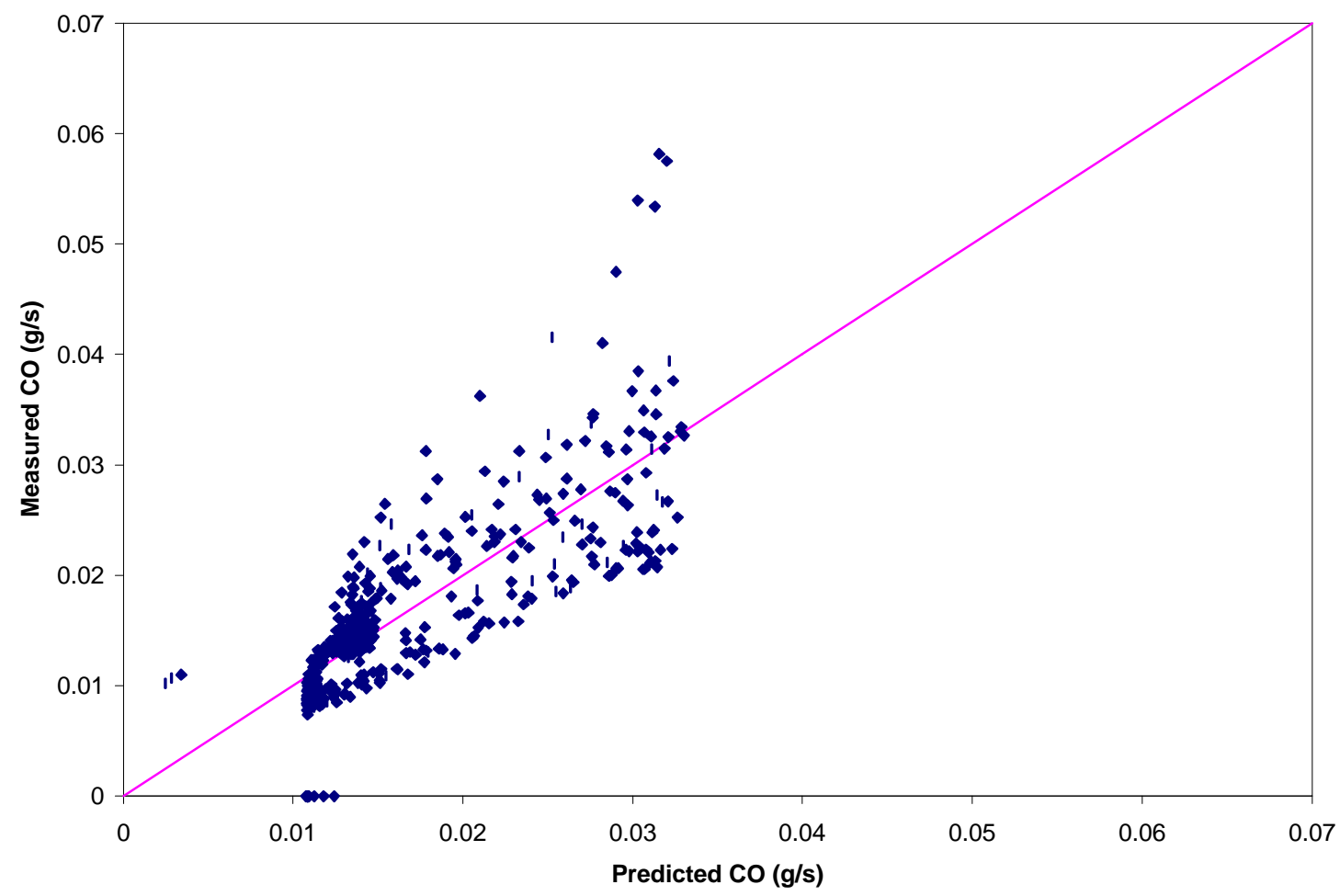

Figure 7-24: Measured vs. Predicted CO for a Transit Bus (vehicle I) with a Detroit Diesel 6V-92 253hp (188kW) engine tested on the CBD cycle. The correlation model based on the dispersed power and rate of change of power data of the cycle is used to predict CO. $\mathrm{R}^{2}$ improved marginally from 0.7123 to 0.7227 . 


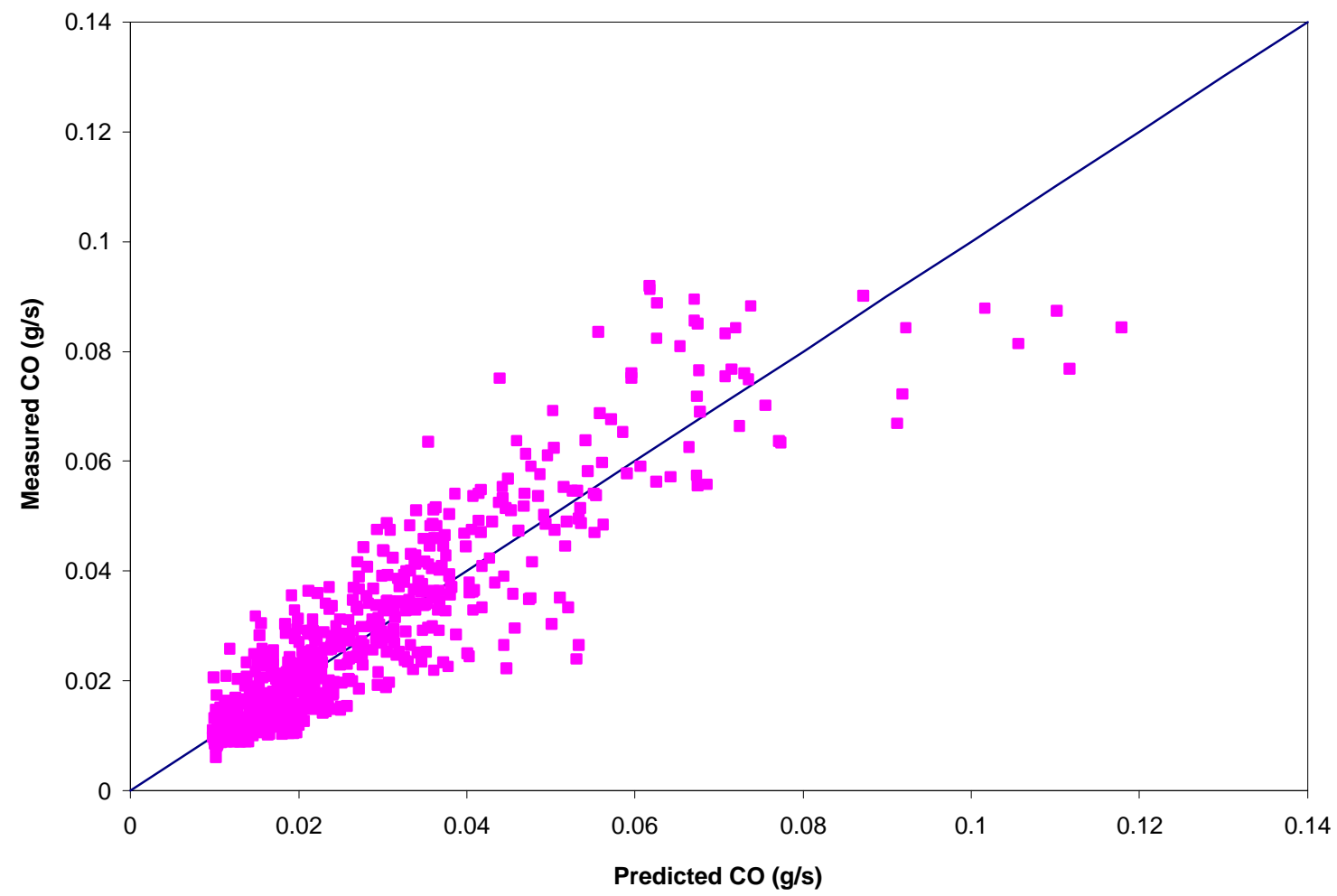

Figure 7-25: Measured vs. Predicted CO for a transit bus (vehicle I) with a Detroit Diesel 6V-92 253hp (188kW) engine tested on the New York Composite cycle. The correlation model based on the dispersed power data of the cycle is used to predict $\mathrm{CO}$. 


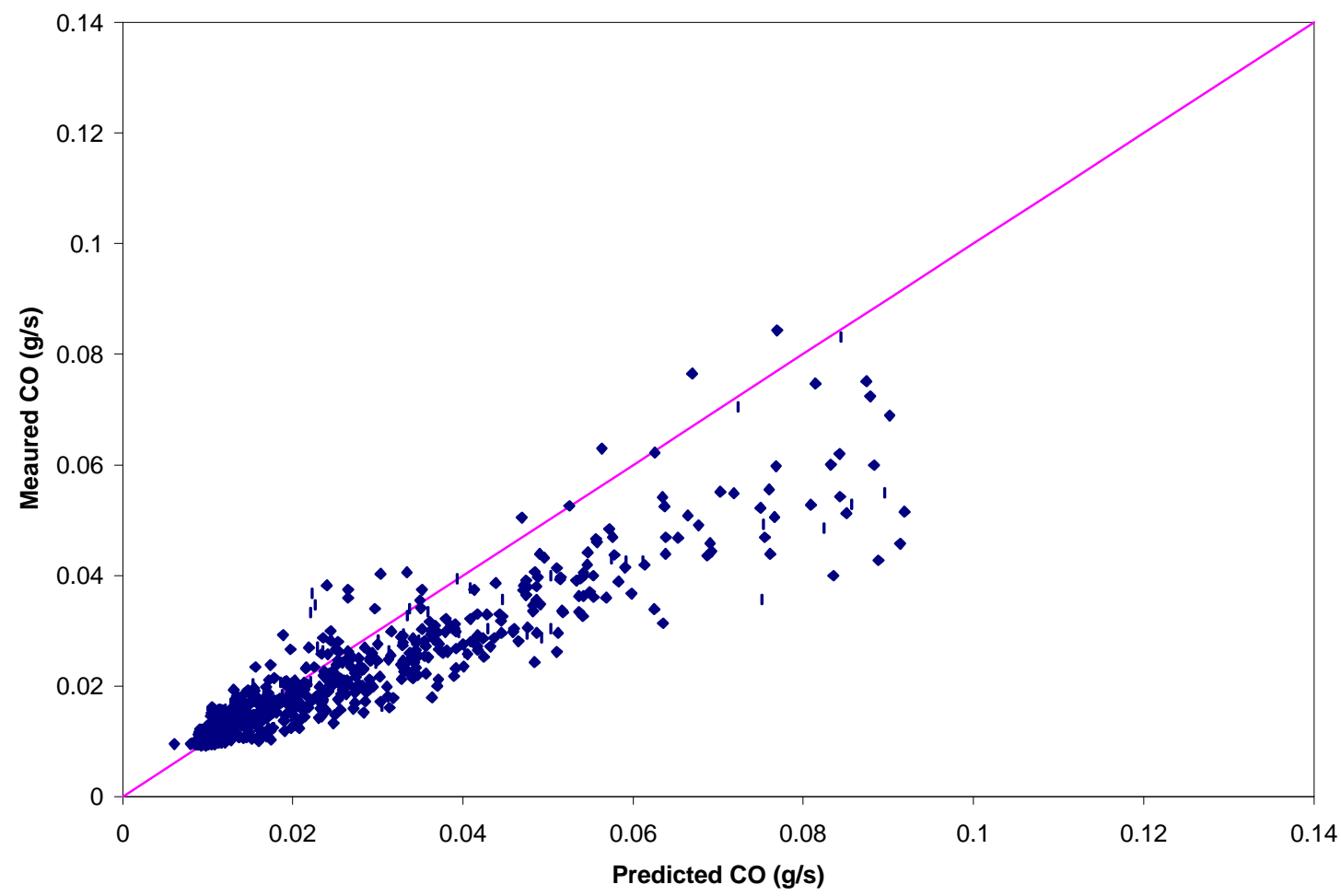

Figure 7-26: Measured vs. Predicted CO for a transit bus (vehicle I) with a Detroit Diesel 6V-92 253hp (188kW) engine tested on the New York Composite cycle. The correlation model based on the dispersed power and the rate of dispersed power data of the cycle, is used to predict $\mathrm{CO}$. The $\mathrm{R}^{2}$ improved marginally from 0.8667 to 0.8889 , with the addition of rate of change of power as a variable. 


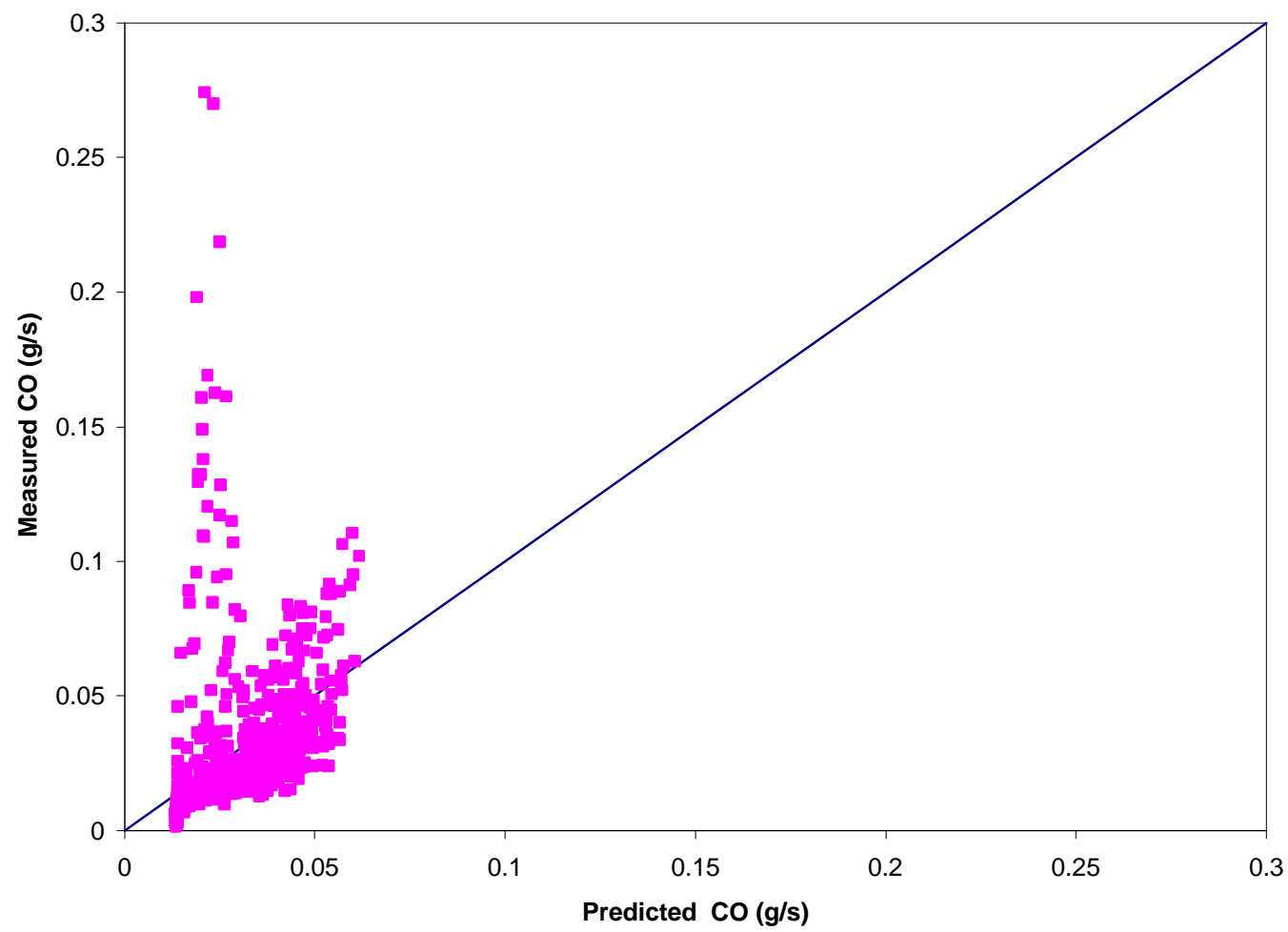

Figure 7-27: Measured vs. Predicted CO for a tractor truck (vehicle J) with a Detroit Diesel 6V-92 300hp (223kW) engine tested on the truck CBD cycle. The correlation model based on the dispersed power data of the cycle is used to predict CO. 


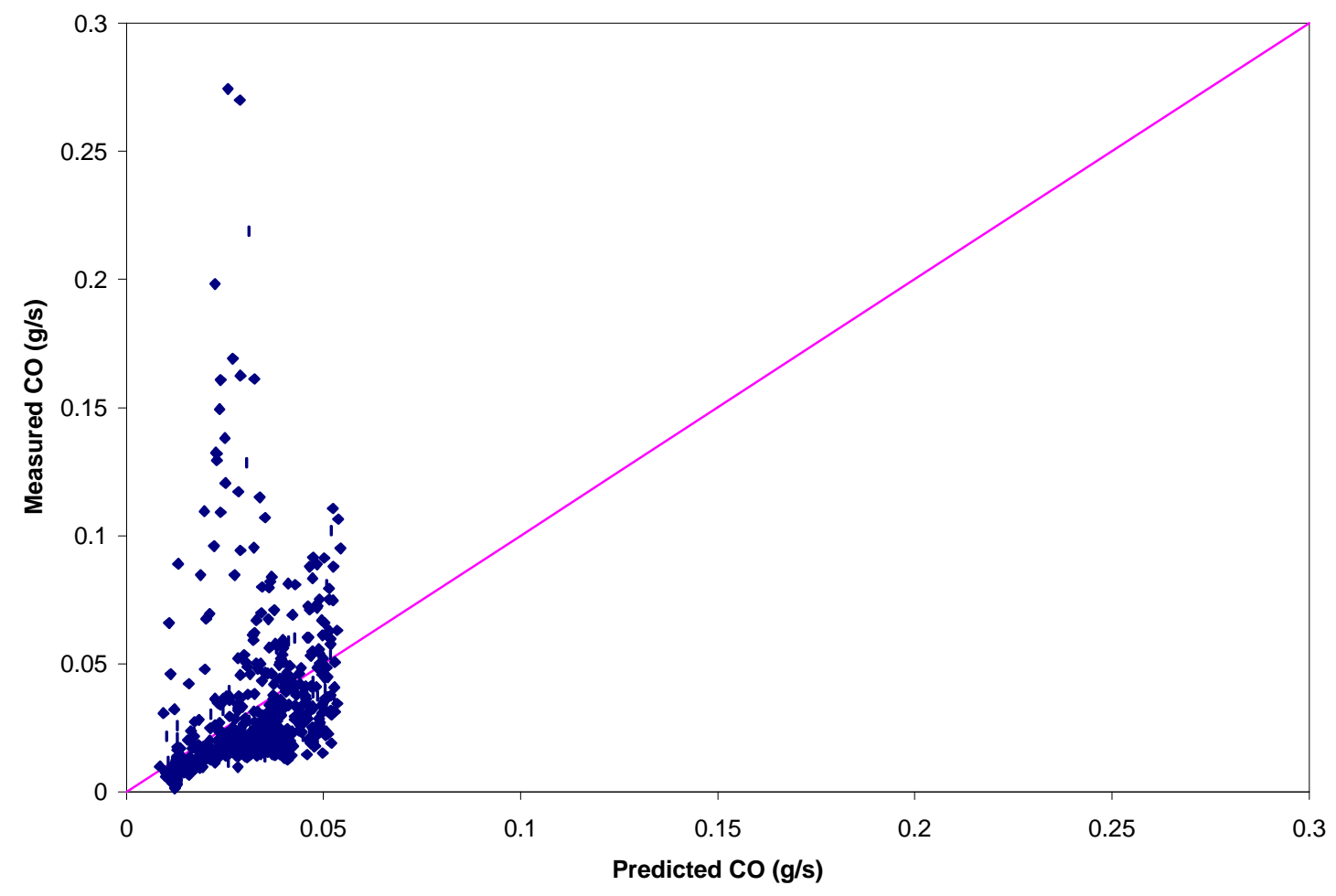

Figure 7-28: Measured vs. Predicted CO for a tractor truck (vehicle J) with a Detroit Diesel 6V-92 300hp (223kW) engine tested on the truck CBD cycle. The correlation model based on the dispersed power; rate of change of dispersed power and square of dispersed power data of the cycle is used to predict $\mathrm{CO}$. The $\mathrm{R}^{2}$ value changed marginally from 0.2111 to 0.2248 . 


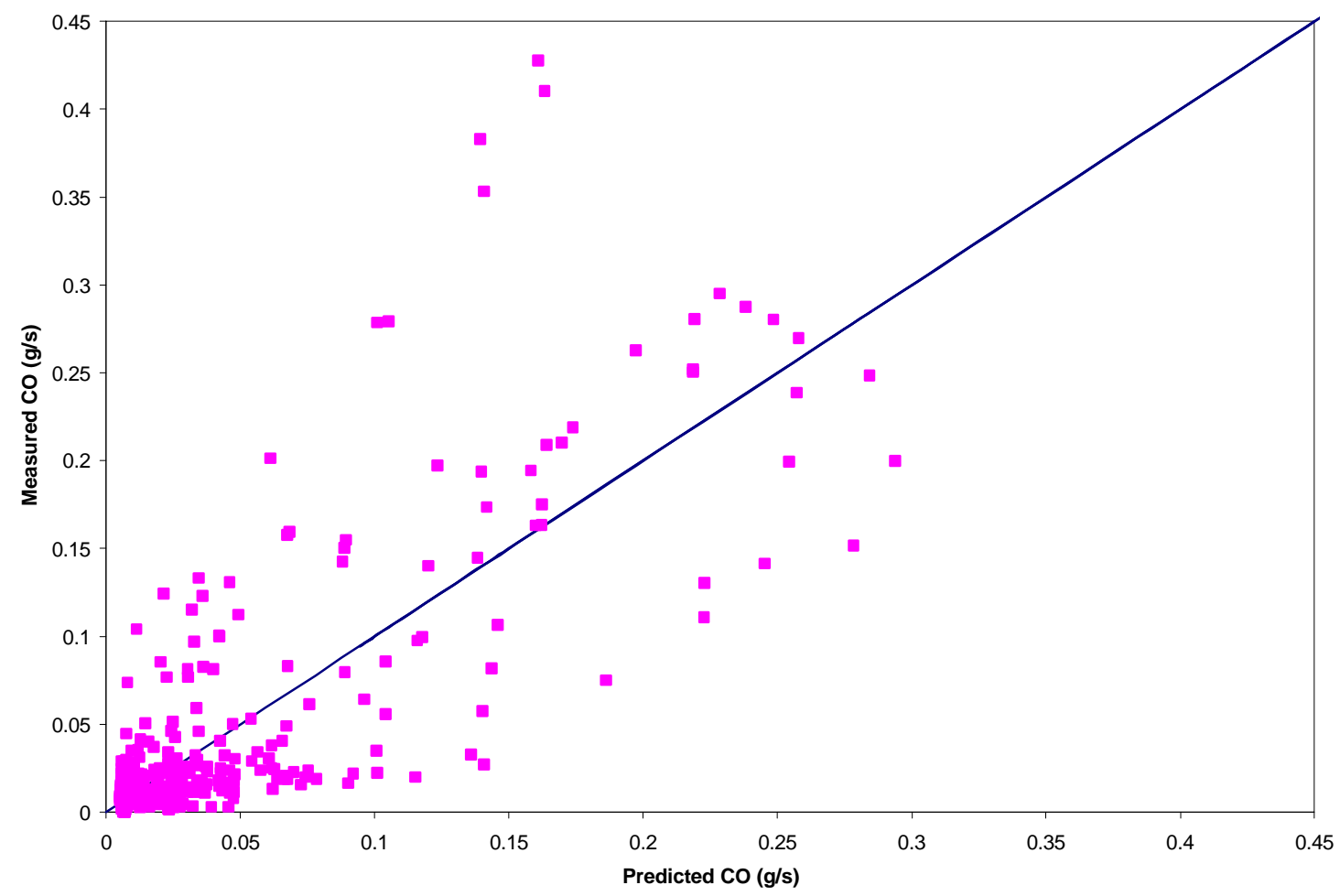

Figure 7-29: Measured vs. Predicted CO for a tractor truck (vehicle J) with a Detroit Diesel 6V-92 300hp (223kW) engine tested on the 5-peak WVU test cycle. The correlation model based on the dispersed power data of the cycle is used to predict CO. The addition of square of the dispersed power data of the cycle is seen to improve the $\mathrm{R}^{2}$ from 0.5139 to 0.6711 . 


\subsection{Particulate Matter (PM)}

\subsubsection{Particulate Matter Data}

Diesel engines are high emitters of particulate matter (PM) into the atmosphere. PM is known to be composed of contributions from the unburned fuel, unburned engine lubricating oil, insolubles (carbon) and moisture. Exhaust PM levels are measured gravimetrically unlike other gaseous emission components, which are measured on a realtime basis by the analyzers. The PM levels from the tail-pipe exhaust are collected on two $70 \mathrm{~mm}$ fluorocarbon filters (primary and secondary). The filters are conditioned in the environmental chamber at least 24 hours prior to obtaining the initial weights. The conditions in the environmental chamber are maintained at $21^{\circ} \mathrm{C}\left(70^{\circ} \mathrm{F}\right)$ and $50 \%$ relative humidity. The filters are reconditioned in the environmental chamber before the final weighing is done. Integrated diluted particulate matter is obtained by calculating the difference in the filter weights before the start and after the test is completed as specified in the CFR 40. The integrated PM of the engine/vehicle is checked for compliance by comparing with the EPA standards.

\subsubsection{Particulate Matter prediction}

PM emissions from diesel engines are real time continuous and depend on engine speed and load. Though PM emissions are dependent on load with relatively high PM emissions occurring during rapid load conditions on turbocharged engines, it is difficult to associate PM to specific operating modes of the engine. PM in the diesel exhaust is mainly caused due to over-fueling or injecting more fuel than the engine can burn for a given amount of oxygen in the combustion chamber. Prediction of PM with instantaneous 
axle power can be done like the other gaseous components only if there is real-time particulate emissions data. Real-time particulate emissions data are necessary to understand the behavior of constituents of PM during the course of the test. Clark et al. [1998] have argued the best available tool at present for integrated PM apportioning over the duration of the cycle is in its linear relation to $\mathrm{CO}$ emissions. The logic behind the approach is that both $\mathrm{CO}$ and PM are co-produced during combustion although contributions from lubricants, $\mathrm{HC}$ and varying PM formation mechanisms make up for the limitations in the approach. PM formation is known to be highly transient dependent like $\mathrm{CO}$, depending on the fuel and control algorithms of the engine. This makes the correlation of PM with axle power highly complex and difficult. Real-time particulate measurement in future is expected to improve the perspective for PM prediction. 


\section{8. $\mathrm{NO}_{\mathrm{x}} / \mathrm{CO}_{2}$ Ratio}

The representation of $\mathrm{NO}_{\mathrm{x}}$ emissions as a mass ratio $\left(\mathrm{NO}_{\mathrm{x}} / \mathrm{CO}_{2}\right)$ is attractive because it remains tractable under idle conditions, is readily translated to units that represent emissions as a mass fraction of fuel burned, and is useful in remote sensing measurements where dilution rates are indeterminate. Remote sensing programs generally detect nitric oxide (NO). Although some $\mathrm{NO}_{2}$ can be produced by diesel engines in addition to NO, it is generally accepted that the NO quantity is a fair representation of the total $\mathrm{NO}_{\mathrm{x}}$ except at high engine speed and light load [Clark et. al., 1998].

Figure 8-1 shows data from the vehicles A, B, C, D as $\mathrm{NO}_{\mathrm{x}} / \mathrm{CO}_{2}$ versus dispersed axle power. It is noted that $\left(\mathrm{NO}_{\mathrm{x}} / \mathrm{CO}_{2}\right)$ varies over a fixed region suggesting the possibilities of cycle independence of the $\left(\mathrm{NO}_{\mathrm{x}} / \mathrm{CO}_{2}\right)$ ratio. A composite scatter plot of the data is shown in Figure 8-1 yields the following average values and linear fits.

Average: $\mathrm{NO}_{\mathrm{x}} / \mathrm{CO}_{2}=0.0106$ by mass; Standard deviation $=0.00356$

Average: $\mathrm{NO}_{\mathrm{x}} /$ gallon of fuel $=115.2 \mathrm{~g}$ of $\mathrm{NO}_{\mathrm{x}} /$ gallon of fuel;

Standard deviation $=38.7$

Linear fit: $\mathrm{NO}_{\mathrm{x}} / \mathrm{CO}_{2}=\mathrm{a}+\mathrm{b} *$ power $=2 * 10^{-5}+0.0102 *$ power

Linear fit: $\mathrm{NO}_{\mathrm{x}} / \mathrm{gallon}$ of fuel $=\mathrm{c}+\mathrm{d}^{*}$ power $=98.4+0.211 *$ power

where $\mathrm{a}$ is dimension less, $\mathrm{b}$ is $(1 / \mathrm{kW}), \mathrm{c}$ is (g/gallon), $\mathrm{d}$ is $(\mathrm{g} /(\mathrm{gallon} * \mathrm{~kW}))$ and power is measured in $\mathrm{kW}$ at the vehicle drive axle.

In reaching these formulae, it is assumed that $3.2 \mathrm{~g}$ of $\mathrm{CO}_{2}$ correspond to $1 \mathrm{~g}$ of diesel fuel with a carbon to hydrogen ratio of 1.7 , and fuel density and mileage of the vehicle are utilized for the calculation. This method does neglect mass losses due to 
blowby past the engine rings. For comparison with the data shown in Figure 8-1, the average $\mathrm{NO}_{\mathrm{x}} / \mathrm{CO}_{2}$ ratios for the whole CBD cycle for buses $\mathrm{A}, \mathrm{B}, \mathrm{C}$ and $\mathrm{D}$ are 0.0113 , $0.0103,0.0117,0.0095$ respectively.

The main thrust has been to provide researchers with instantaneous (continuous) $\mathrm{NO}_{\mathrm{x}}$ emissions levels for heavy duty vehicles as a function of power as they are exercised through transient test schedules. It is evident that the mass rate of $\mathrm{NO}_{\mathrm{x}}$ emissions increases with increasing power, but that the variations of $\mathrm{NO}_{\mathrm{x}}$ with respect to test cycle and vehicle type can be substantial. The data presented, and the simple correlation developed from the data, can be applied to other vehicle duty cycles, although $\mathrm{NO}_{\mathrm{x}}$ values vary substantially at a fixed power: for example $\mathrm{NO}_{\mathrm{x}}$ varies by a factor of 3 at 40kW axle power for vehicle A, a transit bus (model year 96) with a Detroit Diesel Series 50 engine tested on a CBD cycle.

Emissions rates for $\mathrm{NO}_{\mathrm{x}}$ in $\mathrm{g} / \mathrm{ahp}$-hr fall in the range that is suggested by engine certification (FTP) data and transmission efficiencies.

Data for the ratio $\mathrm{NO}_{\mathrm{x}} / \mathrm{CO}_{2}$ are widely scattered, but the average value of 0.0106 , for all vehicles considered, agrees with remote sensing or road tunnel study data for trucks [Countess et al., 1998].

Data gathered by WVU in the future will include engine speed data, in which case engine speed and torque effects will be separable. 


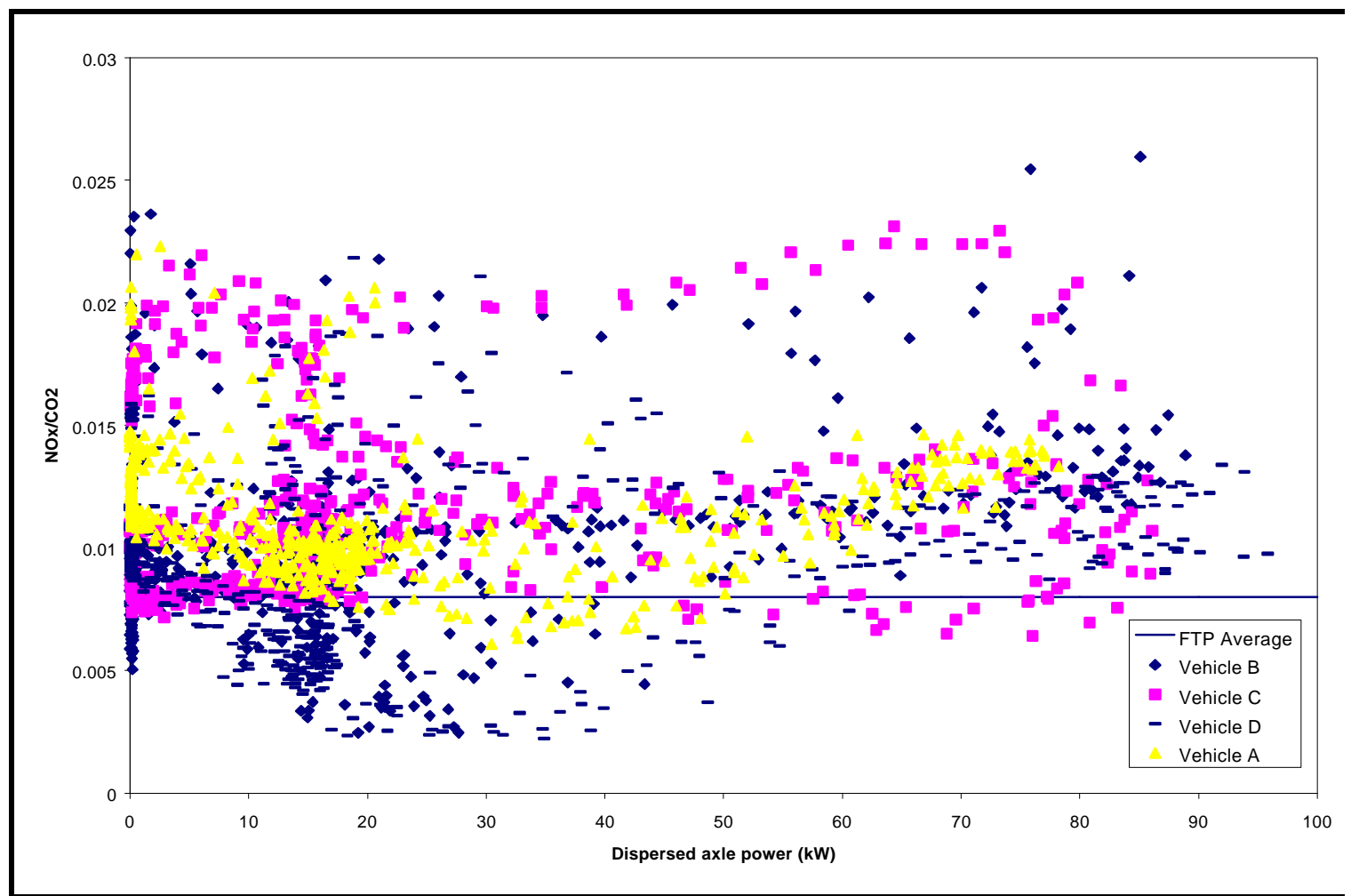

Figure 8-1: $\mathrm{NO}_{\mathrm{x}} / \mathrm{CO}_{2}$ vs. Dispersed axle power for vehicles $\mathrm{A}, \mathrm{B}, \mathrm{C}$ and $\mathrm{D}$. The average $\mathrm{NO}_{\mathrm{x}} / \mathrm{CO}_{2}$ for all the points is found to be 0.0141 . The FTP transient engine emissions average of $\mathrm{NO}_{\mathrm{x}} / \mathrm{CO}_{2}$ for a Navistar T444E engine is found to be 0.0083 . 


\section{Conclusions}

Heavy duty emissions data were acquired by the WVU transportable laboratories by performing chassis dynamometer testing. The vehicles tested include a wide variety of trucks and buses, out of which a sample of vehicles A to J consisting of six buses and four trucks were taken for analysis. The cycles used for testing include the CBD, Truck CBD, 5 peak WVU test cycle, 5 mile route and the New York Composite cycle. The resulting continuous emissions data from trucks and buses (vehicles A to J) were correlated with axle power, but before correlating with axle power it was necessary to perform optimal time alignment or shifting between the emissions and axle power data. Residence time distribution was accounted by applying a dispersion function to axle power before correlation. Residence time distribution coupled with proper time shifting improved the relationship of gaseous emissions with axle power. Emissions inventory data that were presented for heavy duty vehicles (A to J) depends on the vehicle type and the cycles tested. The gaseous emissions data were presented as a function of the axle power of the vehicle. Both $\mathrm{CO}_{2}$ and $\mathrm{NO}_{\mathrm{x}}$ show reliable relationship with axle power. Linear models were developed on basis of axle power to predict $\mathrm{NO}_{\mathrm{x}}$ and $\mathrm{CO}_{2}$ for one driving cycle on basis of the model developed for another driving cycle. Ultimately these models could be applied to known vehicle activity cycles to provide an estimate of the vehicle contribution to the emission inventory. The unique speed-acceleration envelope of each cycle results in cycle specific effects. Bifurcation of the $\mathrm{NO}_{\mathrm{x}}$ data was sometimes seen due to map based strategies: it was the advancing of timing that increases $\mathrm{NO}_{\mathrm{x}}$ emissions leading to poor correlation of data with the best fit curve. It was seen that the axle power as a lone parameter proved superior for prediction of $\mathrm{NO}_{\mathrm{x}}$ to using two 
variables namely engine speed and load. $\mathrm{CO}$ was known to be fuel and engine control specific that makes emission prediction of $\mathrm{CO}$ difficult. $\mathrm{CO}$ emissions were known to depend on engine parameters and could not be modeled reliably with axle power. Particulate Matter (PM) was measured gravimetrically and real-time measurement of PM was necessary for understanding its constituents. PM was expected to act as an intermediate between $\mathrm{NO}_{\mathrm{x}}$ and $\mathrm{CO}$ in the relation with power. Emission inventory data were also presented in the form of $\mathrm{NO}_{\mathrm{x}} / \mathrm{CO}_{2}$ ratio for all the vehicles, which agreed with remote sensing or tunnel study data for trucks [Cadle et al., 1997]

\section{Recommendations}

The heavy duty emissions inventory prediction could be improved for $\mathrm{CO}$ and $\mathrm{HC}$ emissions which are highly dependent on engine transient behavior, by use of additional variables beyond axle power in the model. The additional variables could be vehicle speed, separate axle torque and speed, which are difficult to correlate due to gear change, engine speed, and time derivatives of axle/engine power. The bifurcations occur in the plots of $\mathrm{NO}_{\mathrm{x}}$ emissions versus axle power as a result of "off-cycle behavior". This makes prediction of $\mathrm{NO}_{\mathrm{x}}$ emissions difficult and the solution to this problem needs to be explored. Since PM is measured gravimetrically, as a composite for the whole test, the instantaneous PM is not known and apportioning of PM by different methods need to be attempted. There is a need for additional correction factors accounting for vehicle class, vehicle vocation, effect of weather and altitude, and power to weight ratio in addition to the existing ones to refine the existing heavy duty emissions inventory modeling and prediction. 


\section{References}

1. 1993 SAE Handbook, On-Highway Vehicles and Off-Highway Machinery, Volume 4, "Fuel and Economy Measurement Test (Engineering Type) for trucks and buses", Section 36, SAE J1376, July 1982, SAE, Warrendale, PA, 1993.

2. Air Resources Board, State of California web-site (http: www.arb.ca.gov) "Mobile Source Emission Inventory Program”, On Road Motor Vehicle Emission Inventory (MVEI) Models.

3. Bata, R. M.; Yacoub, Y.; Wang, W.; Lyons, D. L. "Heavy Duty Testing Cycles: Survey and Comparison”, SAE Technical Paper 942263, 1994.

4. Brown, K. F.; Rideout, G. "Urban Driving Cycle Results of Retrofitted Diesel Oxidation Catalysts on Heavy Duty Vehicles", SAE Technical Paper 960134, 1996, Diesel Exhaust Aftertreatment 1996, SAE Special Publication SP-1140, pp. 57, 1996.

5. Cadle, S. H.; Gorse, R. A., Jr.; Belian, T. C.; Lawson, D. R. "Real World Vehicle Emissions: A Summary of the Seventh CRC On-Road Vehicle Emissions Workshop", Journal of Air and Waste Management Association, Vol. 48, pp.174-185, 1997.

6. Chasey, T. D., Design of a Data Acquisition and Control System Hardware and Software for Transportable Emissions Testing Laboratory, West Virginia University Thesis, Morgantown, WV, 1992.

7. Clark, N. N.; McKain, D. L. "Transient Chassis Cycles for Heavy Duty Trucks and Tractors", Heavy Duty System, International Journal of Vehicle Design, Vol. 2, 
Number 2, pp. 143-159, 1995.

8. Clark, N. N.; Gautam, M.; Bata, R. M.; Loth, J. L.; Palmer, G. M.; Wang, W. G.; Lyons, D. W. "Design and Operation of a New Transportable Laboratory for Emissions Testing of Heavy Duty Trucks and Buses", Heavy Vehicle Systems. Special Series, International Journal of Vehicle Design, Vol. 2, No. 3/4, pp. 308-322, 1995.

9. Clark, N. N.; McKain, D. L.; Messer, J. T.; Lyons, D. W. "Chassis Test Cycles for Assessing Emissions from Heavy Duty Trucks”, SAE Technical Paper 941946, 1994.

10. Clark, N. N.; Messer, J. T.; McKain, D. L.; Wang, W. G.; Bata, R. M., Gautam, M., Lyons, D. W. "Use of West Virginia University Truck Test Cycle to Evaluate Emissions from Class 8 Trucks”, SAE Technical Paper 951016, 1995.

11. Clark, N. N.; Jarrett, R. P.; Atkinson, C. M. "Field Measurements of Particulate Matter Emissions and Exhaust Opacity from Heavy Duty Vehicles”, Proceedings of the Air and Waste Management Association, PM 2.5, A Fine Particle Standard Conference, Long Beach, CA, January 28-30, 1998.

12. Clark, N.N.; Lyons, D.W. "Emissions from CNG and Diesel Refuse Haulers Using Six Engine Types in New York City,” Seventh CRC On-Road Vehicle Emissions Workshop, San Diego, April 1997, pp. 5-49 to 5-64.

13. Clark, N. N.; Nine, R. D.; Daley, J. J.; Atkinson, C. M.; Tennant, C. J.; Lyons, D. W. “Heavy Duty Truck Emissions: Vehicle Activity, Driving Routes, and NO/NO 2 Ratios", Proceedings of the Eighth CRC On-Road Vehicle Emissions Workshop, San Diego, CA, April 20-22, 1998.

14. Code of Federal Regulation (CFR), Title 40, Part 86, App. 1, U. S. Government 
Printing Office, Washington D.C., July 11996.

15. Cosby, J. C., EPA Document, "Heavy-Duty Vehicle Pattern and Use Survey. Part I, New York City, EPA-PB-221-656, May 1973.

16. Countess, R. J.; Cohen, L. H.; Countess, S. J.; Bishop, G. A.; Stedman, D. H. "Remote Sensing of Heavy Duty Diesel Truck Exhaust", Proceedings of the Eighth CRC On-Road Vehicle Emissions Workshop, San Diego, CA, April 20-22, 1998.

17. Degobert, P., Automobiles and Pollution, Paris: Editions Technip, 1995.

18. Dietzmann, H.; Warner-Selph, M. A. "Comparison of Emissions from Heavy Duty Engines and Vehicles During Transient Operation", ASME Technical Paper 85DGP-10, 1985.

19. EPA Document, "Heavy Duty Vehicle Cycle Development”, EPA-PB-288-805, July, $1978 b$.

20. EPA Document, "Selection of Transient Cycles for Heavy Duty Vehicles", EPA-PB294-221, June, 1978a.

21. EPA Document, “The Clean Air Act of 1990”, EPA-400-F-92-013, August 1994.

22. Fujita, E. M.; Croes, B. E.; Bennet, C. L.; Lawson, D. R.; Lurmann, F. W.; Main, H. H. "Comparison of Emission Inventory and Ambient Concentration Ratios of CO, NMOG, and $\mathrm{NO}_{\mathrm{x}}$ in California's South Coast Air Basin", Journal of Air and Waste Management Association, Vol. 42, pp. 264-276, 1992.

23. Grumet, J.; Levin, R.; Marin, A. Ed. Heavy Duty Engine Emissions in the Northeast; Northeastern states for Coordinated Air Use Management: Washington, DC, 1997. 
24. Guensler, R.; Daniel, S.; Paul, P. J. "Uncertainty in the Emission Inventory for Heavy Duty Diesel-powered Trucks", Journal of Air and Waste Management Association, $84^{\text {th }}$ Annual Meeting Proceedings, Pittsburgh, PA, June, 1991.

25. Hoppie, J. A., Defining Drivetrain Losses in Developing a Cycle for Engine and Chassis Dynamometer Test Compliance and Uncertainty Analysis of Emissions Test Facilities, West Virginia University Thesis, Morgantown, West Virginia, 1997.

26. King, L.; Prakash, C. "Field Trials of Ethanol in Transit Buses", SAE Technical Paper 922272, 1992.

27. Kirchstetter, W. T.; Harley, A. R.; Levaggi, D.; Kendall, G.; Chan, W. "Measurement of California Light Duty Vehicle Emissions in the Caldecott Tunnel”, Coordinating Research Council On-Road Emissions Workshop, San Diego, CA, 1994.

28. Kirchstetter, W. T.; Miguel, H. A.; Harley, A. R. "On-Road Comparison of Exhaust Emissions from Gasoline and Diesel Engines", Proceedings of the Eighth CRC On-Road Vehicle Emissions Workshop, San Diego, CA, April 20-22, 1998.

29. Levenspiel, O., Chemical Reaction Engineering, $2^{\text {nd }}$ ed.; J. Wiley and Sons; New York, 1972, pp. 253-308.

30. Lyons, D. W.; Bata, R. M.; Wang, W. G.; Clark, N. N.; Palmer, G. N.; Howell, A. D.; Loth, J. L.; Long, T., Jr. "Design and Construction of a Transportable Heavy Duty Vehicle Emission Testing Laboratory", $25^{\text {th }}$ Int. Symp. on Automotive Technology and Automation, Florence, Italy, 1992. Also, Annual Automotive Technology Development Contractors' Coordination Meeting, Dearborn, MI, Oct. 1991, SAE Special Pub., P-256, pp. 593-598. 
31. Machiele, P. A. "Heavy Duty Vehicle Emission Conversion Factors II (1962-2000)", EPA-AA-SDSB-89-01, 1989.

32. McKain, D. L.; Clark, N. N.; McDaniel, T. I.; Hoppie, J. A. "Chassis Test Cycle Development for Engine Test Compliance on Heavy Duty Vehicles", SAE Technical Paper 980407, 1998.

33. Messer, J. T.; Clark, N. N.; Lyons, D. W. "Measurement Delays and Modal Analysis For a Heavy Duty Transportable Emissions Testing Laboratory", SAE Technical Paper 950218, 1995.

34. Messer, J. T., Measurement Delays and Modal Analysis for two Heavy Duty Transportable Emissions Testing Laboratories and a Stationary Engine Emission Testing Laboratory, West Virginia University Thesis, Morgantown, West Virginia, 1995.

35. Plint, M., Martyr, A. J., Engine Testing Theory and Practice, ButterworthHeinemann Ltd., Linacre House, Jordan Hill, Oxford OX2 8DP, 1995.

36. Ramamurthy, R.; Clark, N. N.; Lyons, D. W.; Atkinson, C. M. "Models for Predicting Transient Heavy Duty Vehicle Emissions”, SAE Technical Paper 982652, 1998.

37. SWRI Transient Cycle Emissions Testing Brochure, "Transient Cycle Emissions Testing for Heavy Duty Diesel, Gasoline, and Alternative Fuel Engines-Transient Federal Testing", www.swri.org/3pubs/brochure/d08/trcycle.htm, May 16, 1997, 1:09pm.

38. Thompson, E. D.; Ansari, M.; Eberhard, G. A. "A Truck and Bus Chassis Dynamometer Developed for Fuels and Lubricants Research", SAE Technical Paper 902112, 1990.

39. Wang, W.; Gautam, M.; Sun, X.; Bata, R. M.; Clark N. N.; Palmer, G. M.; Lyons, 
D. W. "Emissions Comparisons of Twenty-six Heavy Duty Vehicles Operated on Conventional and Alternative Fuels", SAE Technical Paper 932952, 1993, Truck Alternative Fuels and Exhaust Gas Emissions, SAE Special Publication P-1001, pp. 31-40, 1993. 


\title{
Appendices
}

\section{Appendix A}

\author{
Speed Correction Factors
}

Correction factors are developed to account for the variations in the vehicle condition, class and variations in the testing environment compared to the real road conditions. The correction factors have been widely used in the estimation of light duty emissions inventory. However, only speed correction factor is used in heavy duty inventories. The Speed Correction Factor (SCF) used by the USEPA for heavy duty emission inventory preparation (USEPA, 1985) is:

$$
\mathrm{SCF}=\mathrm{EXP}\left(\mathrm{A}+\mathrm{B} * \mathrm{~S}+\mathrm{C} * \mathrm{~S}^{2}\right)
$$

Where $\mathrm{S}$ is the vehicle average speed and the empirical constants $(\mathrm{A}, \mathrm{B}, \mathrm{C})$ are pollutant dependent and are assumed to be constant for all model years and truck and engine sizes. The origin and rationale behind the development of SCF are undocumented. The problem that is encountered in using aggregated vehicle speed in SCF is that the relation cannot be correlated to real road driving conditions. The SCF does not represent the emissions from a vehicle at an instantaneous speed but the emissions that would occur at an average speed if the vehicle were driven in the same manner as the testing conditions. The SCF is not defined for higher average speeds more than $65 \mathrm{mph}$ and the cycles generally have a low average speed. The SCF used by the EPA and WVU is equaled for a reference average vehicle speed of $20 \mathrm{mph}$. The WVU SCF is obtained by taking the ratio of the 
emissions at the average speed of the cycle to the emissions during the reference speed of $20 \mathrm{mph}$. The WVU SCF is based on the emissions of the vehicle at average speeds of the vehicle during the different test cycles utilized for testing. The comparison of SCF of the EPA and WVU for $\mathrm{NO}_{\mathrm{x}}$ is shown in Figure A-1. The comparison of EPA and WVU SCF for $\mathrm{CO}$ is shown in Figure A-2. $\mathrm{NO}_{\mathrm{x}} \mathrm{SCF}$ is seen to be low at low average speed while $\mathrm{CO}$ is found to be high. $\mathrm{NO}_{\mathrm{x}}$ emissions are high at high speeds for example when a vehicle is driving on the interstate.

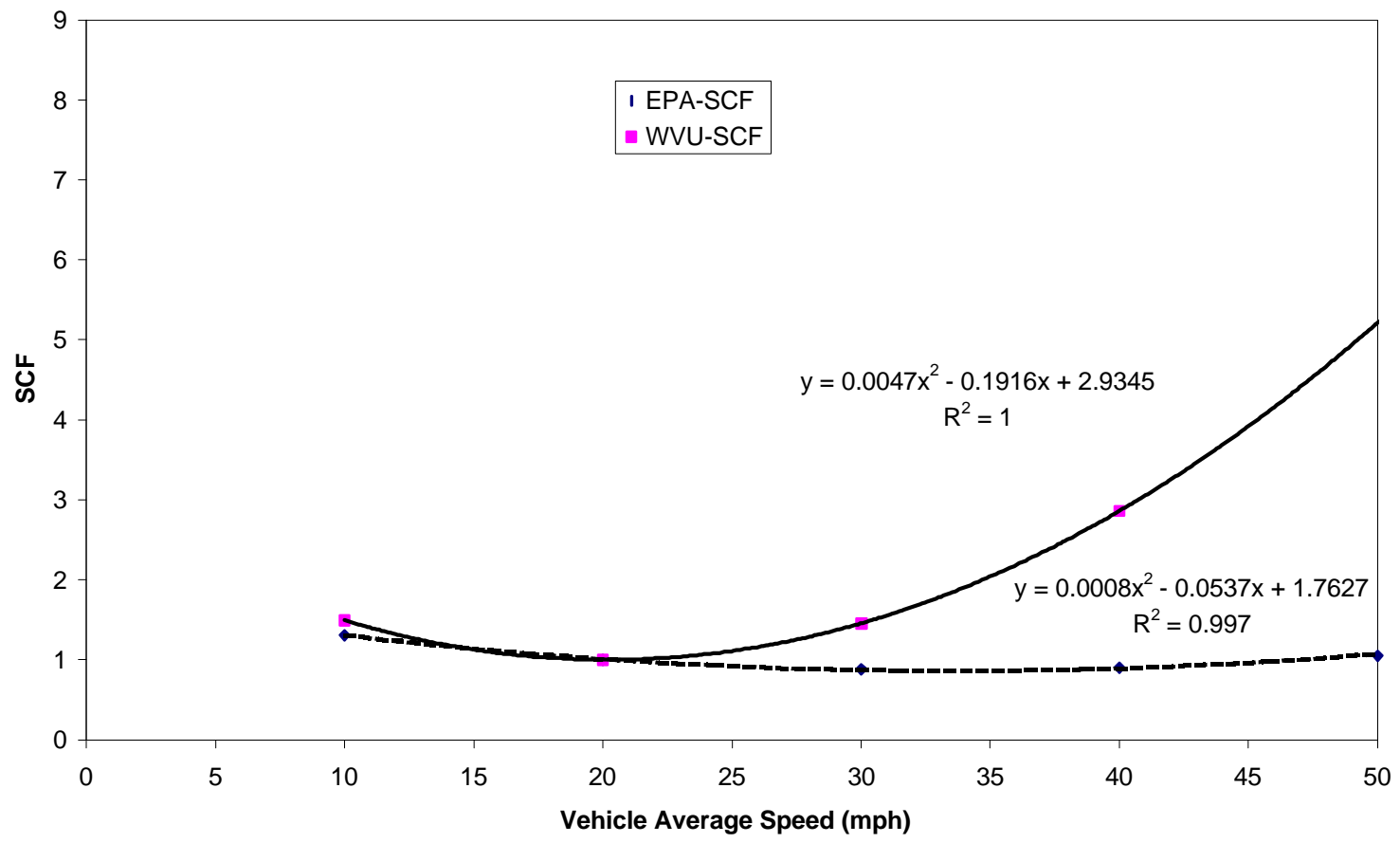

Figure A-1: WVU and EPA Speed Correction Factor $(\mathrm{SCF})$ for $\mathrm{NO}_{\mathrm{x}}$ 


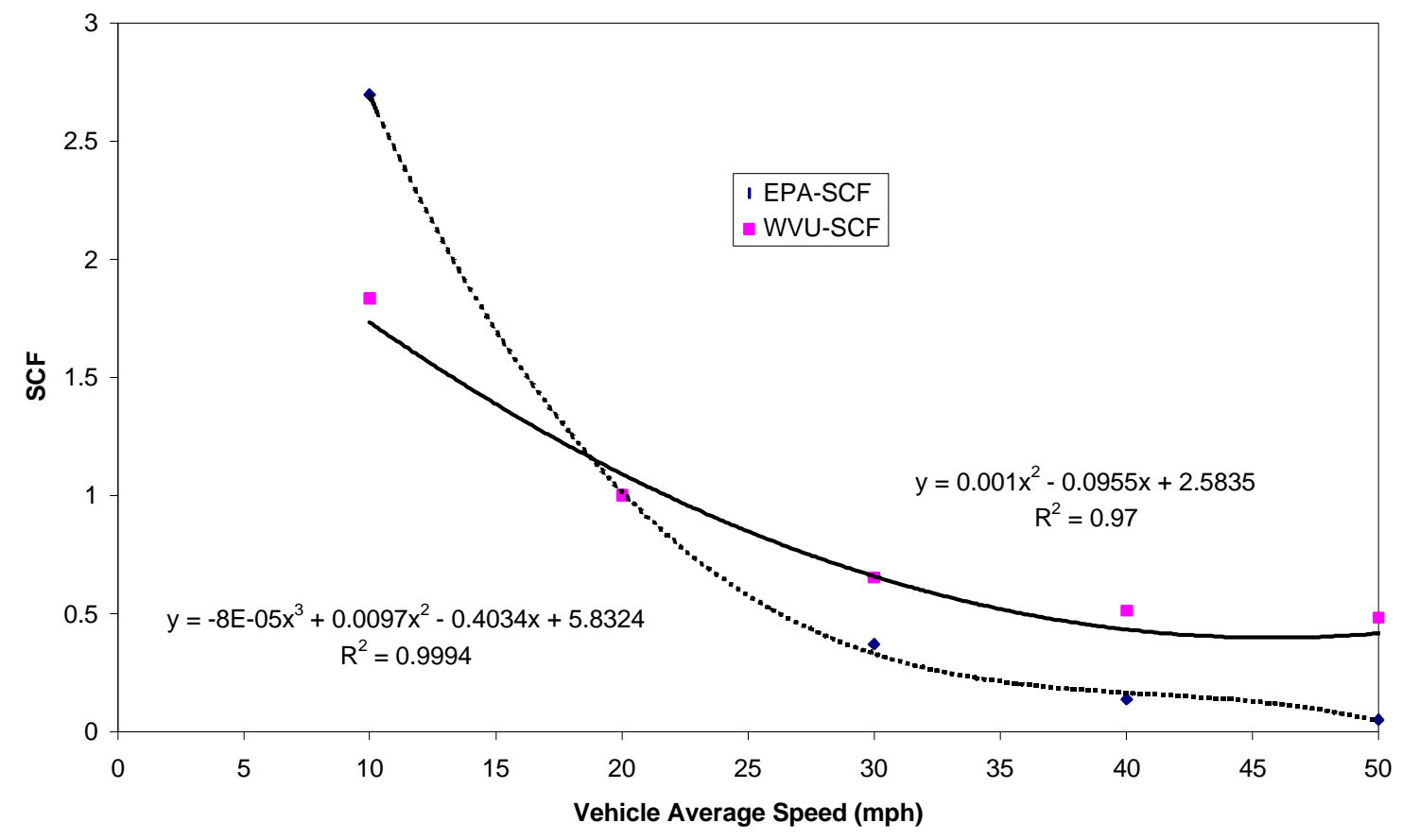

Figure A-2: WVU and EPA Speed Correction Factor (SCF) for CO 


\section{Appendix B}

\section{Cross-correlation Program}

'This program uses a the cross-correlation method to determine the time 'shift between continuous data readings to provide maximum correlation. CLS

DIM dat(2000, 2), v(600, 2) AS SINGLE

OPEN "d:Inncorr1.txt" FOR INPUT AS \#1

'OPEN "c:Ival" FOR OUTPUT AS \#2

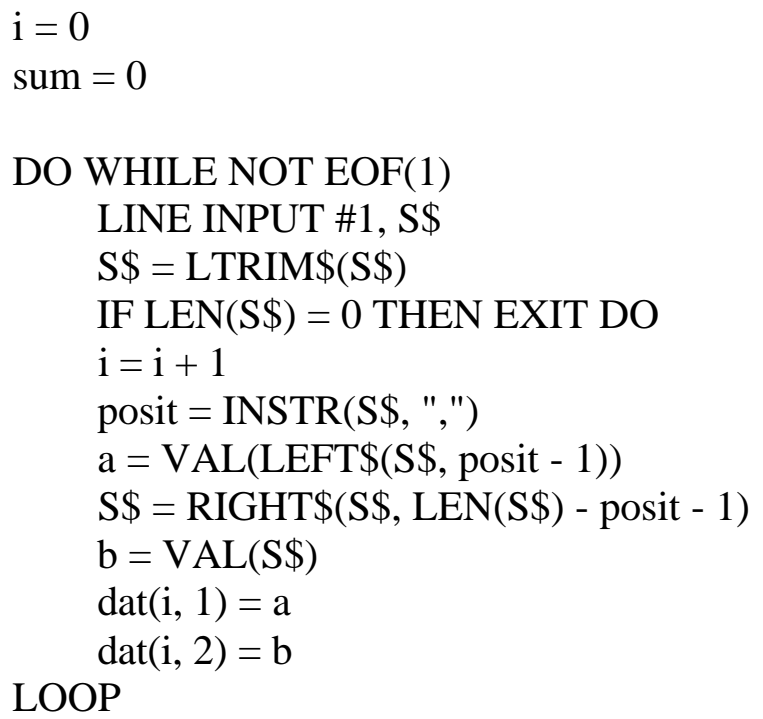

CLOSE \#1

$$
\begin{aligned}
& 1=0 \\
& \text { tot }=0 \\
& \text { FOR } \mathrm{k}=1 \text { TO } 80 \\
& \text { prod }=0 \\
& \text { sum }=0 \\
& 1=1+1 \\
& \text { FOR } \mathrm{j}=0 \text { TO } \mathrm{i}-80 \\
& \operatorname{prod}=\operatorname{dat}(40+\mathrm{j}, 1) * \operatorname{dat}(\mathrm{j}+\mathrm{k}, 2) \\
& \text { sum }=\text { sum }+ \text { prod } \\
& \text { NEXT } j
\end{aligned}
$$


'PRINT sum, tot, $\mathrm{k}$

'PRINT \#2, v(l, 1), v(l, 2)

NEXT k

PRINT "The time shift is"; t; "seconds"

END 


\section{Dispersion Program}

'This program is for determining the theoretical linear diffusion 'of the power as if it where collected further down the dilution tunnel.

CLS

DIM Cn(1000), Ci(1000), dat(2000, 2), OP(2000, 1), x(5000), df(2000, 2), disp(2000, 2), test(2000, 3), dif(1032) AS SINGLE

'INPUT "Enter the spreading range (Ti)", Ti

'INPUT "Enter the delay time (Tbar)", Tb

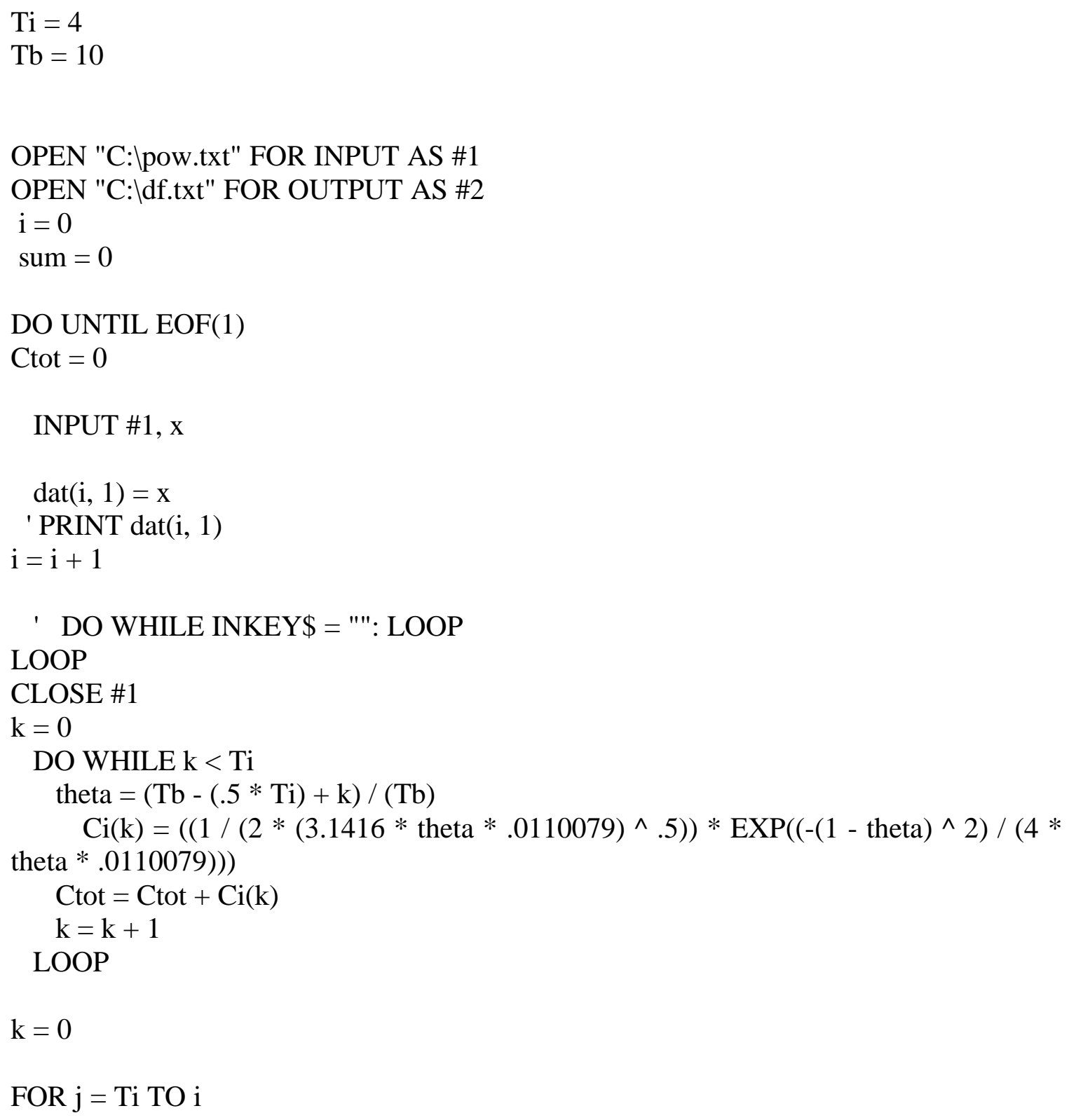

FOR j = Ti TO i 


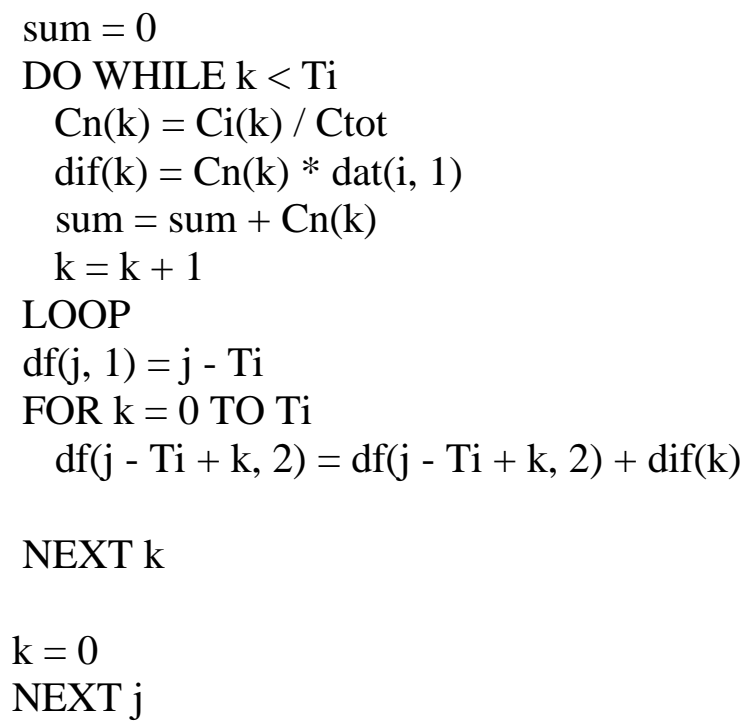

FOR $\mathrm{j}=0$ TO $\mathrm{i}$

PRINT dat(i, 1), df(j, 2)

PRINT \#2, df(j, 1), df(j, 2)

NEXT $j$

'PRINT , sum

'prINT x, df(j, 2)

CLOSE \#1, \#2

END 
Data Reduction Program

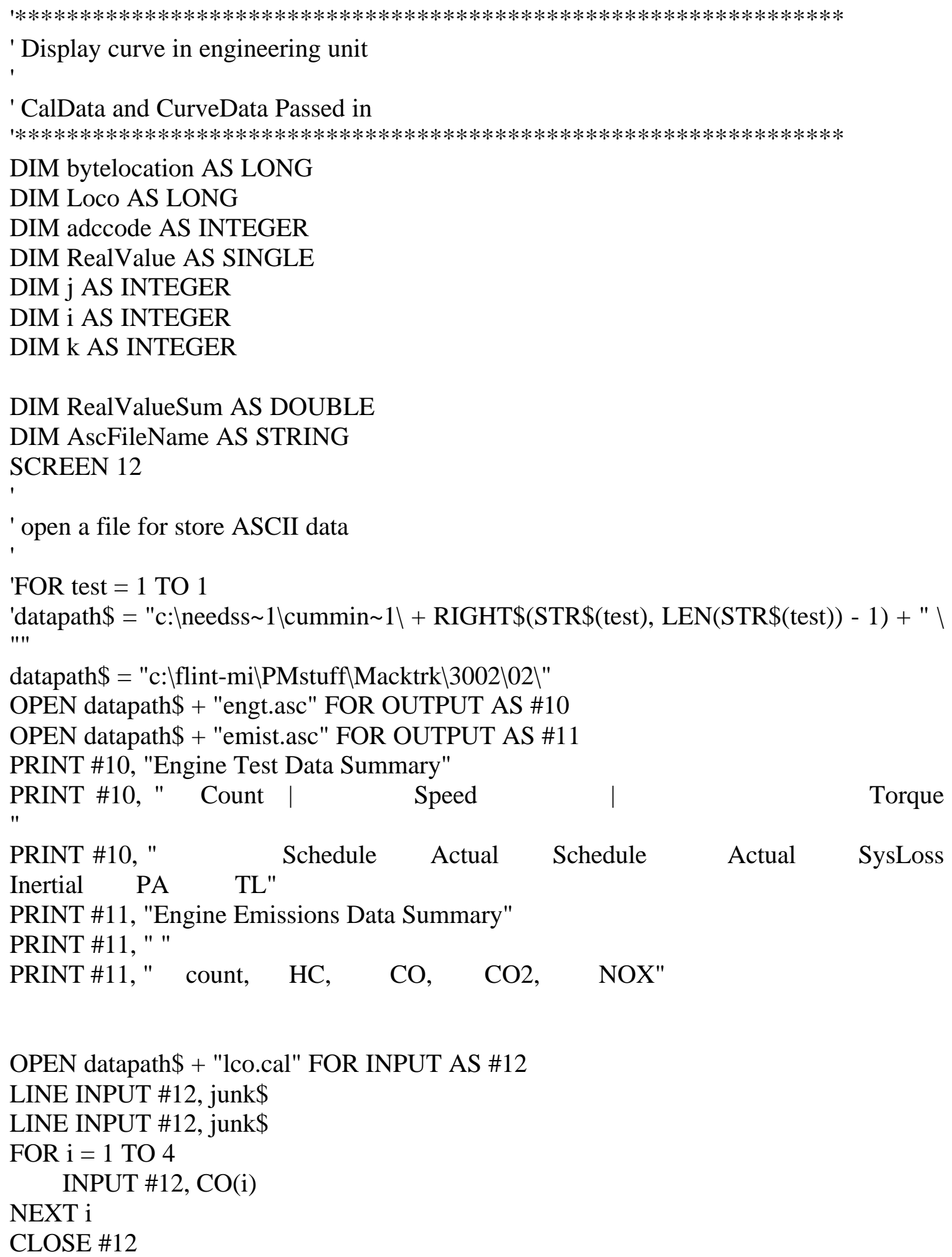


OPEN datapath $\$$ + "co2.cal" FOR INPUT AS \#12

LINE INPUT \#12, junk\$

LINE INPUT \#12, junk\$

FOR $\mathrm{i}=1 \mathrm{TO} 4$

INPUT \#12, CO2(i)

NEXT i

CLOSE \#12

OPEN datapath\$ + "hc.cal" FOR INPUT AS \#12

LINE INPUT \#12, junk\$

INPUT \#12, crap

FOR $\mathrm{i}=1$ TO crap

INPUT \#12, HC(i)

NEXT i

CLOSE \#12

OPEN datapath\$ + "nox.cal" FOR INPUT AS \#12

LINE INPUT \#12, junk\$

LINE INPUT \#12, junk\$

FOR $\mathrm{i}=1 \mathrm{TO} 4$

INPUT \#12, NOX(i)

NEXT i

CLOSE \#12

OPEN datapath\$ + "cyc_bin.dat" FOR BINARY AS \#1

numofscan $=\mathrm{LOF}(1) / 64 / 2$

WINDOW $(0,-300)$-(numofscan, 500)

' find the first data in the data file

' Get Engine Data from Binary File

Loco $=0$

FOR $\mathrm{j}=1$ TO numofscan

$\mathrm{Loco}=\mathrm{Loco}+128$

'Count

Channel $=55$

bytelocation $=(($ Channel +1$) * 2-1)+($ Loco $)$ : GET \#1, bytelocation, adccode RealValueCount $=$ adccode

'Schedule Speed 
Channel $=56$

bytelocation $=(($ Channel +1$) * 2-1)+($ Loco $)$ : GET \#1, bytelocation, adccode RealValueSS $=$ adccode

'Actual Speed

Channel $=57$

bytelocation $=(($ Channel +1$) * 2-1)+($ Loco $)$ : GET \#1, bytelocation, adccode RealValueAS $=$ adccode

'Schedule Torque

Channel $=58$

bytelocation $=(($ Channel +1$) * 2-1)+($ Loco $)$ : GET \#1, bytelocation, adccode RealValueST $=$ adccode

'Actual Torque

Channel $=59$

bytelocation $=(($ Channel +1$) * 2-1)+($ Loco $)$ : GET \#1, bytelocation, adccode RealValueAT $=$ adccode

'SysLoss

Channel $=60$

bytelocation $=(($ Channel +1$) * 2-1)+($ Loco $)$ : GET \#1, bytelocation, adccode RealValueSL $=$ adccode $/ 133.25$

'InertialLoss

Channel $=61$

bytelocation $=(($ Channel +1$) * 2-1)+($ Loco $)$ : GET \#1, bytelocation, adccode RealValueIL $=$ adccode $/ 133.25$

'PATorque

Channel $=62$

bytelocation $=(($ Channel +1$) * 2-1)+($ Loco $)$ : GET \#1, bytelocation, adccode RealValuePA $=$ adccode $/ 133.25$

'TireLoss

Channel $=63$

bytelocation $=(($ Channel +1$) * 2-1)+($ Loco $)$ : GET \#1, bytelocation, adccode RealValueTL $=$ adccode $/ 133.25$

'HC

Channel $=12$

bytelocation $=(($ Channel +1$) * 2-1)+($ Loco $)$ : GET \#1, bytelocation, adccode RealValueHC $=\mathrm{HC}(1)+\mathrm{HC}(2) *$ adccode $+\mathrm{HC}(3) *$ adccode $\wedge 2+\mathrm{HC}(4) *$ $\operatorname{adccode}^{\wedge} 3$ 
'CO

Channel $=8$

bytelocation $=(($ Channel +1$) * 2-1)+($ Loco $)$ : GET \#1, bytelocation, adccode

RealValueCO $=\mathrm{CO}(1)+\mathrm{CO}(2) *$ adccode $+\mathrm{CO}(3) *$ adccode $\wedge 2+\mathrm{CO}(4) *$ $\operatorname{adccode}^{\wedge} 3$

'CO2

Channel $=10$

bytelocation $=(($ Channel +1$) * 2-1)+($ Loco $)$ : GET \#1, bytelocation, adccode

RealValueCO $2=\mathrm{CO} 2(1)+\mathrm{CO} 2(2) *$ adccode $+\mathrm{CO} 2(3) * \operatorname{adccode}^{\wedge} 2+\mathrm{CO} 2(4) *$ adccode $^{\wedge} 3$

'NOX

Channel $=11$

bytelocation $=(($ Channel +1$) * 2-1)+($ Loco $)$ : GET \#1, bytelocation, adccode

RealValueNOX $=\operatorname{NOX}(1)+\operatorname{NOX}(2) *$ adccode $+\operatorname{NOX}(3) * \operatorname{adccode}^{\wedge} 2+\operatorname{NOX}(4)$

$*$ adccode $\wedge$ 3

'temp

Channel $=13$

bytelocation $=(($ Channel +1$) * 2-1)+($ Loco $)$ : GET \#1, bytelocation, adccode

RealValueTemp $=(($ adccode $* .29297)+460)$

'presure

Channel $=14$

bytelocation $=(($ Channel +1$) * 2-1)+($ Loco $)$ : GET \#1, bytelocation, adccode

RealvaluePres $=$ adccode $* 1.44$

$\mathrm{k}=14.746$

Vmix $=\mathrm{k} *$ RealvaluePres $/(\text { RealValueTemp })^{\wedge} .5$

'RealValue1 $=($ adccode $* 8.326190478 \#)$

'RealValue $2=$ adccode $* 8.307142854 \#$

' average data in one second

RealValueCountSum $=$ RealValueCountSum + RealValueCount $/ 10$

RealValueSSSum = RealValueSSSum + RealValueSS $/ 10$

RealValueASSum $=$ RealValueASSum + RealValueAS $/ 10$

RealValueSTSum $=$ RealValueSTSum + RealValueST $/ 10$

RealValueATSum $=$ RealValueATSum + RealValueAT $/ 10$

RealValueSLSum = RealValueSLSum + RealValueSL / 10

RealValueILSum $=$ RealValueILSum + RealValueIL $/ 10$ 


$$
\begin{aligned}
& \text { RealValuePASum }=\text { RealValuePASum }+ \text { RealValuePA } / 10 \\
& \text { RealValueTLSum }=\text { RealValueTLSum }+ \text { RealValueTL } / 10 \\
& \text { RealValueHCSum }=\text { RealValueHCSum }+ \text { RealValueHC } / 10 \\
& \text { RealValueCOSum }=\text { RealValueCOSum }+ \text { RealValueCO } / 10 \\
& \text { RealValueco2Sum }=\text { RealValueco2Sum }+ \text { RealValueCO } / 10 \\
& \text { RealValueNOXSum }=\text { RealValueNOXSum + RealValueNOX } / 10 \\
& \text { VmixSum = VmixSum + Vmix } / 10
\end{aligned}
$$

IF $\mathrm{j}$ MOD $10=0$ THEN

'PSET (j, 200 + RealValueSSSum / 10), 10

'PSET (j, 200 + RealValueASSum / 10), 11

'PSET (j, RealValueSTSum - 50), 14

'PSET (j, RealValueATSum - 50), 15

CO2GS = RealValueco2Sum * Vmix / $60 * 28.3 / 22.4 * 44 / 1000000$ !

PRINT \#10, count, ",", RealValueASSum, ",", RealValueSSSum, ",", (RealValueSSSum - RealValueASSum), ",", RealValueATSum, ",", RealValueSTSum

PRINT \#11, count, ",", RealValueHCSum, ",", RealValueCOSum, ",", RealValueco2Sum, ",", RealValueNOXSum, ",", CO2GS

LOCATE 12, 20: PRINT USING "Processing data point \#\#\#\#\# of test \#\#"; count + 1 ; test

'PRINT Count, RealValueSSSum, RealValueASSum, RealValueSTSum, RealValueATSum, RealValueSLSum, RealValueILSum, RealValuePASum, RealValueTLSum

'DO: LOOP WHILE INKEY\$ = ""

count $=$ count +1

RealValueSSSum $=0$

RealValueASSum $=0$

RealValueSTSum $=0$

RealValueATSum $=0$

RealValueSLSum $=0$

RealValueILSum $=0$

RealValuePASum $=0$

RealValueTLSum $=0$

RealValueHCSum $=0$

RealValueCOSum $=0$

RealValueco2Sum $=0$

RealValueNOXSum $=0$

VmixSum $=0$

END IF

\section{NEXT $j$}

\section{CLOSE}

'count $=1$ 
'NEXT test

'RUN "c: Itrucklftplftpmenu.exe"

END 